\title{
SMOKING AMONG BARIATRIC PATIENTS: THE ROLE OF ADULT ATTACHMENT STYLE, EMOTION REGULATION, AND PSYCHOPATHOLOGY
}

\author{
by \\ Vincent Angelo Santiago \\ Honours Bachelor of Science, University of Toronto, 2013

\begin{abstract}
A thesis
presented to Ryerson University

in partial fulfilment of the requirements for the degree of

Master of Arts

in the Program of

Clinical Psychology
\end{abstract}

Toronto, Ontario, Canada, 2018

(C) Vincent Angelo Santiago 2018 


\section{AUTHOR'S DECLARATION FOR ELECTRONIC SUBMISSION OF A THESIS}

I hereby declare that I am the sole author of this thesis. This is a true copy of the thesis, including any required final revisions, as accepted by my examiners.

I authorize Ryerson University to lend this thesis to other institutions or individuals for the purpose of scholarly research.

I further authorize Ryerson University to reproduce this thesis by photocopying or by other means, in total or in part, at the request of other institutions or individuals for the purpose of scholarly research.

I understand that my thesis may be made electronically available to the public. 
Smoking Among Bariatric Patients: The Role of Adult Attachment Style, Emotion Regulation, and Psychopathology

Master of Arts, 2018

Vincent Angelo Santiago

Clinical Psychology Program

Ryerson University

\begin{abstract}
Cigarette smoking after bariatric surgery is associated with complications and is advised against in clinical guidelines. However, it continues to be problematic and there is a paucity of research regarding the factors related to smoking in this population. This secondary data analysis study uses previously collected longitudinal data and moderated mediation analysis to determine if emotion regulation (Difficulties in Emotion Regulation Scale) mediates the relationship between adult attachment style (Experiences in Close Relationships scale) and the likelihood of smoking postsurgery. Psychopathology (diagnoses and symptom measures [Patient Health Questionnaire9; Generalized Anxiety Disorder-7]) was considered as a moderator. A total of 423 adult patients at the Toronto Western Hospital Bariatric Surgery Program participated. Attachment insecurity predicted emotion dysregulation, which predicted likelihood of smoking. Anxiety scores moderated the mediating effect, such that protective effects were observed for low to average anxiety. Implications for targeting emotion dysregulation and anxiety to reduce smoking are discussed.
\end{abstract}

Keywords: bariatric surgery, smoking, tobacco, adult attachment style, emotion regulation, psychopathology, depression, anxiety, moderated mediation 


\section{Acknowledgements}

I would like to thank several people for their important contributions to this master's thesis project and my overall development. Firstly, I would like to thank my research supervisor, Dr. Stephanie Cassin, for being supportive of my research and my personal and professional development. She is an amazing role model as a researcher, clinician, and leader within the psychology department and I look forward to her continued mentorship. I would also like to thank Dr. Kelly McShane for her valued perspective as a member on my supervisory committee, Dr. Tae Hart for serving on my examination committee, and to Dr. Alexandra Fiocco for chairing my defense. I greatly appreciate the time that all of you have dedicated to overseeing this project.

I would also like to thank the senior HEAL lab members, Lauren, Molly, and Aliza, for their advice, as well as my cohort, Ariella, Arielle, Bev, Iris, Katie, Sasha, Shira, and Tori, for being great friends and inspiring colleagues. I am grateful to my undergraduate supervisor, Dr. Janet Polivy, for giving me an opportunity to begin my research career in an area that I love. Similarly, I would like to thank the talented people at the Toronto Western Hospital Bariatric Surgery Program for welcoming me into their team four years ago. I would especially like to thank Dr. Sanjeev Sockalingam and Dr. Susan Wnuk for their strong work ethic, kindness, and dedication to patient care and research that I strive towards today. Thank you to the patients of the TWH-BSP for sharing your stories with us and thank you to the Canadian Institutes of Health Research and the Ontario Graduate Scholarship program for helping fund this project. I would not be where I am without the support of my friends and family. Thank you to my partner, Noel, for being on this journey with me, and to Raj, Joseph, and my mother, Catherine, who convinced me

to enter clinical psychology and believed that I would succeed. I am fortunate to feel like I am at the right place in my career and every day is a chance to prove that you were right, as usual. 


\section{Table of Contents}

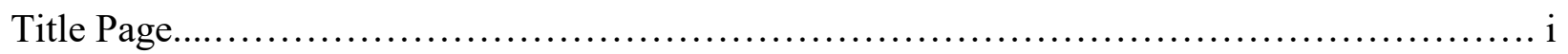

Author's Declaration........................................................... ii

Abstract......................................................................... iii

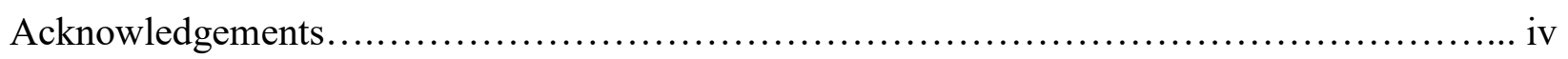

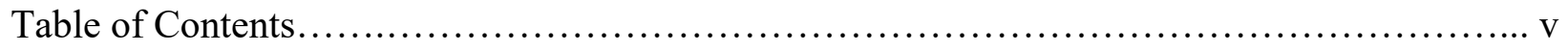

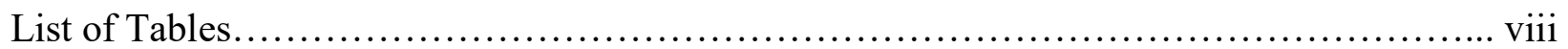

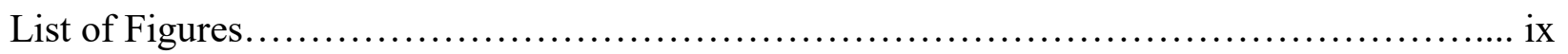

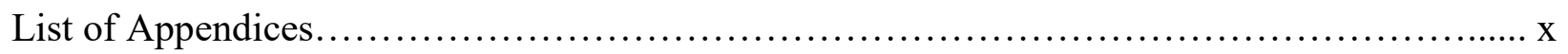

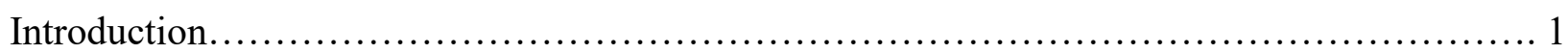

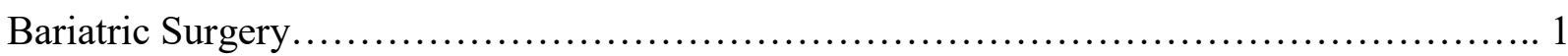

Tobacco and Cigarette Use................................................... 4

Bariatric Surgery Complications Related to Smoking.................................. 5

Psychosocial Factors Related to Smoking Among Bariatric Patients...................... 7

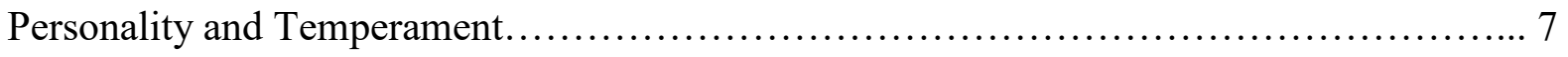

Emotion Regulation and Psychopathology...................................... 9

Early Life Experiences, Parental Styles, and Attachment Style....................... 12

Attachment Styles, Emotion Regulation, and Maladaptive Eating in Bariatric Patients..... 18

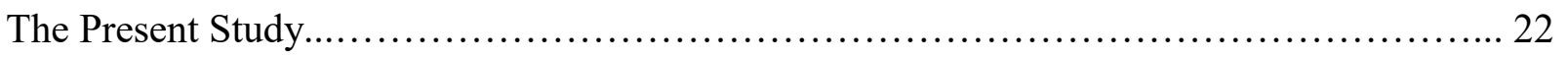

Hypotheses........................................................... 24

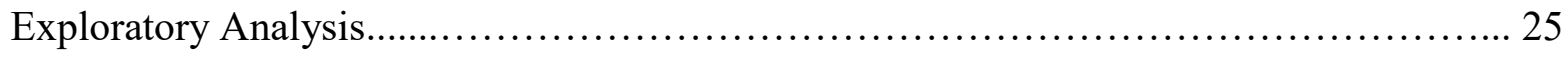


Methods.

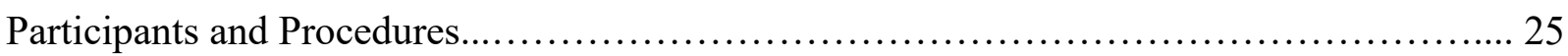

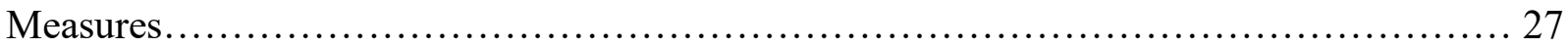

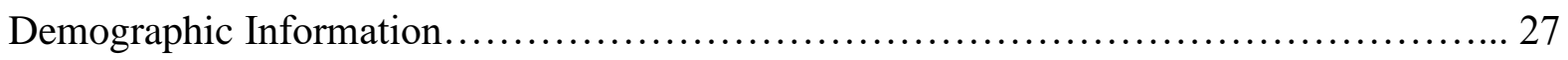

Attachment Style......................................................... 28

Emotion Regulation...................................................... 29

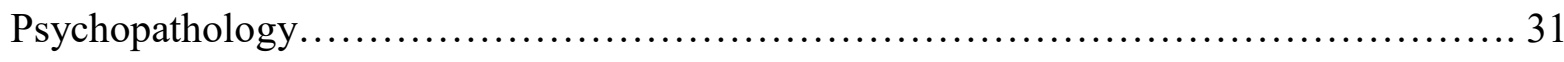

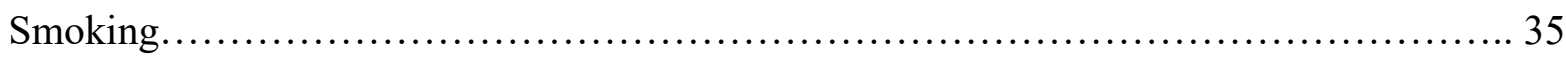

Statistical Analyses.......................................................... 35

Results....................................................................... 37

Demographics Variables...................................................... 37

Model Variables............................................................. 39

Assumptions of Analyses................................................... 40

Primary Mediation Analyses................................................... 41

Probing Partial Moderated Mediation.............................................. 44

Post-hoc Mediation Analyses.................................................. 45

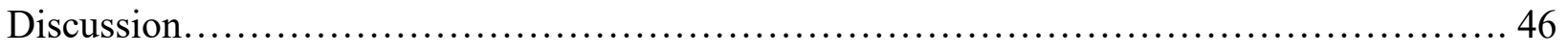

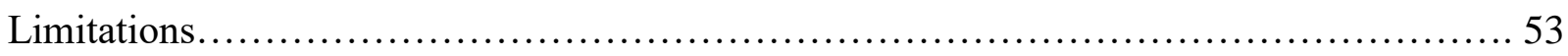


Sampling Limitations.

Methodological Limitations...................................................... 59

Clinical Implications, Future Research, and Conclusions.................................6. 62

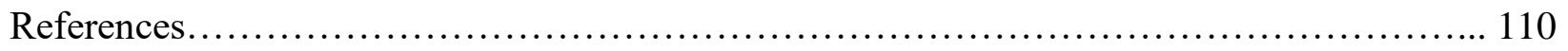




\section{List of Tables}

Table 1. Descriptive statistics of continuous variables for the ECR-ANX/AVO datasets........ 66

Table 2. Descriptive statistics of categorical variables for the ECR-ANX/AVO datasets...... 67

Table 3a. Descriptive statistics for model variables for ECR-ANX data................... 68

Table 3b. Descriptive statistics for model variables for ECR-AVO data..................... 69

Table 4. Bivariate Pearson correlations between model variables for ECR-ANX/AVO data..... 70

Table 5a. Collinearity statistics with smoking as the dependent variable................... 71

Table 5b. Collinearity diagnostics with smoking as the dependent variable.................. 71

Table 6. Maximum likelihood estimates of regression coefficients using a second stage dual

moderated mediation model using the ECR-ANX data................................. 72

Table 7. Maximum likelihood estimates of regression coefficients using a second stage dual

moderated mediation model using the ECR-AVO data................................ 73 


\section{List of Figures}

Figure 1. Concept diagram from Introduction studies..................................... 74

Figure 2. Second stage dual moderated mediation model using GAD-7 and PHQ-9 scores with

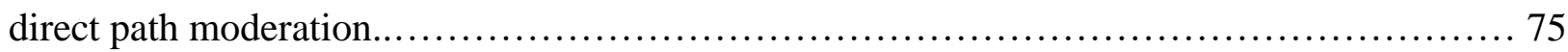

Figure 3. First stage dual moderated mediation model using GAD-7 and PHQ-9 scores with

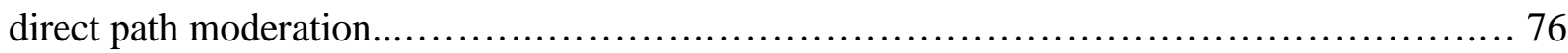

Figure 4. First stage moderated mediation model using psychological disorders with direct path

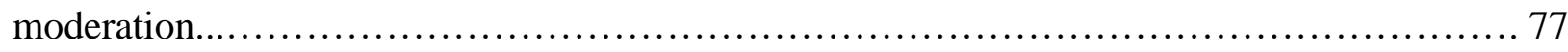

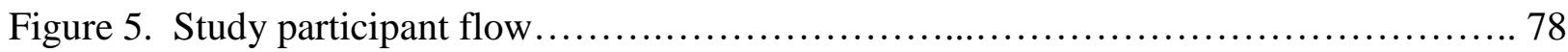

Figure 6a. Histogram and boxplot for ECR-Anxious scores for ECR-ANX data................. 79

Figure 6b. Histogram and boxplot for DERS scores for ECR-ANX data...................... 80

Figure 6c. Histogram and boxplot for GAD-7 scores for ECR-ANX data....................... 81

Figure 6d. Histogram and boxplot for PHQ-9 scores for ECR-ANX data......................... 81

Figure 7. Statistical path diagram of second stage dual moderated mediation model............. 82

Figure 8. Indirect effect of ECR-ANX/AVO scores on logit smoking....................... 83 


\section{List of Appendices}

Appendix A. PROCESS output for ECR-ANX data using second stage moderated mediation

model using GAD-7 and PHQ-9 scores............................................ 84

Appendix B. PROCESS output for ECR-AVO data using second stage moderated mediation

model using GAD-7 and PHQ-9 scores............................................ 87

Appendix C. PROCESS output for ECR-ANX data using first stage moderated mediation model

using GAD-7 and PHQ-9 scores................................................. 90

Appendix D. PROCESS output for ECR-AVO data using first stage moderated mediation model

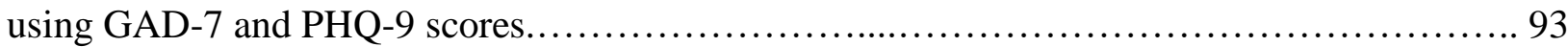

Appendix E. PROCESS output for ECR-ANX data using first stage moderated mediation model

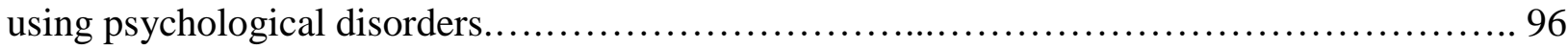

Appendix F. PROCESS output for ECR-AVO data using first stage moderated mediation model using psychological disorders................................................. 99

Appendix G. Experiences in Close Relationships scale (ECR-M16)...................... 102

Appendix H. Difficulties in Emotion Regulation Scale (DERS)....................... 105

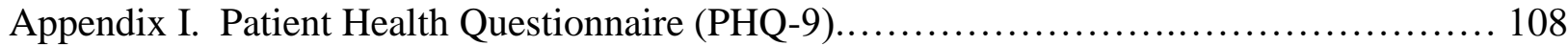

Appendix J. Generalized Anxiety Disorder Scale (GAD-7).......................... 109 
Smoking Among Bariatric Surgery Patients:

The Role of Adult Attachment Style, Emotion Regulation, and Psychopathology

Since 1975, the prevalence of obesity has almost tripled worldwide (World Health Organization [WHO], 2017). Elevated Body Mass Index (BMI; calculated as weight [kg] divided by height squared $\left.\left[\mathrm{m}^{2}\right]\right)$ is a major risk factor for cardiovascular diseases, diabetes, musculoskeletal disorders such as osteoarthritis, and cancers such as breast, ovarian, prostate, kidney, and colon cancers (WHO, 2017). Free fatty acids and cytokines are released from abdominal or visceral body fat, potentially leading to chronic inflammation and the interruption of cellular processes such as insulin signaling, thus leading to conditions like insulin resistance and type 2 diabetes mellitus (T2DM; Boyett, Magnuson, \& Schweitzer, 2016). This obesity-related inflammation negatively impacts organ systems and is thought to contribute to reductions in life expectancy (Boyett et al., 2016). The Prospective Studies Collaboration (2009) examined results from 57 prospective studies involving almost 900,000 adults and found that above a BMI of $25 \mathrm{~kg} / \mathrm{m}^{2}$, every five-unit increase in BMI was related to a 1.29 times increase in overall mortality (Hazard Ratio $[H R]=1.29,95 \% \mathrm{CI}[1.27,1.32])$ and a 1.41 times increase in mortality due to vascular disease $(H R=1.41,95 \%$ CI $[1.37,1.45])$. Furthermore, individuals with a BMI between 30 and $35 \mathrm{~kg} / \mathrm{m}^{2}$ had a 2- to 4-year reduction in life expectancy, and those with a BMI between 40 and 45 $\mathrm{kg} / \mathrm{m}^{2}$ had an 8- to 10-year reduction in life expectancy, which is similar to the effects of regular smoking (Prospective Studies Collaboration, 2009; Sakata et al., 2012).

\section{Bariatric Surgery}

Bariatric (weight loss) surgery is considered the most effective treatment for Class II obesity (BMI of 35 to $39.9 \mathrm{~kg} / \mathrm{m}^{2}$ ) and Class III obesity (BMI $\geq 40 \mathrm{~kg} / \mathrm{m}^{2}$; Corey \& Stahl, 2016). Accordingly, bariatric surgery is recommended by the American Society for Metabolic and 
Bariatric Surgery (ASMBS; Mechanick et al., 2013), the United Kingdom's National Institute for Health Care Excellence (NICE, 2014), and Canadian clinical practice guidelines (Canadian Institute for Health Information, 2014) for individuals with Class III obesity or those with Class II obesity and obesity-related comorbidities, such as T2DM.

There are four common types of bariatric surgery: (1) Roux-en-Y gastric bypass (RYGB), (2) laparoscopic adjustable gastric banding (LAGB), (3) sleeve gastrectomy, and (4) biliopancreatic diversion (BPD) with duodenal switch (Mayo Clinic Staff, 2016). RYGB is characterized by the formation of a small pouch at the top of the stomach that is connected to a lower part of the small intestine. Food therefore bypasses the rest of the stomach and the upper part of the small intestine, limiting food intake in the pouch and reducing absorption of nutrients in the intestine. The upper part of the small intestine is reattached to the lower part to allow for the continued flow of digestive juices from the larger portion of the stomach. LAGB involves the use of an adjustable band placed on the upper part of the stomach, thereby also restricting food intake but not reducing absorption. The sleeve gastrectomy involves the removal of part of the stomach, resulting in a smaller tube shape for reduced food intake, but does not involve changes to the intestine or absorption of nutrients. The BPD is similar to the sleeve gastrectomy in that it also involves removal of part of the stomach but it also includes detaching and reattaching the upper part of the small intestine (duodenum) to the last part of the small intestine, bypassing the middle section of the intestine and limiting nutrient absorption (i.e., the duodenal switch). The middle section is also reattached to the final section of the small intestine to allow for the continued flow of bile and pancreatic digestive juices (i.e., the biliopancreatic diversion).

Patient health outcomes typically vary with each type of surgery. One such outcome is excess body weight loss (EBWL), or the loss of weight considered the difference between current 
weight and ideal body weight (conventionally set at a BMI of $25 \mathrm{~kg} / \mathrm{m}^{2}$, as the normal weight range spans BMI 18.5 to $24.9 \mathrm{~kg} / \mathrm{m}^{2}$; Boyett et al., 2016; Brethauer, Kashyup, \& Schauer, 2013). The mean EBWL in percentage for patients two years postsurgery is $70 \%$ to $80 \%$ for BPD with or without duodenal switch, $60 \%$ to $70 \%$ for RYGB, $50 \%$ to $60 \%$ for sleeve gastrectomy, and $40 \%$ to $45 \%$ for LAGB (Boyett et al., 2016). The proposed mechanisms for weight loss include physical restriction of food intake, malabsorption, decreased hunger signals due to hormonal changes, increased energy expenditure and diet-related heat production, changes in food preference, and changes in the gut microbiome (Boyett et al., 2016).

Procedures resulting in higher EBWL are generally associated with greater risks of longand short-term complications, thus, there is a trade-off between desired weight loss and surgical risk (Boyett et al., 2016). For example, while mortality rates for all procedures are generally low at less than or approximately 1\% (Ma \& Madura, 2015), mortality within the first 30 days after surgery is the highest for BPD with duodenal switch $(0.76 \%$ for open surgery and $1.11 \%$ for laparoscopic surgery) compared to other bariatric surgeries (Buchwald, Estok, Fahrbach, Banel, \& Sledge, 2007). The mortality rate is $0.18 \%$ for open gastric banding, $0.06 \%$ for laparoscopic gastric banding, $0.44 \%$ for open gastric bypass, and $0.16 \%$ for laparoscopic gastric bypass (sleeve gastrectomy was not included in this meta-analysis; Buchwald et al., 2007).

Mortality has been primarily associated with the combination of leaks at the anastomosis (surgical connection between structures) and peritonitis (inflammation of abdominal lining), or blood clotting in the lungs (Pandolfino, Krishnamoorthy, \& Lee, 2004). Common complications following bariatric surgery include nausea and vomiting usually related to dietary noncompliance (e.g., drinking fluids and eating during the same meal) or marginal ulcers at the anastomosis (Pandolfino et al., 2004). The reported incidence of these types of ulcers range from 3\% to $20 \%$. 
One third of patients also develop gallstones postsurgery (Pandolfino et al., 2004). Thus, due to the mortality risks, adverse experiences of complications such as epigastric pain (Ma \& Madura, 2015), and costly treatment of these complications through revisional surgery (e.g., on average over $\$ 14,000$ USD to convert a gastric band to a sleeve gastrectomy; Gangemi et al., 2018), it is important to identify and minimize the effects of the factors that increase the risk for postsurgical complications.

\section{Tobacco and Cigarette Use}

Similar to obesity, tobacco use is another public health concern that is attributed to approximately 7 million deaths each year worldwide and causes cardiovascular diseases, respiratory diseases, and cancers such as lung, mouth, throat, kidney, stomach, and cervical cancers (WHO, 2018a; 2018b). In the Prospective Studies Collaboration study (2009), daily cigarette use was fairly consistent across BMI categories, as a five-unit increase in BMI was associated with only a $0.65(S E=0.04)$ and $0.18(S E=0.05)$ increase in daily cigarette use for male and female smokers, respectively. Among bariatric surgery candidates specifically, approximately $10 \%$ to 39\% are current smokers (Adams, Gabriele, Baillie, \& Dubbert, 2012; Chatkin, Mottin \& Chatkin, 2010; Conason et al., 2013; Grace, Pederson, Speechley, \& McAlpine, 1990; King, Engel, et al., 2012; Lent et al., 2013; Levine, Kalarchian, Courcoulas, Wisinski, \& Marcus, 2007; Livingston, Arterburn, Schifftner, Henderson, \& DePalma, 2006; Sjöström et al., 2007; Tae et al., 2014; Zhang, Mason, Renquist, \& Zimmerman, 2005). The rates from these 11 studies were similar to or higher than the 2016 estimate of $15.5 \%$ of adult Americans who currently smoke cigarettes (Centers for Disease Control and Prevention [CDCP], 2018) and the 2017 estimate of $16.2 \%$ of Canadians aged 12 and over who smoke occasionally or daily (Statistics Canada, 2018). In addition, the studies that used a longitudinal design reported rates of postoperative cigarette use that were similar to 
ones of preoperative use (Conason et al., 2013; Grace et al., 1990; Lent et al., 2013; Tae et al., 2013). Interestingly, Adams et al. (2012) found that all nine patients (15.5\% of their sample) who quit smoking within five months prior to surgery continued smoking within two years postsurgery. Thus, smoking is a concern within both the general and bariatric surgery populations due to the health risks.

\section{Bariatric Surgery Complications Related to Smoking}

Elevated rates of smoking in the bariatric population are of particular concern because of the postsurgical complication risks. For example, in a sample of almost 19,000 patients, a history of tobacco use at the time of bariatric surgery more than doubled the hazard of mortality following surgery (Hazard Ratio $[H R]=2.05, p<.001,95 \%$ CI $[1.67,2.52]$; Zhang et al., 2005). Tobacco use prior to or following RYGB increased the odds of developing nonhealing marginal ulcers by fourteen times $(O R=14.1, p=.003,95 \% \mathrm{CI}[2.5-80.4])$ using a multivariate analysis in a sample of 328 patients (El-Hayek, Timratana, Shimizu, \& Chand, 2012). Another study with 226 patients found that smoking following RYGB conferred a 30-fold increase in the odds for developing marginal ulcers (Adjusted $O R[A O R]=30.6, p<.001,95 \%$ CI $[6.4-146]$ ) and a 20-fold increase in the odds for a staple-line dehiscence or a rupture of an incision $(A O R=20.9, p=0.046,95 \% \mathrm{CI}$ [1.1, 411]; Wilson, Romagnuolo, Byrne, Morgan, \& Wilson, 2006; Wound Care Centers, n.d.). In a study examining 33,000 patients who underwent bariatric surgery, only a minority $(0.6 \%)$ developed pneumonia postsurgery (Gupta et al., 2012). However, smoking cigarettes within one year prior to surgery increased the odds of developing pneumonia by 1.56 times $(A O R=1.56,95 \%$

CI [1.06, 2.29]; Gupta et al., 2012). Another study has shown that a preoperative history of smoking increases the odds of post-RYGB venous thromboembolism, which includes deep vein blood clots and clotting in the lungs, by almost seven times $(O R=6.7, p<.01,95 \%$ CI $[1.90$, 
23.57]; American Heart Association, 2017; Gonzalez et al., 2006). There is even a persistent increased risk for up to six months post-bariatric surgery $(O R=1.86,95 \%$ CI $[1.06,3.27]$, Steele et al., 2011). In terms of general complications within the first 30 days after RYGB surgery, smoking within the year before surgery increased the odds of complications by 1.46 in a sample of 2,438 patients $(O R=1.46, p<.02,95 \%$ CI [1.06, 2.00]; Lautz et al., 2007).

Complications have even been reported in individuals with a history of heavy smoking who abstained from smoking prior to surgery. In a study of 575 American veterans who had bariatric surgery, only $1.8 \%$ of patients who abstained from smoking within one year prior to surgery and had a lifetime history of smoking that was less than 20 pack-years (equal to one pack of cigarettes per day for 20 years; National Cancer Institute, n.d.) failed to wean from a ventilator within 48 hours of surgery (Livingston et al., 2006). In contrast, significantly higher rates of failure-to-wean were reported for patients who abstained from smoking within one year prior to surgery but had a smoking history that was greater than 20 pack-years $(5.8 \%$ failed to wean, $p=.0085)$ and in patients who had smoked within one year prior to surgery and had a greater than 20 pack-year smoking history $(11.1 \%$ failed to wean, $\mathrm{p}<.0001)$. This final group of patients had a five-fold increase in the odds of failure-to-wean from a ventilator within 48 hours; $O R=5.16,95 \% \mathrm{CI}[1.92$, 13.84]; Livingston et al., 2006). As a result of the mounting evidence regarding the particularly harmful effects of smoking among bariatric patients, evidence-based guidelines sponsored by the ASMBS and other scientific organizations have advised patients to quit tobacco use at least six weeks prior to bariatric surgery and to maintain cessation postsurgery (Mechanick et al., 2013). However, bariatric centres of excellence within Ontario take a more conservative approach to reduce the risks of complications and advise patients to quit smoking six months prior to bariatric surgery and to remain abstinent following surgery (Ontario Bariatric Network, 2015). This is in 
line with the inclusion criteria for bariatric surgery programs in other provinces such as Newfoundland and Labrador and Manitoba (Eastern Health, 2017; Winnipeg Regional Health Authority, n.d.).

\section{Psychosocial Factors Related to Smoking Among Bariatric Patients}

Despite the many studies demonstrating the link between smoking and complications related to bariatric surgery, there is a paucity of research in terms of the psychosocial factors related to smoking among bariatric patients. Why do bariatric surgery patients smoke cigarettes? What are some possible mechanisms that influence smoking among bariatric patients? What are the differences between smokers and non-smokers in the bariatric population?

\section{Personality and Temperament}

Previous studies have reported that some aspects of personality and temperament are related to smoking (e.g., lower drive and higher anger temperaments; Bisol, Soldado, Albuquerque, Lorenzi, \& Lara, 2010), weight gain (e.g., higher novelty seeking; Hintsanen et al., 2012), and obesity (e.g., higher novelty seeking and more cyclothymic, irritable, and anxious temperaments compared to controls without obesity; Amann et al., 2009; Sullivan, Cloninger, Przybeck, \& Klein, 2007). Thus, Mombach, de Souza Brito, Padoin, Casagrande and Mottin (2016) examined the association between temperament and smoking among 420 bariatric surgery candidates. Mombach et al. (2016) used the self-report Affective and Emotional Composite Temperament Scale (AFECTS; Lara et al., 2012), which is based on the AFECT model and combines affective and emotional temperament models (e.g., Akiskal et al., 2005; Cloninger, Svrakic, \& Przybeck, 1993). This model seeks to explain normal and pathological mood, behaviour, and personality through temperament - a self-regulated system composed of six emotional dimensions (volition, anger, inhibition, sensitivity, coping, and control; Lara et al., 
2012). These emotional dimensions also combine to form 12 affective temperament types, which include cyclothymic, irritable, and anxious (Lara et al., 2012). The AFECTS is fairly new and most research using this scale has been conducted in Brazil (e.g., Carvalho et al., 2013; Leite, Machado, \& Lara, 2014) and thus requires further independent testing. However, the initial study has shown adequate to very good internal consistencies for its six emotional dimensions (Cronbach's $\alpha=0.75$ to 0.90 ; Lara et al., 2012).

Mombach et al. (2016) categorized bariatric surgery candidates into three types of smokers: current smokers (self-reported smoking >100 lifetime cigarettes and smoking daily or most days), ex-smokers (self-reported smoking >100 lifetime cigarettes but have not smoked in the past 90 days or more), and non-smokers (self-reported never smoking or smoking < 100 lifetime cigarettes or were not current smokers). Mombach et al. (2016) found that when excluding patients currently using psychiatric medications, bariatric surgery candidates who were current smokers scored lower in the control dimension than non-smokers $(p=.032)$. This difference remained significant when adjusting for age and sex $(p=.009)$. The control dimension refers to the monitoring of one's environment via attention, focus, awareness, and planning strategies (Lara et al., 2012) and is similar to the conscientiousness construct in the Big Five model of personality (McCrae \& Costa, 1987). Additionally, current smokers scored higher on anxious temperament than non-smokers ( $p$ $=.005)$ and ex-smokers $(p=.007$; Mombach et al., 2016). Individuals with anxious temperament are characterized by excessive worry, caution, insecurity, apprehension, and vigilance, and often avoid risks (Lara et al., 2012). For a subgroup of patients with a BMI $>50 \mathrm{~kg} / \mathrm{m}^{2}$, Mombach et al. (2016) found that ex-smokers had higher scores on coping $(p=.018)$ and control $(p=.023)$ compared to current smokers. Coping refers to the ability to adapt to challenges, find solutions, and learn from experiences (Lara et al., 2012). To summarize, bariatric surgery candidates who 
were smokers had greater anxiety and lower control temperaments than non-smokers, and for patients with BMI $>50 \mathrm{~kg} / \mathrm{m}^{2}$, smokers had lower control and coping temperaments compared to ex-smokers (Mombach et al., 2016).

\section{Emotion Regulation and Psychopathology}

Lara et al. (2012) included control, coping, and environmental sensitivity in their AFECT model as the authors viewed these as important factors for emotional self-regulation. Sensitivity refers to an individual's reaction to stressors (e.g., rejection and loss) and can be shaped by early life stressors (Lara et al., 2012). High sensitivity refers to a tendency to develop conditioned fears and may lead to the development of mental disorders (Lara et al., 2012). Farris, Zvolensky, and Schmidt (2016) describe emotion regulation in four dimensions: (1) modulating instead of eliminating emotional distress through the flexible use of adaptive strategies, (2) maintaining control of one's behaviour during distress, (3) being aware, understanding, and accepting of one's emotions, and (4) being willing to be emotionally distressed in order to take part in activities that are meaningful. Farris et al. (2016) add that difficulties in these dimensions represent emotion dysregulation and may lead to the persistence of negative affect and even the development or maintenance of psychopathology. For example, common and specific relationships exist between components of emotion dysregulation and symptoms of generalized anxiety disorder, major depression, and social anxiety disorder (Mennin, Holaway, Fresco, Moore, \& Heimberg, 2007).

Thus, the concepts of control, coping, and sensitivity (Lara et al., 2012) seem to fit well with the dimensions that characterize emotion regulation (Farris et al., 2016). If smoking among bariatric surgery candidates is associated with low control and coping (Mombach et al., 2016), could this translate to emotion regulation difficulties? Furthermore, considering the findings by Mombach et al. (2016) regarding anxious temperament and the implications of other temperaments 
on psychopathology (e.g., the possibly protective effects of high coping and high control and low sensitivity against psychopathology; Lara et al., 2012), as well as the association between emotion dysregulation and psychopathology (Mennin et al., 2007), it is important to examine the potential roles of emotion regulation and psychopathology in the smoking behaviour of bariatric patients.

Farris et al. (2016) examined the effects of emotion dysregulation and psychopathology on the smoking cessation of 250 current smokers who self-reported smoking eight or more cigarettes daily for at least one year. These individuals were followed over 28 days and were non-bariatric patients that were recruited from the community and who reported motivation to quit smoking (Farris et al., 2016). Emotion regulation was assessed using the Difficulties in Emotion Regulation Scale (DERS; Gratz \& Roemer, 2004). Approximately $40 \%$ of participants met criteria for a current psychological disorder (within the past 12 months) as assessed using the Structured Clinical Interview-Non-Patient Version (SCID-I/NP; First, Spitzer, Gibbon, \& Williams, 2007) for the fourth edition of the Diagnostic and Statistical Manual of Mental Disorders (DSM-IV; American Psychiatric Association [APA], 1994). Farris et al. (2016) found that past-year psychopathology and emotion regulation on their own did not significantly predict likelihood of smoking lapse $(O R=1.14, p=.44,95 \%$ CI $[0.82,1.61] ; O R=1.01, p=.14,95 \%$ CI [1.00-1.01], respectively) after adjusting for the effects of gender, age, baseline level of nicotine dependence, and smoking cessation treatment condition (standard cognitive behavioural strategies or the standard treatment plus anxiety-related strategies).

Interestingly, the interaction between psychopathology and emotion regulation was significant $(O R=0.98, p=.021,95 \%$ CI [0.97-0.99]), such that the significant conditional effect of psychopathology on the likelihood of smoking lapse occurred only when DERS scores were low, meaning when participants reported lower emotion dysregulation ( $0.5 S D$ below the mean), 
but not higher emotion dysregulation (0.5 SD above the mean; Farris et al., 2016). Participants who had past-year psychopathology and low DERS scores compared to those without past-year psychopathology and low DERS scores had a significantly increased likelihood of lapse $(O R=$ $1.70,95 \%$ CI $[1.06,2.72])$, whereas the likelihood did not significantly differ between those who did and did not have past-year psychopathology and high DERS scores $(O R=0.96,95 \%$ CI $[0.70$, 1.40]; Farris et al., 2016). Thus, Farris et al. (2016) concluded that individuals with low emotion regulation difficulties and recent psychopathology, as well as individuals with high emotion regulation difficulties with or without recent psychopathology represent relatively comparable groups of smokers who are psychologically vulnerable to early distress after quitting smoking, and thus are at greater risk for smoking lapse compared to individuals without recent psychopathology and low emotion regulation difficulties. Farris et al. (2016) added that these results are generally supportive of negative reinforcement models of addiction (e.g., Baker, Piper, McCarthy, Majeskie, $\&$ Fiore, 2004) which suggest that the reduction of negative affective states following substance use reinforces and motivates recurring substance use. Past studies have shown that negative affect does precede smoking lapses when measured prospectively and in real-world settings (Shiffman, 2005; Shiffman et al., 2007; Shiffman \& Waters, 2004).

According to the 2016 National Survey on Drug Use and Health (Substance Abuse and Mental Health Services Administration, 2017), approximately 18.3\% of all Americans over 18 years of age had a mental illness (any mental, behavioural, or emotional disorder, excluding developmental and substance use disorders), such that DSM-IV Axis I diagnostic criteria were met for the past year. This is in contrast to the higher estimates of current DSM-IV Axis I disorders in bariatric surgery candidates (estimates range from 21-56\%; Kalarchian et al., 2016; Lier, Biringer, Stubhaug, \& Tangen, 2013; Mauri et al., 2008; Mühlhans, Horbach, \& de Zwaan, 2009; 
Rosenberger, Henderson, \& Grilo, 2006). Since $2 \%$ to $8.5 \%$ of bariatric surgery candidates meet criteria for current alcohol use disorder or alcohol abuse or dependence (Black, Goldstein, \& Mason, 2003; Ertelt et al., 2008; King, Chen, et al., 2012) and 11\% meet criteria for a non-alcohol substance use disorder before or up to three years after surgery (Mitchell et al., 2015), individuals diagnosed with substance use disorders, as excluded in the 2016 National Survey, still compose a minority of bariatric surgery candidates. Furthermore, while attention-deficit/hyperactivity disorder, classified as a neurodevelopmental disorder in the fifth edition of the DSM (DSM-5; APA, 2013), was estimated at a higher rate of $19.2 \%$ in bariatric surgery candidates (Taymur et al., 2016), a substantial portion of individuals with other types of Axis I disorders is still unaccounted for. Thus, considering the high prevalence of mental disorders in bariatric surgery patients, it is important to examine if the interaction between psychopathology and emotion regulation for smoking relapse holds in this population. This population is different from the community sample examined by Farris et al. (2016) because surgery candidates may or may not be motivated to quit smoking but are required to by surgical guidelines (e.g., Ontario Bariatric Network, 2015).

\section{Early Life Experiences, Parental Styles, and Attachment Styles}

In their AFECT model, Lara et al. (2012) described the construct of sensitivity to external events, which can be shaped by early life stress, as one of the factors relevant to emotional selfregulation. While sensitivity was not a temperament factor that significantly differentiated smoking behaviours in bariatric surgery candidates in the study by Mombach et al. (2016), attachment style is a related construct that may play a role in smoking.

Bowlby (1969) argued that early attachment experiences of children, such as repeated interactions with the primary caregiver, lead to long-term expectations and attitudes (i.e., working 
models) about how reliable and supportive others are, including oneself. These beliefs are in turn hypothesized to shape emotional experiences and behaviours throughout life (Bowlby, 1969). Work by Ainsworth, Blehar, Waters, and Wall (1978) led to the conceptualization of three attachment types that characterized children's reactions when separated from their parents and then reunited. The attachment types were labelled "secure" (the child sought reassurance and was easily comforted), "anxious-avoidant" (the child was more withdrawn or indifferent), and "anxious-ambivalent" (the child was not easily comforted and simultaneously showed anger and sought closeness; Ainsworth et al., 1978). Ainsworth et al. (1978) theorized that when a parent cares for their child in a warm, responsive, and consistent way, the child will likely develop secure working models of attachment and view others as available and supportive when necessary. If the caregiver is cold and rejecting, the child may be more likely to develop an anxious-avoidant attachment, and if the caregiver is inconsistent in their care, this may lead to an anxious-ambivalent attachment (Ainsworth et al., 1978). It is argued that a child with these latter insecure attachments would be at risk of developing working models that view others with distrust and the self as unlovable, which may then negatively impact how one reacts to interpersonal difficulties (Bowlby, 1969; Kassel, Wardle, \& Roberts, 2007).

These theories of attachment have since been extended to adult relationships with the development of measures of adult attachment styles (e.g., Bartholomew \& Horowitz, 1991; Brennan, Clark, \& Shaver, 1998; Collins \& Read, 1990; Hazan \& Shaver, 1987). Hazan and Shaver (1987) hypothesized that infant attachment styles guide the development of romantic attachment styles in adults. They found that the prevalence of the three attachment styles was similar in adults as it was previously found in infants (Campos, Barrett, Lamb, Goldsmith, \& Stenberg, 1983), and that individuals with the three different styles experienced love in different 
but expected ways (Hazan \& Shaver, 1987). For example, secure individuals described their experiences with love as friendly, happy, and trusting, whereas avoidant individuals mentioned a fear of closeness, and anxious-ambivalent individuals reported jealous and emotionally labile relationships (Hazan \& Shaver, 1987). With regards to emotion regulation, individuals with secure attachments are described as being prone to seek closeness to others and capable of managing emotional distress in an effective way (Shaver, Mikulincer, \& Chun, 2008). However, individuals with anxious attachments tend to underestimate their ability to cope on their own, to be overdependent on others for emotional soothing, and to express their affect (e.g., through distress) to maintain proximity to attachment figures (Hunter \& Maunder, 2001). Individuals with avoidant attachments tend to rely solely on themselves, overregulate their affect so that little is expressed, and deny a need for others even when it is necessary, such as when one has a major medical illness (Hunter \& Maunder, 2001).

Demonstrating the long-term influence of early attachment experiences, prospective data have shown that the attachment styles of $72 \%$ of 12 -month old children remained the same 20 years later when these participants were assessed with an adult attachment interview (Waters, Merrick, Treboux, Crowell, \& Albersheim, 2000). While the concept of attachment stability has been criticized on the basis that working models are subject to environmental change (e.g., Kagan, 1996; Lewis, 1997; Lewis 1999; Lewis, Feiring, \& Rosenthal, 2000), a meta-analysis of longitudinal studies by Fraley (2002) and further longitudinal work by Fraley, Vicary, Brumbaugh, and Roisman (2011) suggest that attachment security is moderately stable and that there is a stable factor that underlies temporary changes in attachment that is not accounted for by personality.

Early life experiences may play an important role in the attachment styles and smoking behaviours of individuals. For example, neglectful parenting style (low care and low control) has 
been found to be associated with a greater likelihood of cigarette use in adolescents (Foxcroft \& Geoff, 1995; Radziszewska, Richardson, Dent, \& Flay, 1996; Wang et al., 2015). A recent study found that maternal parenting style that was perceived as neglectful was associated with significantly higher odds of being a smoker $(O R=32.5, p=.02$; Csala et al., 2016). However, the group of cigarette users in this study was much older $(M$ age $=51.2, S D=12.4)$ compared to the non-smoking control group of medical students $(M$ age $=22.4, S D=2.1$; Csala et al., 2016). Nonetheless, parenting styles may have long-term implications for children. Perceived parenting style of parents of individuals in their twenties ( $M$ age $=23.4, S D=2.3$ ) has been shown to be associated to the adult attachment style of these individuals 35 years later (Wilhelm, Gillis, \& Parker, 2016). Gender moderated results such that high parental control may be detrimental to attachment security in women, whereas high control, when combined with high care, may be beneficial for men's attachment style (Willhelm et al., 2016). Another recent study by Le, Mann, Levitan, George, and Maunder (2017) found that in a cross-sectional study of 348 primary care patients $(M$ age $=44.6, S D=10.9)$, greater childhood adversity (various forms of abuse, neglect, and household dysfunction) was associated with greater attachment anxiety (standardized $\beta=.30$, $p=.002$ ), and greater attachment anxiety was associated with greater likelihood of current smoking $(\beta=.33, p=.04)$ in women. There was a potential mediating effect of attachment anxiety between childhood adversity and current smoking among women (95\% CI, [.003, .236]; Le et al., 2017); however, causality cannot be established because of the cross-sectional nature of the data. None of the variables were significantly associated with one another for current smoking among men, and attachment avoidance was not related to current smoking for either gender (Le et al., 2017). To summarize, early life experiences, such as parental style, may influence adult attachment styles and smoking behaviours; however, prospective research is needed to establish causal relationships. 
One such prospective study was conducted by Kassel et al. (2007). In a sample of 212 college students $(M$ age $=20.3, S D=5.1)$, Kassel et al. (2007) studied the relationship between adult attachment style and the frequency of cigarette, alcohol, and marijuana use, as mediated by dysfunctional attitudes about the self and self-esteem. The authors examined the latter two constructs because of the parallels between negative working models about the self and others (Ainsworth et al., 1978; Bowlby 1969) and dysfunctional attitudes about the self and the world, which are theorized to be important factors in depression (e.g., Beck, 1987). Kassel et al. (2007) proposed that childhood insecure attachment could initiate the types of depressive thoughts about oneself found later in adulthood. However, they further noted that merely holding dysfunctional attitudes does not necessarily lead to affective distress or psychopathology. Rather, these attitudes must be activated through relevant experiences (e.g., interpersonal rejection). Thus, low selfesteem may serve as an indication of the activation of these dysfunctional attitudes about oneself (Kassel et al., 2007). Finally, studies have demonstrated links between low self-esteem and substance use (Griffin-Shelley, Sandler, \& Lees, 1990; Leary, Schreindorfer, \& Haupt, 1995; Vega, Zimmerman, Warheit, Apospori, \& Gil, 1993; Wu, Wong, Shek, \& Loke, 2014; Zhai et al., 2015). One possible mechanism explaining this relationship is that substances are used to diminish negative affect related to rejection or depression (Kassel et al., 2007), which would be consistent with negative reinforcement models of addiction (e.g., Baker et al., 2004).

Attachment style, dysfunctional attitudes, and self-esteem were assessed at baseline, and drug use was assessed eight weeks later (Kassel et al., 2007). Adult attachment was measured by the Adult Attachment Scale (Collins \& Read, 1990), dysfunctional attitudes were measured by the Dysfunctional Attitude Scale (DAS; Weissman \& Beck, 1978), self-esteem was measured by the Rosenberg Self-Esteem Scale (Rosenberg, 1979), and drug use over the past eight weeks was 
measured using a Likert scale (from none [0] to everyday [5]; Kassel et al., 2007). The authors found that greater anxious attachment style (fear of abandonment or being unloved) was positively related to greater dysfunctional attitudes $(\beta=.30, p<.001)$ and negatively related to greater selfesteem $(\beta=-.30, p<.01)$. Greater comfort with being close to others was negatively associated with dysfunctional attitudes $(\beta=-.17, p<.05)$ and positively associated with greater self-esteem $(\beta=.18, p<.01)$. Greater dysfunctional attitudes were associated with lower self-esteem $(\beta=-$ $.37, p<.001)$. In turn, greater self-esteem was associated with lower cigarette $(\beta=-.20, p<.01)$ and marijuana use $(\beta=-.24, p<.01)$, but there was no significant relationship to alcohol use. Lastly, there was a direct positive relationship between anxious attachment and cigarette use $(\beta=$ $.16, p<.05)$, even when controlling for the effects of the other variables.

Participants were also asked how often they used cigarettes, alcohol, and marijuana as a means of coping with stress or negative affect (Kassel et al., 2007). Findings were similar to the general drug use reported above. However, greater self-esteem was negatively related to alcohol use when stressed $(\beta=-.18, p<.01)$ and was not significantly related to marijuana use when stressed $(\beta=-.12, p \geq .05)$. There was also a direct positive relationship between greater anxious attachment and stress-motivated cigarette $(\beta=.19, p<.01)$ and alcohol use $(\beta=.14, p<.05)$ when controlling for the effects of the other variables. Thus, Kassel et al. (2007) generally found that maladaptive attachment styles, such as being anxious about relationships and reporting difficulties with closeness, were related to increased substance use. The findings were extended to using substances as a means of coping with stress and negative affect, lending support to negative reinforcement models of addiction (e.g. Baker et al., 2004). Kassel et al. (2007) also found evidence for the mediating roles of dysfunctional attitudes and self-esteem, supporting the hypothesis that attachment style is related to beliefs held about the self, and that the activation of 
negative beliefs about the self results in lowered self-esteem, which then leads to substance use. Interestingly, anxious attachment style directly influenced general and stress-motivated cigarette use, exerting a unique effect not accounted for by dysfunctional attitudes and self-esteem (Kassel et al., 2007).

\section{Attachment Styles, Emotion Regulation, and Maladaptive Eating in Bariatric Patients}

Two final studies of relevance were conducted at the Toronto Western Hospital Bariatric Surgery Program (TWH-BSP; Shakory et al., 2015; Taube-Schiff et al., 2015) and serve as models for the current study. Both studies examined the potential mediating role of emotion regulation difficulties in the relationship between attachment style and binge eating (Shakory et al., 2015) or emotional eating (Taube-Schiff et al., 2015).

Shakory et al. (2015) analyzed cross-sectional data from 1,388 bariatric surgery candidates $(M$ age $=44.69 ; S D=10.59)$. Attachment style was assessed using the 16-item version of the Experiences in Close Relationships-Modified scale (ECR-M16; Lo et al., 2009), emotion regulation was assessed using the DERS (Gratz \& Roemer, 2004), binge eating was assessed using the Binge Eating Scale (BES; Gormally, Black, Daston, \& Rardin, 1982), and general disordered eating was assessed using the Eating Disorder Examination Questionnaire (EDE-Q 6.0; Fairburn \& Beglin, 1994). Higher scores on these scales refer to greater attachment insecurity, emotion dysregulation, binge eating severity, and disordered eating severity, respectively. Binge eating, as measured by the BES, is characterized by consuming too much food within a short period, losing control while eating, and feeling guilty after overeating (Gormally et al., 1982). General disordered eating (e.g., weight concern and dietary restraint) was used as a covariate to control for variability between patients and for the relationships to binge eating (Shakory et al., 2015). 
Using bootstrapping methods outlined by Preacher and Hayes (2004; 2008), the authors found that the indirect effect of anxious attachment on binge eating, as mediated by emotion regulation, was significant (point estimate $=0.01, S E=.001 ; 95 \%$ CI $[0.008,0.012]$; Shakory et al., 2015). Furthermore, the significant direct effect of anxious attachment on binge eating (unstandardized $B=0.02, p=.001$ ) became non-significant ( $B=0.01, p=.112$ ) when controlling for the emotion regulation mediator, avoidant attachment, and general disordered eating, indicating a strong mediation effect (Shakory et al., 2015). With regards to avoidant attachment, the indirect effect on binge eating via emotion regulation was also significant (point estimate $=0.08, S E=$ $.011 ; 95 \% \mathrm{CI}[0.06,0.12])$. Interestingly, the direct effect of avoidant attachment on binge eating changed from non-significant $(B=-0.02, p=.354)$ to significant $(B=-0.10, p=.006)$ when controlling for the emotion regulation mediator, anxious attachment, and general disordered eating, and in the opposite direction as the indirect effect (Shakory et al., 2015). Shakory et al. (2015) suggested that this was a sign of competitive mediation, in which both effects are significant and opposing, and could be due to an omitted mediator (Zhao, Lynch, \& Chen, 2010). Alternative models where binge eating was posited as the mediator between attachment styles and emotion regulation were explored. Results indicated a significant but weak mediation for anxious attachment, and a non-significant mediation for avoidant attachment, thus supporting the initial models (Shakory et al., 2015).

To summarize, Shakory et al. (2015) found that emotion regulation difficulties significantly mediated the relationship between insecure attachment styles and binge eating in bariatric surgery candidates. The finding for anxious attachment was consistent with the idea that anxiously attached individuals are prone to emotion dysregulation and underregulate and overexpress their affect (as they rely on others and potentially binge eating for emotion regulation; Hunter \& 
Maunder, 2001; Shakory et al., 2015). The finding of the direct, negative association between avoidant attachment and binge eating was potentially consistent with the idea that individuals with this attachment style overregulate affect and even behaviours like binge eating (Shakory et al., 2015). At the same time, a potentially different facet of avoidant attachment shows an indirect, positive relationship to binge eating through greater emotion regulation difficulties (Shakory et al., 2015). In this case, binge eating may increase when used as a maladaptive form of suppressing emotion, which characterizes avoidant individuals (Hunter \& Maunder, 2001; Shakory et al., 2015). Studies have supported the notion that binge eating can be brought on by negative affect and can be used as a maladaptive emotion regulation strategy (e.g., Gianini, White, \& Masheb, 2013; Svaldi, Griepenstroh, Tuschen-Caffier, \& Ehring, 2012; Whiteside et al., 2007). This is broadly similar to the negative reinforcement models of addiction (e.g., Baker et al., 2004), in which substances such as cigarettes are used as a way of coping with negative affect or stress, as found in the study by Kassel et al. (2007), or with psychopathology, as suggested by Farris et al. (2016).

In a similar vein, emotional eating is specifically defined as a maladaptive strategy for coping with negative affect, and is thought to be indicative of emotion regulation issues (Gianini et al., 2013; Taube-Schiff et al., 2015). Taube-Schiff et al. (2015) used a similar cross-sectional design as Shakory et al. (2015), but instead of using bootstrapping methods, they used structural equation modelling to determine the fit of a model that proposed a mediating role of emotion regulation between attachment style and emotional eating. Emotion regulation was assessed using the DERS (Gratz \& Roemer, 2004), attachment style was assessed using the ECR-M16 (Lo et al., 2009), and emotional eating was assessed using the Emotional Eating Scale (EES; Arnow, Kenardy, \& Agras, 1995). Higher EES scores indicate a greater desire to eat in response to 
negative affect, with three specific subscales measuring one's urge to eat in response to anger/frustration, anxiety, and depression (Arnow et al., 1995). A number of other scales were administered to assess covariates: depressive symptoms were assessed using the Patient Health Questionnaire-9 (PHQ-9; Kroenke, Spitzer, \& Williams, 2001; Spitzer, Kroenke, \& Williams, 1999), anxiety symptoms were assessed using the Generalized Anxiety Disorder-7 scale (GAD-7; Spitzer, Kroenke, Williams, \& Löwe, 2006), and general disordered eating was assessed using a subscale of the EDE-Q (Black \& Wilson, 1996). Other covariates controlled for in the mediation model included age, gender, and BMI (Taube-Schiff et al., 2015). Demographic data and complete questionnaires were collected from 646 bariatric surgery candidates (Taube-Schiff et al., 2015).

Taube-Schiff et al. (2015) found a good overall model fit for their mediation model $($ RMSEA $<.06, \mathrm{CFI}=1.00 ; \mathrm{SRMR}<.08)$. When controlling for the covariates, higher anxious and avoidant attachment scores were significantly and positively related to greater emotion dysregulation (unstandardized $B=.50, S E=0.5, p<.001 ; B=.51, S E=.06, p<.001$, respectively). Additionally, greater emotion dysregulation was significantly and positively related to emotional eating when angry, anxious, and depressed $(B=.10, S E=.02, p<.01 ; B=.07, S E=.02, p<.01$; $B=.04, S E=.01, p<.01$, respectively). All of the indirect effects from attachment style to emotion regulation and then to emotional eating were significant ( $a b$ paths ranged from $B=.02$ to .05 ; all $p<.001)$. The only two significant direct effects from attachment style to emotional eating were (1) a positive relationship between anxious attachment and emotional eating in response to anger $(B=.08, S E=.03, p<.05)$, and (2) a negative relationship between avoidant attachment and eating in response to anxiety $(B=-.05, S E=.04, p<.05)$. The authors concluded that even when accounting for anxiety, depression, and general disordered eating, attachment insecurity may increase emotion dysregulation and subsequently emotional eating (Taube-Schiff et al., 2015). 
Even so, direct effects suggest emotional eating in response to anger may be resistant to interventions intended to improve emotion regulation due to a unique influence from anxious attachment (Taube-Schiff et al., 2015). Furthermore, the negative direct relationship between avoidant attachment and emotional eating in response to anxiety is suggestive of the notion that individuals who are avoidantly attached overregulate their affect by strategies such as emotionally disengaging (Hunter \& Maunder, 2001; Maunder \& Hunter, 2012) and perhaps use other strategies that do not involve emotional eating when anxious.

It should be noted that while Shakory et al. (2015) explored an alternative model to rule out competing processes and Taube-Schiff et al. (2015) used path modelling, due to the crosssectional data, lack of temporal precedence makes it difficult to determine the direction of the effects and the causal relationships (Shakory et al., 2015; Taube-Schiff et al., 2015). In a review of the requirements for establishing a mediator, Lemmens, Müller, Arntz, and Huibers (2016) note that establishing statistical mediation is important but not sufficient. They argue that the next most important step is to determine the direction of causality (e.g., through the measurement of constructs at multiple timepoints; Lemmens et al., 2016).

\section{The Present Study}

If binge eating and emotional eating in bariatric surgery candidates are indirectly influenced by attachment style through emotion regulation (Shakory et al., 2015; Taube-Schiff et al., 2015), and these eating behaviours are used as maladaptive ways of coping with emotions (e.g. Gianini et al., 2013), as can be the case with cigarette use (e.g., Kassel et al., 2007) and as proposed by negative reinforcement models of addictions (e.g., Baker et al., 2004), could the same mediation process also be implicated in cigarette smoking? Furthermore, could an interaction between 
psychopathology and emotion regulation moderate smoking behaviour, as found in the study by Farris et al. (2016)?

The studies reviewed thus far have provided support for various paths of this process. For example, smoking behaviours among bariatric surgery candidates have been associated with high anxious temperament and low control and coping (Mombach et al., 2016). Along with the concept of sensitivity, the latter two dimensions have been proposed to be implicated in emotion regulation (Lara et al., 2012). Farris et al. (2016) found that emotion regulation did play a role in the smoking cessation of non-bariatric community members but only when there was an interaction with pastyear psychopathology, such that high emotion regulation was only protective in terms of reduced likelihood of smoking lapse if psychopathology was not present. In addition, adult attachment styles are theorized to be implicated in emotion regulation. For example, individuals who are anxiously attached may be overdependent on others for emotion regulation and individuals who are avoidantly attached may overregulate their affect on their own, while those with secure attachments are thought to manage emotional distress effectively (Hunter \& Maunder, 2001; Maunder \& Hunter, 2012; Shaver et al., 2008). These attachment styles are thought to be related to early life experiences, as reflected by infant attachment styles (e.g., Fraley, 2002; Hazan \& Shaver, 1987; Waters et al., 2000) and parenting styles (Wilhelm et al., 2016). The latter has been shown to be related to smoking (e.g., Csala et al., 2016; Le et al., 2017). Thus, there is reason to believe that adult attachment is related to smoking behaviours in bariatric patients, perhaps directly or indirectly through emotion regulation. Kassel et al. (2007) found that adult attachment styles exert a direct influence on general and stress-motivated cigarette use, but also indirectly through dysfunctional attitudes about the self and lowered self-esteem. These types of cognitions could also be related to psychopathology (e.g., depression; Beck, 1987) and the belief that one can 
effectively regulate affect on one's own (Hunter \& Maunder, 2001), although these thoughts will not be directly tested in the present study. Some support for theories regarding the differences between anxious and avoidant attachment in terms of affect under- or overregulation (Hunter \& Maunder, 2001; Maunder \& Hunter, 2012; Shaver et al., 2008) as manifested by maladaptive eating behaviours were discussed in the studies by Shakory et al. (2015) and Taube-Schiff et al. (2015). Figure 1 summarizes these concepts discussed in these articles.

The purpose of this study was to determine whether or not emotion regulation would mediate the relationship between adult attachment style and cigarette smoking among bariatric surgery patients. Additionally, psychopathology was tested as a moderator of the relationship between emotion regulation and smoking. An important focus of the present study was the use of prospective data (see Methods below) in order to elucidate any potentially causal relationships. By identifying the mechanisms related to smoking following bariatric surgery, potential targets for smoking cessation treatment can be determined and potentially used to lower the risk of smoking and its adverse health consequences after surgery. Additionally, by identifying the moderators related to psychopathology, treatment may be optimized for certain groups and not others, based on groups who are more vulnerable to postsurgical smoking.

Hypotheses. In the present study, it was hypothesized that emotion regulation will mediate the relationship between adult attachment style and cigarette smoking among bariatric patients. It was also hypothesized that current psychopathology will moderate this mediation through the indirect $b$ path from emotion regulation to smoking (i.e., there will be a moderated mediation process; Hayes, 2018). This proposed primary model is illustrated in Figure 2 and includes an additional pathway in which psychopathology moderates the direct effect between attachment and smoking. Hayes $(2015,2018)$ describes this additional moderation effect as optional and that it 
does not affect the mathematics involved in deriving the index of moderated mediation and the equations described in the Results section below. Since this accounts for another potential moderation, this direct effect moderation was included in the analyses. The specific hypotheses were:

1) Insecure attachment (anxious and avoidant) will be positively associated with emotion dysregulation,

2) Emotion dysregulation will be positively associated with a greater likelihood of smoking,

3) There will be a direct positive relationship between greater anxious attachment and likelihood of smoking,

4) There will be direct negative relationship between greater avoidant attachment and likelihood of smoking,

5) The mediating effect of emotion regulation will only hold in the absence of psychopathology or when scores on measures of psychopathology are low.

Exploratory analysis. Based on Figure 2, there is an added analysis that examines whether or not psychopathology moderates the direct relationship between attachment style and smoking. Based on the inverse of hypothesis 5 (the indirect effect), it is predicted that the direct effect will hold only in the presence of psychopathology or when scores of psychopathology measures are high, potentially reflecting facets of attachment that are not related to emotion regulation but are somehow associated with psychopathology and smoking.

\section{Methods}

\section{Participants and Procedures}

The present secondary data analysis study used data previously collected for a larger, prospective study that began June 14, 2010 and continues today. These data were collected at the 
Toronto Western Hospital Bariatric Surgery Program (TWH-BSP), located in Toronto, Ontario, Canada. The larger study is investigating psychosocial predictors of bariatric surgery outcomes and has been approved by the University Health Network (UHN) and Ryerson University Research Ethics Boards (REBs). Inclusion criteria for this larger study includes: 1) bariatric surgery assessment and follow-up at TWH-BSP; 2) being able to speak and read English; and 3) being able to provide informed consent. The inclusion criteria for the present study includes the above, as well as completion of all study measures described below and at all required time points.

The present study was approved by the UHN and Ryerson University REBs. The TWHBSP program is part of the Toronto Bariatric Surgery Centre of Excellence (TBSCE), a multihospital program that is also accredited by the Metabolic and Bariatric Surgery Accreditation and Quality Improvement Program (Sockalingam et al., 2017). Patients are referred to the TWH-BSP through the Ontario Bariatric Network (2015), a provincial bariatric surgery registry, and they are considered for surgery if their BMI is $\geq 40 \mathrm{~kg} / \mathrm{m}^{2}$ or $\geq 35 \mathrm{~kg} / \mathrm{m}^{2}$ with at least one obesity-related comorbidity, such as T2DM, coronary heart disease, or hypertension. Candidates for bariatric surgery are assessed by an interprofessional team (e.g., nurses, dietitians, psychologists, psychiatrists, social workers, and surgeons). The presurgery assessment process has been previously described by Sockalingam et al. (2013) and Pitzul et al. (2014). Unless surgically contraindicated, laparoscopic RYGB surgery is the routine procedure performed at the TWH-BSP (e.g., in one study of 156 patients at the TWH-BSP, 91\% of patients received the RYGB vs. $9 \%$ who received the sleeve gastrectomy; Sockalingam et al., 2017).

The TWH-BSP follows the same policies regarding smoking as outlined by the Ontario Bariatric Network (2015), which requires patients to quit six months prior to surgery and to maintain cessation afterwards. Patients are also required to quit smoking at least three months 
prior to the first preoperative assessment. If patients report smoking within this period, a nurse will normally request a urine sample. Patients are informed of this policy at their orientation into the program, and if they are suspected of smoking before surgery (e.g., through self-report, inconsistencies in reporting, or by the detection of cigarette odour during assessments), urinalysis is conducted to test for the presence of nicotine. If patients are unable to maintain cessation based on three positive screens (either through self-reported admissions or positive urinalysis tests), they are discharged from the program for non-compliance and must be rereferred by a doctor to be considered for surgery at least one year later. While the stakes for smoking cessation are high presurgery, once patients undergo surgery there is no exclusion to the program related to smoking. That is, patients are not discharged from the postoperative program if it becomes known that they are smoking, as it is part of routine care to follow-up with them and provide resources as necessary. Thus, smoking may only be reported postsurgery within the context of related complications (e.g., ulcers), which may require medical attention and treatment.

Once patients undergo surgery, they are expected to follow-up with the TWH-BSP team at six months and then annually for a total of five years. Patients complete a battery of psychosocial questionnaires at presurgery, and then again at each timepoint postsurgery. Additional medical appointments occur at one and three months postsurgery and patients may disclose smoking at these appointments, although psychosocial questionnaire data are not collected at these times.

\section{Measures}

Demographic Information. Age, gender, race/ethnicity, relationship status, education, household income, and employment status were collected from electronic patient records and psychology or social work presurgical assessment reports. Pre-surgical BMI was collected from referral information or the nursing assessment reports. At the TWH-BSP, the priority has been for 
research assistants to enter the questionnaire data first, and then the demographics information on a less consistent basis. Thus, electronic patient records were reviewed and demographics variables were updated specifically for the 423 participants in the present study. Missing data ranged from 0\% missing (BMI) to 54\% missing (total household income; see Tables 1 and 2).

Attachment Style. The ECR-M16 (Appendix G; Lo et al., 2009) is a 16-item self-report measure of adult attachment style that is adapted from the 36-item ECR (Brennan, et al. 1998). The shortened version was adapted for medical patients and focuses on close relationships and not exclusively on romantic relationships in order to account for patients who may not have a romantic partner or for patients who consider their romantic relationships irrelevant to their health issues (Lo et al., 2009; Maunder \& Hunter, 2016). The ECR-M16 consists of the anxious subscale (fear of rejection and abandonment) and the avoidant subscale (discomfort with being close with and depending on others). Both scales consist of eight statements about how one feels in close relationships with others (e.g., "I worry about being abandoned," p. 498; Lo et al., 2009). Each statement has 7-point Likert scale response options ranging from 1 (disagree) to 7 (agree). Higher scores indicate greater attachment insecurity, for a range of total scores of 8-56 for each subscale.

The ECR-M16 has been validated with advanced cancer patients $(N=309$ at baseline, $M$ age $=60.7, S D=11.3$ at baseline) when compared to the longer version (Lo et al., 2009). For the anxiety and avoidance subscales, the internal reliabilities were good at baseline and 4-6 months following baseline (Cronbach's $\alpha=.81-.86$ ). The test-retest reliabilities between these time points for 120 patients were high ( $r=0.82$ for anxious attachment and $r=0.73$ for avoidant attachment). In terms of construct validity, attachment anxiety and avoidance were negatively associated with self-esteem ( $r=-0.36$ and $r=-0.33$, respectively) as measured by the Rosenberg Self-Esteem Scale (Rosenberg, 1979) and negatively associated with social support $(r=-0.34$ and $r=-0.40$, 
respectively) as measured by the Medical Outcomes Study Social Support Survey (Sherbourne \& Stewart, 1991). Anxious and avoidant attachment were also positively associated with depressive symptoms ( $r=0.42$ and $r=0.19$, respectively) as measured by the Beck Depression Inventory-II (Beck, Steer, \& Brown, 1996). These correlations were in the predicted directions and were all significant at $p<.05$ (Lo et al., 2009). The ECR-M16 has also been previously used with presurgical and postsurgical bariatric surgery patients (e.g., Sockalingam et al., 2011; Sunil et al., 2017). Attachment style in the present moderated mediation analysis was assessed at presurgery. In the present study, the internal reliability for the attachment anxiety subscale $(N=418)$ was high at Cronbach's $\alpha=.90$. For the attachment avoidance subscale $(N=421)$, it was also high at Cronbach's $\alpha=.86$.

Emotion Regulation. The DERS (Appendix H; Gratz \& Roemer, 2004) is a 36-item selfreport measure that assesses difficulties with emotion regulation. The items consist of statements about experiences related to emotions (e.g., "I am confused about how I feel," p. 48; Gratz \& Roemer, 2004). Each item has a 5-point Likert scale response referring to how often the experiences occur, ranging from 1 (almost never or 0-10\%) to 5 (almost always or 91-100\%). Higher scores refer to greater emotion dysregulation, for a range of total scores from 36 to 180 .

The DERS was originally validated using an undergraduate sample $(N=357$ at baseline, $M$ age $=23.1, S D=5.7$; Gratz $\&$ Roemer, 2004). Factor analysis led to the selection of six facets: 1) nonacceptance of emotional responses; 2) difficulties in engaging in goal-directed behaviour when experiencing negative emotions; 3) difficulties in controlling impulses when experiencing negative emotions; 4) lack of emotional awareness; 5) limited access to emotion regulation strategies perceived as effective once one is upset; and 6) lack of clarity in the emotions one feels (Gratz \& Roemer, 2004). Internal consistency was high for the total scale (Cronbach's $\alpha=.93$ ) 
and adequate for each of the subscales (all Cronbach's $\alpha>.80$ ). In terms of construct validity, Lo and colleagues (2009) compared the DERS to three scales: 1) the Generalized Expectancy for Negative Mood Regulation Scale (Catanzaro \& Mearns, 1990), which is a common measure of expectations that one can regulate one's emotions; 2) the Acceptance and Action Questionnaire (Hayes et al., 2004), which assesses the tendency to avoid internal experiences, such as emotions; and 3) the Emotional Expressivity Scale (Kring, Smith, \& Neale, 1994), which assesses general expression of emotions. As predicted, DERS total scores were negatively correlated with higher expectancies of emotion regulation $(r=-0.69)$, positively correlated with experiential avoidance $(r=0.60)$, and negatively correlated with emotional expressivity $(r=-0.23)$, all $p<.01$ (Gratz \& Roemer, 2004). Test-retest reliability was assessed by administering the DERS 4-8 weeks after baseline. For a sample size of $n=21$, the intraclass correlation coefficient was deemed good at $\rho_{i}$ $=0.88, p<.01$ (Gratz \& Roemer, 2004). These values were generally lower for the subscales $\left(\rho_{i}\right.$ $=0.57-0.89$, all $p<.01)$.

The DERS has since been tested with a medical sample of $N=207$ chronic pain patients ( $M$ age $=52.0, S D=12.9 ;$ Kökönyei, Urbán, Reinhardt, Józan, \& Demetrovics, 2014). The original six-factor structure was not supported, but after replacing one item due to misplaced loading and deleting six items due to weak loadings, a more acceptable fit was reached (Kökönyei et al., 2014). Kökönyei et al. (2014) mentioned that issues arose concerning the Awareness factor due to low intercorrelations with almost all of the subscales and so the authors suggested excluding it in the total score. Meanwhile, Gianini, White, and Masheb (2014) validated the DERS with $N=326$ adults with obesity who were seeking treatment for a DSM-IV diagnosis of binge eating disorder ( $M$ age $=45.5, S D=10.5$ years $)$. The internal consistency ranged from Cronbach's $\alpha=.74-.89$ for the subscales and $\alpha=0.87$ for the total score. More recently, the DERS was tested with $N=427$ 
treatment-seeking adults $(M$ age $=36.0, S D=14.4$ years $)$ diagnosed with one or more DSM-5 anxiety, mood, obsessive-compulsive, or trauma-related disorders (Hallion, Steinman, Tolin, \& Diefenbach, 2018). Good internal consistency was found for all subscales in the full 36-item version (all Cronbach's $\alpha>.80$; Hallion et al., 2018). However, the Awareness subscale for shorter versions of the DERS fell below Cronbach's $\alpha=.80$ and Hallion et al. (2018) suggested that this may be due to this subscale assessing a different construct. Since internal consistency was still high using the original long-form of the DERS and since total DERS scores have been used in previous studies with adults with obesity and binge eating disorder (Gianini et al., 2014), bariatric patients (e.g., Shakory et al., 2015; Taube-Schiff et al., 2015), and smoking outcomes in nonbariatric patients (Farris et al., 2016), total DERS scores were used in the present analyses for consistency with these previous studies. Emotion regulation in the moderated mediation analysis was assessed at six months postsurgery, the next timepoint after baseline when psychosocial measures are collected. In the present study, the internal consistencies for the six subscales were as follows ( $N=418$ for the ECR-ANX dataset): 1) Nonacceptance of emotional responses: Cronbach's $\alpha=.85 ; 2$ ) Difficulties engaging in goal-directed behaviour: $\alpha=.85 ; 3$ ) Impulse control difficulties: $\alpha=.78$; 4) Lack of emotional awareness: $\alpha=.82$; 5) Limited access to emotion regulation strategies: $\alpha=.85$; and 6) Lack of emotional clarity: $\alpha=.79$. For the ECR-AVO dataset $(N=421)$, the internal consistencies for the subscales in the same order are: Cronbach's $\alpha=.85$, $.85, .78,81, .85, .78$. Since the total internal consistency for all 36 items of the DERS was high (Cronbach's $\alpha=.92$ for both datasets) and the subscale internal consistencies were above or close to .80 , including the Awareness subscale, this strengthened the choice for using total DERS scores.

Psychopathology. While Taube-Schiff et al. (2015) used symptoms of depression and anxiety as covariates in their path analysis, the current study specifically included psychopathology 
in its model, and so the primary model (Figure 2) used measures of depression and anxiety symptoms. Since affective and anxiety disorders are among the most common psychiatric disorders in bariatric surgery candidates (Malik, Mitchell, Engel, Crosby, \& Wonderlich, 2014), these measures may serve as useful indicators of psychopathology. Responses to these measures were collected at six months postsurgery. To compare the primary model (Figure 2) to other possible models, an alternative model (Figure 3) was tested in a post-hoc analysis of moderated mediation in which PHQ-9 and GAD-7 scores were measured at presurgery.

Since psychological disorders were not assessed at six months postsurgery and did not fit the proposed timeline in Figure 2, current psychological disorders (i.e., up to the past 12 months) assessed at presurgery were used in a post-hoc analysis of moderated mediation as another alternative model (Figure 4). These disorders were based on DSM-IV diagnoses made by psychologists or psychiatrists at the TWH-BSP using the structured Mini-International Neuropsychiatric Interview (MINI; Sheehan et al., 1998). Psychopathology was conceptualized as a dichotomous variable $(0=$ no past-year psychological disorders; $1=$ one or more past-year psychological disorders; as in Farris et al., 2016).

Depressive symptoms were assessed using the PHQ-9 (Appendix I; Kroenke et al., 2001; Spitzer et al., 1999), which is a 9-item self-report measure. The items refer to how often one has been bothered by depressive symptoms in the past two weeks (e.g., "little interest or pleasure in doing things,” p. 613; Kroenke et al., 2001) and there are 4-point Likert responses for each item, ranging from 0 (not at all) to 3 (nearly every day), for a range of 0 to 27 in a summed total score. The cut point scores are 5, 10, 15, and 20 for mild, moderate, moderately severe, and severe levels of depression, respectively (Kroenke et al., 2001). 
The PHQ-9 is widely used in medical populations and has been previously validated with bariatric surgery patients (Cassin et al., 2013; Marek, Heinberg, Lavery, Merrell Rish, \& Ashton, 2016). The PHQ-9 was originally validated with $N=3,000$ patients $(M$ age $=46, S D=17)$ in primary care settings in one study, and $N=3,000$ patients ( $M$ age $=31, S D=11$ years) in obstetricsgynecology settings in another study (Kroenke et al., 2001). Internal reliability was high (Cronbach's $\alpha=.86-.89$ ) and test-retest reliability from administration of the scale within the clinic to within 48 hours over the phone was high $(r=0.84)$. Criterion validity was also high based on a Receiver Operating Curve (ROC) analysis of PHQ-9 scores predicting a major depressive disorder diagnosis made by a mental health professional (Area Under ROC Curve $[A U C]=0.95$ ). Construct validity was high based on associations between increased PHQ-9 scores and decreased function and quality of life on all subscales of the 20-Item Short Form Health Survey (SF-20; Stewart, Hays, \& Ware, 1988). In another study, Cassin et al. (2013) compared PHQ-9 scores to MINI depression diagnoses in a sample of $n=244(M$ age $=43.8, S D=10.7)$ bariatric surgery candidates and a replication sample of an additional $n=275$ surgical candidates ( $M$ age $=44.5$, $S D=10.9)$. The AUC values for the ROC analyses were 0.78 (95\% CI [0.5-1.0] and $0.80(95 \%$ CI [0.6-0.9]) for the two samples, respectively (Cassin et al., 2013). An optimal cutoff score of $\geq$ 15 was selected for $75 \%$ sensitivity and $75-76 \%$ specificity based on the two samples. This cutoff differs from the standard cutoff of 10 for depression screening (Spitzer et al., 1999) and may help distinguish between somatic symptoms of depression and somatic symptoms of obesity (Cassin et al., 2013). In the present study, the internal consistencies for the PHQ-9 using the ECR-ANX and ECR-AVO datasets ( $N=418,421$, respectively) were both high at Cronbach's $\alpha=.83$.

Anxiety symptoms were assessed using the GAD-7 (Appendix J; Spitzer et al., 2006), which is a 7-item self-report measure. Similar to the PHQ-9, the items refer to how often one has 
been bothered by symptoms in the past two weeks (e.g., "feeling nervous, anxious or on edge," p. 1094; Spitzer et al., 2006), and the response options are the same as in the PHQ-9. The items are summed for a total score range of 0 to 21 . The severity cut point scores are 5,10 , and 15 for mild, moderate, and severe levels of anxiety (Spitzer et al., 2006). A cut point score of 10 was identified as a reasonable score in identifying cases of GAD, based on a sensitivity of $89 \%$ and a specificity of $82 \%$ (Spitzer et al., 2006).

The GAD-7 was originally validated in a sample of $N=2,740$ primary care patients ( $M$ age $=47.4, S D=15.5$ ) by Spitzer et al. (2006). Internal consistency was high (Cronbach's $\alpha=.92)$, test-retest reliability was good (intraclass correlation $=0.83$ ), and the comparison to mental health professional interviews using DSM-IV diagnostic criteria was also good (intraclass correlation = 0.83). In terms of construct validity, increasing GAD-7 scores were related to worsening function on all SF-20 scales as well as increased disability days, physician visits, and difficulties related to symptoms (Spitzer et al., 2006). The GAD-7 also showed good convergent validity with the Beck Anxiety Inventory ( $r=0.72$; Beck, Epstein, Brown, \& Steer, 1988) and the anxiety subscale of the Hopkins Symptom Checklist ( $r=0.74$; Derogatis, Lipman, Rickels, Uhlenhuth, \& Covi, 1974). Lastly, factorial validity was determined using principal component analysis and by GAD-7 items loading highly on one factor (Spitzer et al., 2006). In another study by de Zwaan et al. (2014), internal consistency of the GAD-7 was high (Cronbach's $\alpha=.90$ ) in a sample of $n=79$ bariatric surgery candidates $(M$ age $=48.7, S D=8.0)$ and $n=314$ postsurgical patients $(M$ age $=47.9, S D$ =9.9-11.3). The GAD-7 has been used in other studies with patients who have undergone bariatric surgery (e.g., Azin et al., 2014; Sockalingam et al., 2017; Sunil et al., 2017). In the present study, the internal consistencies for the GAD-7 using the ECR-ANX and ECR-AVO datasets $(N=418$, 421, respectively) were both high at Cronbach's $\alpha=.90$. 
Smoking. Smoking status was the outcome in the moderated mediation models and this information was collected from postsurgical nursing follow-up appointments anytime after six months postsurgery up to the maximum five years that patients are followed at the TWH-BSP. The nurses ask all postsurgical patients if they currently are smoking (yes/no), regardless of any reported symptoms such as pain from ulcers, and add any additional comments in their report, such as the number of cigarettes smoked per day. Since the number of cigarettes was inconsistently reported, postsurgical smoking was computed as a dichotomous variable based on self-reports $(0$ $=$ not currently smoking; $1=$ currently smoking). Urinalysis is also used preoperatively to verify if a patient is suspected of smoking and the results are recorded in nursing reports. However, urinalysis is not typically used postoperatively as smoking is no longer an exclusion criterion to being in the bariatric surgery program at this point. The smoking data were collected beginning in June-August 2016 from nursing reports found in the clinical charts and then recorded in a database by the TWH-BSP data support specialist. In the present study, the smoking data were extracted from this database and then merged with the demographics variables and questionnaire responses.

\section{Statistical Analyses}

Data were assessed for missing responses and outliers. Total questionnaire scores were calculated and used in the analyses only if participants completed every item on the scales. Demographic information is reported and compared between patients who did and did not complete the study measures and are excluded from analysis in order to determine bias. Values of total scores, means, standard deviations, skewness, and kurtosis of all predictor variables are reported. Pearson product-moment correlation coefficients are calculated between each predictor variable as a first step to determine if collinearity is an issue (Field, 2013). If so, collinearity 
statistics (e.g., variance inflation factor and tolerance) were computed to identify if collinearity is a concern, as it results in predictors explaining little unique variance in outcomes (Field, 2013).

The moderated mediation models were tested using the PROCESS macro version 2.16.3 by Hayes (2013) using IBM SPSS Statistics version 20. Tests were conducted with 5000 bootstrap samples with replacement, bias-corrected bootstrap confidence intervals (CI) of 95\% confidence, ordinary least squares/maximum likelihood confidence intervals, and heteroscedasticity-consistent standard errors. Logistic regression analyses were used for the binary outcome of smoking. Each model was tested for the anxious and avoidant attachment subscales as the independent variable. Based on the exploratory analysis, it is conceivable that anxious and depressive symptoms may dually moderate the direct impact of insecure attachment on smoking. Since two moderators ("dual" moderation) in these models moderate the relationship between the mediator and the outcome variable (the $b$ path), this is called second stage dual moderated mediation (Hayes, 2018). This is in contrast to first stage moderated mediation, in which the moderators moderate the relationship between the independent variable and the mediator (the $a$ path). Second stage moderated mediation is the primary model used in this study and is reflected in Figure 2. To compare theoretical and statistical model fits between the primary model and alternative models, first stage moderated mediations were tested and compared to the second stage moderated mediations. These first stage models used pre-operative PHQ-9 and GAD-7 scores (Figure 3) and pre-operative MINI psychological disorders (Figure 4) as the moderators. Thus, a total of three models (Figures 2-4) were tested across the two different insecure attachment subscales for a total of six tests. 


\section{Results}

\section{Demographics Variables}

Data from 5,805 patients who consented to research at the TWH-BSP from June 14, 2010 to May 11, 2018 were initially considered. This included 272 individuals who reported smoking cigarettes at any time during the assessment period (through urinalysis results or self-reports) or postsurgery (through self-reports). From these 272 patients, 87 reported smoking any time after 6 months postsurgery. To conduct the planned analyses, only data from patients who completed all of the measures of interest were included. Therefore, the samples consisted of $N=418$ (including 17 reported smokers) for analyses using anxious attachment data ("ECR-ANX") and $N=421$ (including 18 reported smokers) for analyses using avoidant attachment data (“ECR-AVO”). These samples are nearly identical but since five more patients completed the avoidant attachment subscale but not the anxious attachment subscale, and two more patients completed the anxious subscale but not the avoidant subscale, the sample sizes differ by three (total $N$ used =423). Many participants who consented to research were excluded due to incomplete data and this is likely due to a variety of reasons, such as participants completing presurgical measures but not proceeding with surgery, or participants not attending follow-up appointments and thus not completing the questionnaires after undergoing surgery. These reasons are described further in the discussion.

The study participant flow is depicted in Figure 5 and presurgical demographic variables are summarized for included samples in Tables 1 and 2. The samples included $(n=418-421)$ and excluded $(n=5,384-5,387)$ in the analyses were compared. Using independent samples t-tests, presurgical BMI and age did not significantly differ (all $p>.05$ ). However, household income was significantly higher at $p<.05$ for the included sample (approximately $\$ 82,500, S D=\$ 46,000$ ) compared to the excluded sample (approximately $\$ 66,500, S D=\$ 47,600$ ). Using chi-square tests, 
race/ethnicity and relationship status did not significantly differ between included and excluded participants (all $p>.05$ ). However, the included sample had more women (83\%) than the excluded sample $(77 \%)$ for both the ECR-ANX data, $X^{2}(1)=7.21, p=.007$, and the ECR-AVO data, $X^{2}(1)$ $=7.78, p=.005$. The included sample also had a greater percentage of the sample that had at least some post-secondary education (75\%) compared to the excluded sample (68\%) for the ECR-ANX and ECR-AVO data, (both $\left.X^{2}(6)=17.1, p=.009\right)$. Lastly, a greater percentage of the included sample was employed part-time or full-time (76\%) as opposed to being unemployed, retired, or on social assistance or disability compared to the excluded sample (65\% employed), for the ECRANX data, $X^{2}(5)=22.6, p<.001$, and the ECR-AVO data, $X^{2}(5)=20.8, p=.001$. All of the cells for the chi-square tests met the assumption of expected counts greater than five.

In comparing smokers $(n=17-18)$ and non-smokers $(n=401-403)$ in the included samples, the same analyses were conducted. Independent samples t-tests indicated non-significant differences between smokers and non-smokers for presurgical BMI, age, and income (all $p>.05)$. Chi-square tests indicated that there were no significant differences in gender, race/ethnicity, relationship status, education, and occupational status (all $p>.05$ ). However, even after collapsing categories to form a maximum of 2 x 2 cells (e.g., smokers and non-smokers employed or not vs. full-time, part-time, unemployed, retired, etc.), three categories (gender, race/ethnicity, and occupation) still each had one cell with an expected count of less than five, violating this assumption. Thus, Fisher's exact test was used to address small sample sizes (Field, 2013). Even with this correction, the tests were still non-significant (all $p>.05$ ). Thus, there were no statistically significant differences in demographic variables between smokers and non-smokers. 


\section{Model Variables}

Descriptive statistics for all variables included in the models are included in Tables 3a-3b, and bivariate Pearson correlations between all model variables are included in Table 4, with the tables split by ECR-ANX and ECR-AVO data. ECR-AVO scores were included in the ECR-ANX data and vice-versa to determine if collinearity was an issue. It should be noted that most patients scored within the non-anxious and non-depressed symptom severity ranges (scores $=0-4$ ) for GAD-7 (83.8\%; $M$ score $=2.27, S D=3.54)$ and PHQ-9 $(80.1 \% ; M$ score $=2.79, S D=3.64)$. Since significant correlations were determined between many of the variables, further testing of collinearity using linear regression (Field, 2013) was conducted and is presented in Tables 5a and 5b. Statistics were the same across ECR-ANX and ECR-AVO data.

According to Field (2013), if the Variance Inflation Factor (VIF), which specifies whether there is a strong linear relationship between predictors, is greater than 10 , then there is "cause for concern" (Field, 2013, p. 325), and the regression may be biased if the average VIF is much greater than one. Table 5a indicates that none of the VIF values approach $10(M=2.05)$. Furthermore, Field (2013) states that tolerance, the reciprocal of VIF (1/VIF), below 0.1 suggests a "serious problem" (p. 325) and below 0.2 suggests a "potential problem" (p. 325). However, neither is the case with these data. Further collinearity diagnostics in Table $5 \mathrm{~b}$ show that the eigenvalues of the predictors are relatively similar except for ECR-Anxiety (eigenvalue $=4.76$ ). Field (2013) states that if an eigenvalue is "much larger" (p. 795) than the others, this suggests that the regression parameters may be highly influenced by small predictor changes. However, the condition indices, which compare eigenvalues based on the largest eigenvalue, are fairly similar. Field (2013) states that there are no clear rules for how large the condition index needs to be to indicate collinearity; however, the value of 13.47 in these data does not approach the problematic value of 81.30 that 
Field (2013) cites. The last collinearity statistic is the variance proportion associated with each eigenvalue and each predictor variable's coefficient. Field (2013) states that predictors with high proportions on the same small eigenvalue are problematic because they suggest coefficients that are not independent. In the present data, none of the predictor variables have high proportions on the smallest three eigenvalues and suggest that collinearity is not a concern.

In summary, given that smokers and non-smokers do not differ significantly with respect to demographic variables and collinearity was not deemed a concern across model variables, covariates were not included in the subsequent mediation analyses.

\section{Assumptions of Analyses}

In terms of distribution, a sample of variables for the ECR-ANX data is shown in Figures 6a-6d. While ECR-ANX scores are fairly normally distributed, DERS, GAD-7, and PHQ-9 scores had numerous outliers that could not be reasonably trimmed or substituted (Field, 2013) due to the number of outliers. Furthermore, transformations such as a logarithmic transformation (Field, 2013) were unnecessary since the logistic regressions already transform the data in this way. The mediation analyses relied on bootstrapping and this is robust against violations of assumptions of logistic regression, including lack of normality (Field, 2013), and is recommended by Hayes (2015, 2018) due to its already widespread use in mediation analysis. PROCESS also has the option of including heteroscedasticity-consistent standard errors, which addresses heteroscedasticity and its bias on confidence intervals and significance tests (Field, 2013). This option was selected for all mediation analyses. Field (2013) also notes two additional assumptions important to logistic regression: (1) independence of errors and (2) linearity, which is the assumption of the relationship between continuous predictor variables and the logit of the outcome variable as being linear. Independence of errors is theoretically assumed to be met in this sample as it is assumed that the 
scores on the measures and the likelihood of smoking are independent from patient to patient. On the rare occasion, there may be bariatric patients who know each other (e.g., spouses) that may influence each other's scores, but this cannot be determined given the current data and its effect is assumed to be negligible. The assumption of linearity was tested by multiplying the predictor variables by their log transformation (Field, 2013). None of the interaction terms were significant $(p>.05)$, indicating that the assumption of linearity was met.

\section{Primary Mediation Analyses}

Two equations estimate the second stage dual moderated mediation model in Figure 2, given the assumptions of linear relationships between variables, including mediator $M$ 's effect on dependent variable $Y$ as a linear function of $W$ and $Z$, which are moderators that can be dichotomous or quantitative (Hayes, 2018). The two equations (1, 2a-2b; Hayes, 2018) are:

$$
\mathrm{M}=\mathrm{i}_{\mathrm{M}}+\mathrm{aX}+\mathrm{e}_{\mathrm{M}}
$$

The unmoderated effect of independent variable $X$ on $M$ (the "a" path); $i=$ intercept, $e=$ error.

$$
Y=i_{Y}+c^{\prime} X+b_{1} M+b_{2} W+b_{3} Z+b_{4} M W+b_{5} M Z+e_{Y}
$$

The effect of $X$ on $Y$, as a function of $W$ and $Z$, where the conditional effect of $M$ on $Y$ (the "b" path) changes as a function of $W$ and $Z$ :

$$
\Theta_{M \rightarrow Y}=b_{1}+b_{4} W+b_{5} Z
$$

When determining the indirect effect of $X$ on $Y$ through $M$, the "a" and "b" paths are multiplied:

$$
(a)\left(\Theta_{M} \rightarrow \mathrm{Y}\right)=a\left(b_{1}+b_{4} W+b_{5} Z\right)=a b_{1}+a b_{4} W+a b_{5} Z
$$

In this equation, when $W$ and $Z$ are zero, $a b_{1}$ is the conditional indirect effect of $X$ on $Y$ through $M$. When $Z$ is held constant, $a b_{4}$ is the index of partial moderated mediation or rate of change (slope) of the indirect effect of $X$ on $Y$ through $M$ based on values of $W$. Likewise, when $W$ is held 
constant, $a b_{5}$ is the index of partial moderated mediation based on values of $Z$ (Hayes, 2018).

Table 6 displays the regression coefficients, standard errors, and $p$ values of all paths in the model for the ECR-ANX data (see Figure 7 for the path diagram from Hayes, 2018). Table 7 displays this information for the ECR-AVO data. The PROCESS output from SPSS is presented in Appendix A for ECR-ANX data and Appendix B for ECR-AVO data.

For the ECR-ANX data "a" path using linear regression, as ECR-ANX scores increase by one unit, DERS scores increase by 0.529 units $(b=0.529, p<.001,95 \%$ CI $[0.391,0.666])$. For the ECR-AVO data, as ECR-AVO scores increase by one unit, DERS scores increase by 0.518 units $(b=0.518, p<.001,95 \%$ CI $[0.355,0.681])$. All other analyses were conducted using logistic regression. For the ECR-ANX data "b" (bl) path, as DERS scores increase by one unit, the likelihood of smoking increases $(b=0.072, p=.004,95 \%$ CI $[0.023,0.120], O R=1.075)$. The direct "c"" $(c$ 'l) path from ECR-ANX to smoking was non-significant. Similarly, the moderators of GAD-7 and PHQ-9 scores did not significantly predict smoking on their own ( $b 2$ and $b 3$ paths, respectively). For the ECR-AVO data, the "b" (bl) path was also significant. As DERS scores increase by one unit, the likelihood of smoking increases $(b=0.080, p=.001,95 \% \mathrm{CI}[0.032$, 0.128]). There were no other significant paths or interactions for this dataset.

The only interaction that was significant was between the ECR-ANX $(X)$ and GAD-7 $(W)$ in the optional moderated direct ( $\left.c^{\prime} 2\right)$ path from ECR-ANX to smoking $(b=.021, p=.023,95 \%$ CI $[0.003,0.039])$. This moderation is broken down into nine simple slopes in the PROCESS output in Appendix A for ECR-ANX. Of the nine possible combinations between low, medium, and high GAD-7 and PHQ-9 scores, only one regression was significant. When GAD-7 scores are low $(W=0)$ and PHQ-9 scores are high $(Z=6.43$ or one $S D$ above the mean), there is a significant negative relationship between ECR-ANX scores and the logit of smoking $(b=-0.106, p=.0418$, 
95\% CI [-0.207, -0.004], OR = 0.90). In other words, when anxiety scores are low and depression scores are high, the odds of smoking are reduced as anxious attachment increases.

Hayes $(2018,2015)$ notes that when using the inferential approach to moderated mediation using an index, there does not need to be a significant relationship between $M$ and $Y$ or a significant interaction between $M$ and a moderator to test moderated mediation. This is because the $a, b 4$, and $b 5$ paths (see Figure 7) do not reflect the relationship between the moderators and the indirect effect. As discussed, this is indicated by the indices of partial moderated mediation, $a b 4$ and $a b 5$. Using the data in Table 6 for the ECR-ANX data:

$$
\begin{aligned}
& a\left(b_{1}+b_{4} W+b_{5} Z\right)=a b_{1}+a b_{4} W+a b_{5} Z \\
& =(0.529)(0.072)+(0.529)(-0.012) W+(0.529)(0.0003) Z \\
& =0.038-0.0064(W)+0.0002(Z)
\end{aligned}
$$

Using the data in Table 7 for the ECR-AVO data:

$$
\begin{aligned}
& a\left(b_{1}+b_{4} W+b_{5} Z\right)=a b_{1}+a b_{4} W+a b_{5} Z \\
& =(0.518)(0.080)+(0.518)(-0.010) W+(0.518)(-0.005) Z \\
& =0.041-0.0054(W)-0.0025(Z)
\end{aligned}
$$

Equations 4 and 5 are depicted in Figure 8, where the $\mathrm{x}$-axis plots $W$ or GAD-7 scores, the y-axis plots the indirect effect of ECR-ANX/ECR-AVO scores on the logit of smoking, and the separate lines refer to when $Z$ or PHQ-scores are held at zero or one.

For ECR-ANX data, the indices of moderated mediation are -0.0064 for $W$ or GAD-7 (SE $=0.0035,95 \% \mathrm{CI}[-0.0135,-0.006])$ and 0.0002 for $Z$ or PHQ-9 (SE $=0.0030,95 \%$ CI $[-0.0051$, 0.0071]). Since the confidence interval (CI) for GAD-7 is completely below zero, this means that GAD-7 scores negatively moderate the indirect effect irrespective of any potential indirect effect moderation by PHQ-9. This is reflected in the slope of the bottom two lines in Figure 8. Since the CI for PHQ-9 does include zero, this means that irrespective of the effect of GAD-7 on the 
indirect effect, it cannot be stated with $95 \%$ confidence that the indirect effect differs across PHQ9 scores (i.e., PHQ-9 scores do not moderate the indirect effect). This index of moderated mediation of $Z$ is normally reflected in a gap between the bottom two lines in Figure 8 (Hayes, 2018). However, as Figure 8 shows, there is no visible gap and the two lines nearly overlap, reflecting the almost non-existent $a b_{5}$ index of 0.0002 .

For ECR-AVO data, the indices of moderated mediation are -0.0054 for $W$ or GAD-7 (SE $=0.0032,95 \%$ CI $[-0.0124,-0.0001])$ and -0.0025 for $Z$ or PHQ-9 $(S E=0.003,95 \%$ CI $[-0.005$, 0.007]). Like above, the CI for GAD-7 is completely below zero and so GAD-7 scores negatively moderate the indirect effect regardless of any potential PHQ-9 moderation. However, the CI for PHQ-9 does include zero and so it cannot be concluded that PHQ-9 moderates the indirect effect. The index of moderated mediation of -0.0025 for $Z$ is represented by the gap between the top two lines in Figure 8 and is visible compared to the two bottom lines representing the ECR-ANX data.

\section{Probing Partial Moderated Mediation}

Since one index of moderated mediation was deemed significant for both ECR-ANX and ECR-AVO datasets, the moderation on the indirect effect is broken down using the PROCESS output in Appendix A for ECR-ANX and Appendix B for ECR-AVO. Since it was already determined that the indirect effect of $X$ on $Y$ cannot be claimed to differ across PHQ-9 scores, comparisons between conditional indirect effects focused on GAD-7 scores and not PHQ-9 scores (see Hayes, 2018 for a similar example). The PHQ-9 value that was held constant across comparisons was the mean $(Z=2.787)$.

Thus, for ECR-ANX data, when GAD-7 scores are low $(W=0)$, the indirect effect is $b=$ $0.038,95 \% \mathrm{CI}[0.012,0.705], O R=1.039$. When GAD-7 scores are average $(W=2.270)$, the indirect effect is $b=0.024,95 \% \mathrm{CI}[0.029,0.046], O R=1.024$. When GAD-7 scores are high $(W$ 
$=5.808)$, the indirect effect is $b=0.001,95 \% \mathrm{CI}[-0.028,0.026], O R=1.001$. As can be inferred by the odds ratio approaching 1.00 when GAD-7 scores are high, the indirect effect is no longer significant at high scores of GAD-7, unlike when scores are low or average.

For ECR-AVO data, when GAD-7 scores are low $(W=0)$, the indirect effect is $b=0.034$, 95\% CI [0.010, 0.067], OR $=1.035$. When GAD-7 scores are average $(W=2.268)$, the indirect effect is $b=0.022,95 \%$ CI $[0.030,0.042], O R=1.022$. When GAD-7 scores are high $(W=5.800)$, the indirect effect is $b=0.003,95 \%$ CI $[-0.200,0.026], O R=1.003$. Similar to the ECR-ANX data, the indirect effect of $X$ on $Y$ is significantly moderated only at low and average scores of GAD-7 but not high scores.

\section{Post-hoc Mediation Analyses}

In order to determine if the second stage model using GAD-7 and PHQ-9 scores had relatively good fit with the data, an alternative model using these same measures but at presurgery in a first stage model was tested in a post-hoc analysis (Figure 3; Appendices C and D for ECRANX and ECR-AVO PROCESS output, respectively). Since psychological disorders were not assessed at the six-month postsurgical timepoint, a post-hoc first stage moderated mediation using presurgical diagnoses was also tested (Figure 4; Appendices E and F for ECR-ANX and ECRAVO PROCESS output, respectively). Theoretically, according to findings by Farris et al. (2016) it was hypothesized that psychopathology would moderate the relationship between emotion regulation and smoking. Could psychopathology in the form of psychological disorders or anxious and depressive symptoms also moderate the relationship between insecure attachment and emotion regulation?

In linear regression, the squared multiple correlation coefficient $R^{2}$ is used to determine the goodness of fit between the model and the data (i.e., the variance of the outcome variable 
accounted for by the model; Field, 2013). However, logistic regression relies on analogues of this value, such as Nagelkerke's $R^{2}$ (Field, 2013). In the second stage moderated mediation model, Nagelkerke's $R^{2}$ was $15.1 \%$ for ECR-ANX data and $14.7 \%$ for ECR-AVO data (Appendices A and $\mathrm{B}$, respectively). Using PHQ-9 and GAD-7 scores, this alternative first stage moderated mediation model had Nagelkerke's $R^{2}$ as $12.6 \%$ for ECR-ANX data and $10.9 \%$ for ECR-AVO data (Appendices $\mathrm{C}$ and $\mathrm{D}$, respectively). In the alternative first stage moderated mediation model using psychological disorders, Nagelkerke's $R^{2}$ was $8.1 \%$ for ECR-ANX data and $6.6 \%$ ECRAVO data (Appendices E and F, respectively). Lastly, all of these alternative analyses produced indices of moderated mediation that had 95\% CIs that crossed zero. Therefore, the planned second stage moderated mediation model (Figure 2) explained the greatest variance, had the greatest fit to the data, and demonstrated significant moderation mediation indices.

\section{Discussion}

To summarize, the present study found that anxiety symptoms but not depressive symptoms negatively moderated the mediating effect of emotion regulation on the relationship between adult attachment insecurity and the odds of smoking following bariatric surgery. Importantly, this secondary data analysis used prospectively collected data in which the ECR-M16 (attachment style) was administered at presurgery, the DERS (emotion regulation), GAD-7 (anxiety), and PHQ-9 (depression) measures were administered at six-months postsurgery, and reports of smoking were collected at any time after six months to five-years postsurgery, allowing for stronger inference for the direction of causality compared to when using cross-sectional data (Lemmens et al., 2016).

The specific findings addressing the hypotheses were: 
1) As predicted, greater anxious attachment was positively related to greater emotion dysregulation $(b=0.529, p<.001,95 \% \mathrm{CI}[0.391,0.666])$, and greater avoidant attachment was positively related to greater emotion dysregulation $(b=0.518, p<.001,95 \%$ CI $[0.355$, $0.681])$.

2) As predicted, greater emotion dysregulation was positively related to greater likelihood of smoking $(b=0.072, p=.004,95 \%$ CI [0.023, 0.120], OR $=1.075$ for ECR-ANX data; $b=$ $0.080, p=.001,95 \% \mathrm{CI}[0.032,0.128], O R=1.083$ for ECR-AVO data).

3) It was predicted that there would be a direct positive relationship between greater anxious attachment and likelihood of smoking. This relationship was negative but non-significant $(b=-0.029, p=.421,95 \%$ CI $[-0.100,0.042], O R=0.971)$.

4) It was predicted that there would be a direct negative relationship between greater avoidant attachment and the likelihood of smoking. This relationship was also negative and nonsignificant $(b=-0.048, p=.257,95 \%$ CI [-0.131, 0.035], OR $=0.953)$.

5) It was predicted that the mediating effect of emotion regulation would only hold in the absence of psychopathology or when scores on measures of psychopathology are low. For both anxious and avoidant attachment, this was supported for anxiety symptoms. The indices of moderated mediation for GAD-7 were -0.0064 $(S E=0.004), 95 \%$ CI [-0.014, 0.006] for the anxious attachment analysis and -0.0054 (SE $=0.003), 95 \%$ CI [-0.012, 0.0001] for the avoidant attachment analysis. Depressive symptoms did not significantly moderate the mediation. Thus, when GAD-7 scores are low or reflect an absence of symptoms $(W=0)$ and when they are average $(W=2.27)$, the conditional indirect effects are significant with 95\% CIs for the effects above zero. However, they become nonsignificant once GAD-7 scores are high (i.e., one $S D$ above the mean; $W=5.81$ ). Since the 
indices of moderated mediation were negative, there is a negative moderation on the indirect effect, such that the logit odds of smoking decrease by 0.0064 for every one unit increase on the GAD-7 for the anxious attachment analysis. For the avoidant attachment analysis, the logit odds decrease by 0.0054 for every one unit increase on the GAD-7. This relationship is significant until an unknown point when GAD-7 scores become high.

The exploratory analysis of direct moderation predicted that psychopathology would moderate the direct relationship between attachment and smoking. However, none of the conditional direct effects of anxious attachment to smoking at values of the moderators were significant except for when GAD-7 scores were low $(W=0)$ and PHQ-9 scores were high $(Z=$ 6.43). This effect was negative $(b=-0.106, p=.0418,95 \%$ CI $[-0.207,-0.004], O R=0.90)$. None of the interactions between avoidant attachment and the moderators were significant, nor were the conditional direct effects (all $p>.05$ ). This exploratory analysis also predicted that the direct relationship would only hold in the presence or with high scores of psychopathology. This was only partially supported, as the only significant direct moderated path, as described above, occurred when GAD-7 scores were low and PHQ-9 scores were high.

In other words, as bariatric patients at presurgery report greater discomfort with being close to others (avoidant attachment) or fears around being abandoned by others (anxious attachment), they report greater emotion regulation difficulties at six months postsurgery. Such difficulties are in turn related to a greater likelihood of cigarette smoking beyond six months postsurgery. However, this mediating process is attenuated by symptoms of anxiety such that individuals at six months postsurgery with low to average anxiety (falling within the non-anxious range of a selfreport measure) benefit from a lowered likelihood of smoking beyond six months postsurgery and as attachment insecurity increases. At statistically "high" levels of anxiety (still falling within the 
non-anxious range but higher than the low or average scores), this attenuation disappears. In addition, there was a unique instance in which attachment insecurity directly impacted the likelihood of smoking outside the influence of emotion regulation. When anxiety is low and depression is high (falling within mild levels of depression on a self-report measure), the likelihood of smoking is also lowered as attachment insecurity increases.

Farris et al. (2016) found that when study participants had a past-year psychological disorder, DERS scores did not differentially impact smoking lapse likelihood, but for those without a past-year psychological disorder, lower DERS scores meant a significantly lower likelihood of smoking compared to those with higher DERS scores. This was consistent with the present finding that the indirect effect of DERS scores was present only in the absence of psychopathology or when scores on measures of psychopathology were low, specifically for GAD-7. Furthermore, the significant $b$ path in which greater DERS scores meant greater likelihood of smoking was consistent with the conditional effects from Farris et al. (2016). While no hypotheses were made regarding the direction of the moderation on the mediating effect, it was unexpected that increasing anxiety would negatively moderate the mediating effect, meaning there is a protective effect of increasing anxiety in terms of decreasing one's likelihood of smoking. Based on negative reinforcement models of addiction (Baker et al., 2004) and the study by Kassel et al. (2007), in which greater anxious attachment positively predicted cigarette use related to negative affect, as well as another study in which anxiety psychopathology was associated with smoking relapse risk (Zvolensky et al., 2008), it is reasonable to expect that increasing anxiety would lead to increased cigarette use, especially if one has emotion regulation difficulties. However, the indirect effect in this study decreases as anxiety increases (Figure 8), meaning that the "protective" nature of anxiety decreases until it no longer exists. Past this point of high anxiety, the direct path between 
increasing DERS scores and increasing odds ratios of smoking is no longer attenuated. This attenuation could be a result of an "adaptive" form of anxiety, in which some anxiety could be helpful in achieving goals, such as smoking cessation. Related concepts include challenge and threat states, in which factors such as self-efficacy can impact how one views a performance situation as a challenge or a threat (Hase, O’Brien, \& Freeman, 2018; Rossato, Uphill, Swain, \& Coleman, 2018). For example, Rossato et al. (2018) found a negative correlation between challenge and anxiety $(r=-0.16, p<.05)$ and a positive correlation between threat and anxiety $(r$ $=0.39, p<.05$ ). A systematic review by Hase et al. (2018) found that in $74 \%$ of 84 studies examining challenge and threat states, there were reports of better performance for challenge states compared to threat states across various tasks (e.g., math tests, golf putting, simulated surgery). While not completely overlapping with anxiety, this line of research points to how related concepts can be adaptive in situations that involve goals, evaluation, and stress (Hase et al., 2018). This can potentially include postsurgical appointments that evaluate one's postsurgical progress or attempts to quit smoking.

Another relevant construct is health anxiety, which refers to anxiety about one's health and arises from physical sensations or bodily changes that are believed to reflect illness (Asmundson, Abramowitz, Richter, \& Whedon, 2010; Taylor \& Asmundson, 2004). Health anxiety is common and can be adaptive when it motivates one to seek appropriate care (Taylor \& Asmundson, 2004), such as when an individual who has undergone bariatric surgery experiences severe abdominal pain and visits a hospital. However, it can also be maladaptive when it is excessive and out of proportion to the medical risks, leading to impaired functioning and overuse of medical services (Asmundson et al., 2010; Taylor \& Asmundson, 2004). Since the PHQ-9 does not specify the type of anxiety that one has been experiencing in the last two weeks (e.g., "feeling nervous, anxious or 
on edge," p. 1094; Spitzer et al., 2006), it is possible that this measure was tapping into health anxiety for some participants. Health anxiety may be particularly salient at six-months postsurgery when the PHQ-9 is administered in the present study. For example, dumping syndrome, which is characterized by abdominal pain, heart palpitations, nausea, vomiting, diarrhea, sweating, and dizziness and is associated with eating carbohydrates commonly occurs within the first year after Roux-en-Y gastric bypass surgery (up to $24.3 \%$ prevalence; Ma \& Madura, 2015) and has also been reported following sleeve gastrectomy (Tzovaras et al., 2012). One recommendation to prevent these symptoms is to avoid foods that result in dumping syndrome. Patients who develop marginal ulcers, which are associated with smoking, present with similar symptoms, such as abdominal pain and vomiting (Ma \& Madura, 2015). Thus, patients at this early stage postsurgery may be experiencing adaptive health anxiety that is triggered by unpleasant bodily changes that may be indicative of dumping syndrome or ulceration. This may then result in positive behavioural changes such as dietary modifications or smoking cessation. One possible scale to measure health anxiety is the Health Anxiety Inventory (HAI; Salkovskis, Rimes, Warwick, \& Clark, 2002). In the validation studies of this scale, patients diagnosed with hypochondriasis, a diagnosis in the DSM-IV (APA, 1994) and conceptualized as an extreme form of health anxiety (Salkovskis et al., 2002), scored higher on this scale compared to patients with anxiety disorders (i.e., panic disorder and social phobia) and nonclinical controls (Salkovskis et al., 2002). Patients with hypochondriasis also scored higher on the Beck Anxiety Inventory (BAI; Beck et al., 1988) compared to nonclinical controls but had comparable BAI scores to patients with anxiety disorders (Salkovskis et al., 2002). This suggests that health anxiety can be distinguished from general anxiety but general anxiety can be similarly detected in those with health anxiety and other anxiety issues. Thus, future studies should examine health anxiety and physical symptoms to determine 
whether they are related to the protective aspect of general anxiety found in this study. It is unknown why depression did not provide similar protective effects in the mediation model in the same way that anxiety did. Depression may not be "adaptive" and so these results make sense. Still, this is interesting in light of the significant conditional direct effect from anxious attachment to likelihood of smoking. This direct effect was negative and held only when GAD-7 was zero and PHQ-9 was one SD above the mean. Why would high depressive symptomatology confer protective effects outside of the mediating role of emotion regulation? Individuals may be less likely to smoke due to aspects of depression outside of the realm of emotion regulation that also interact with anxious attachment. Leventhal and Zvolensky (2015) note that anhedonia, a lack of interest and pleasure in activities and a key symptom of major depressive disorder (APA, 2013), increases smoking lapse over and above other factors, such as anxiety symptoms, negative affect (e.g., sadness), and somatic symptoms related to depression (e.g., sleep and concentration issues). They further discuss how individuals with anhedonia may be aware of their inability to experience pleasure without intense reinforcers, and that research has shown these individuals are more sensation seeking and likely to engage in activities such as skydiving (Franken, Zijlstra, \& Muris 2006). Smoking is another potent reward that may counteract deficiencies in the dopamine system of the mesolimbic area of the brain implicated in anhedonia (Leventhal \& Zvolensky, 2015). If individuals are engaging in more adaptive behaviours while anhedonic, this would involve behavioural control, awareness of emotions, and willingness to be distressed in order to take part in meaningful activities. This would not fit the emotion dysregulation description as described by Farris et al. (2016) and as measured by facets of the DERS (Gratz \& Roemer, 2004). To explain the negative direct effect on smoking, individuals who are anxiously attached and also anhedonic may seek proximity and support from others instead of smoking or engage in other highly- 
rewarding behaviour. However, this is only speculative and requires further testing of specific variables such as anhedonia, which is primarily captured in only one item in the PHQ-9.

\section{Limitations}

Sampling limitations. Three main sampling limitations are noted for this study: 1) differences between included and excluded patients; 2) small sample size of patients who reported smoking; and 3) reporting issues for smoking.

One major difference between included and excluded patients in this study is the sample size. Depending on the analysis, between $n=418$ to 421 were included and $n=5,384$ to 5,387 were excluded. There are many potential reasons for this difference. Firstly, a large portion of participants who consent to research do not complete the presurgical assessment and continue on to surgery. For example, in a study conducted at the TWH-BSP, 47.4\% ( $n=172)$ of candidates did not proceed with the program after the first presurgical assessment visit (Sockalingam et al., 2013). Secondly, even if patients undergo surgery, attendance at postsurgical follow-up appointments tend to decrease over time after surgery (Lara et al., 2005), and this study requires measure completion at six-months postsurgery. For example, attendance at appointments threeweeks following gastric bypass surgery was $100 \%$ in a sample of $N=150$ patients, decreasing to 64-85\% at six-months postsurgery, and to $36-70 \%$ at nine-months postsurgery, depending on travel distance to clinic (Lara et al., 2005). In a sample of $N=375$ bariatric surgery patients, only $50 \%$ of patients were adherent to appointments three months following surgery (Wheeler, Prettyman, Lenhard, \& Tran, 2008). In another sample of $N=112$ gastric bypass patients, the attrition rate was $72 \%$ for two-year follow-up appointments (Toussi, Fujioka, \& Coleman, 2009). At the TWHBSP, weekly average no-show rates of postsurgical appointments at six-months to five-years postsurgery were $13.5 \%$ and advanced cancellation rates were $18.8 \%$ over a period of 41 weeks 
(Santiago et al., in press). Lastly, even if patients attend their appointments, not all patients are willing to complete the questionnaire packages, even if they have previously consented to research. Collectively, these factors would have had a substantial impact on the sample size of participants meeting the inclusion criteria in the current study.

The present study only included complete data at all data collection points and is therefore a conservative approach. Missing data could be addressed with other statistical methods, such as mean imputation, in which missing numerical values (e.g., on questionnaires) are replaced with the mean of nonmissing values (Wicklin, 2017). However, this results in three issues: 1) reduced variance of the replaced values; 2) reduced standard errors, which likely invalidates hypothesis tests and confidence intervals; and 3) changes to the relationships between variables (e.g., correlations; Wicklin, 2017). Other alternatives include multiple imputation, in which each missing value is replaced with a set of possible but random values that estimate the uncertainty of the missing value (SAS Institute Inc., 2017). These data sets are then analyzed using the standard analyses for the complete data (e.g., logistic regression) and then combined with the complete data analyses to form an inference (SAS Institute Inc., 2017). However, multiple imputation usually relies on the assumption that the data are missing at random (SAS Institute Inc., 2017) or are nonignorable, which means that there is a reason for the missing values, such as when individuals in a higher socioeconomic group are less likely than those in a lower socioeconomic group to report their income (Grace-Martin, n.d.; Terrell, 2010). In the present study, the variable with the highest percentage of missing information was income (54\% missing) and likely represent nonignorable data. Thus, other methods that handle nonignorable missing values such as multiple partial imputation have been described (Yang, Li, \& Shoptaw, 2008) but are also considered quite complicated (Field, 2013). Another way to address the missing data in the event that entire time 
points are missed is to use multilevel modeling (e.g., nesting questionnaire data collected at multiple time points within each participant; Field, 2013). This method does not require data for every time point and does not require imputation of values or deletion of participant cases (Field, 2013). However, this would require a different study design than the one in the present study. Future studies could examine these methods as possible alternatives to using only complete data. Differences in demographics variables between included and excluded patients also present another sampling limitation. Compared to patients who were excluded, a greater percentage of patients who were included identified as women ( $83 \%$ vs. $77 \%)$, had at least some post-secondary education ( $75 \%$ vs. $68 \%$ ), were employed ( $76 \%$ vs. $65 \%)$, and on average had a higher household income $(\$ 82,500$ vs. $\$ 66,500)$. With regards to possible reasons for this finding, one study showed that compared to women, men were less likely to seriously consider bariatric surgery when adjusting for sociodemographic variables and BMI, and this was partially explained by women having a lower ideal weight $(O R=0.29,95 \% \mathrm{CI}[0.19,0.45]$; Wee et al., 2014). Another study using nationally representative Canadian data found that for those with obesity, individuals who were eligible for bariatric surgery were more likely to be female ( $62 \%$ vs. $44 \%$ ) compared to individuals ineligible for bariatric surgery (Padwal, Chang, Klarenbach, Sharma, \& Majumdar, 2012). However, Padwal et al. (2012) found that patients eligible for surgery were more likely to be less educated (43\% vs $35 \%$ ) and in the lowest socioeconomic tertile (41\% vs. $34 \%$ ), which is in line with findings by Martin, Beekley, Kjorstad, and Sebesta (2010). However, characteristics at eligibility may not translate to individuals who go on to attend postoperative appointments. For example, Larjani et al. (2015) found that patients who were employed part-time or full-time before surgery were significantly more likely to attend their follow-up appointments $(O R=1.9 ; p=.017)$. This may also account for the difference in income found in the present study, as individuals with 
a higher income may be able to afford to miss work (Larjani et al., 2015). In summary, differences between included and excluded patients in this study are likely due to selection processes and access issues that lead patients through the surgical consent, surgery, and postsurgical stages. Thus, while the data in the present study may not generalize to all patients who consider or undergo bariatric surgery, the data may generalize more to individuals who receive surgery, regularly attend postsurgical follow-up appointments, and complete study questionnaires.

Another sampling limitation was the very small number of individuals endorsing smoking relative to the number of non-smokers ( $n=17-18$ smokers vs. $n=401-403$ non-smokers, depending on the analysis). Unlike the self-report questionnaires, which were administered since data collection began in June 2010, collection of previous and current smoking data by the data support specialist began more recently around June-August of 2016, and thus represent a more limited sample of information based on data collection time alone. This limitation must be addressed with additional data collection of those who reported smoking in order to infer a more normally distributed sampling distribution, and thus to obtain more accurate estimates of test statistics (Field, 2013). While large sample sizes typically greater than 30 demonstrate a normal distribution based on the central limit theorem, the analyses in the present study relied on bootstrapping, which approximates the sampling distribution by randomly sampling the data with replacement 5,000 times (Field, 2013). Thus, the estimates of the 95\% bootstrap confidence intervals are not influenced by the distribution of scores (Field, 2013). Furthermore, the groups of smokers and non-smokers did not significantly differ with respect to presurgical BMI, age, household income, gender, race/ethnicity, relationship status, education, and occupational status, suggesting similarities between these groups despite differences in sample size. Nonetheless, 
theoretically, this sample of 17-18 smokers may not accurately represent and generalize to all bariatric surgery patients who report smoking following surgery.

In terms of sample size calculations, a feasibility check at the beginning of the secondary data analysis used $n=65$ as the initial number of individuals who reported smoking, as this was the total number not taking into account completion of the other study measures. At the time, the largest sample size was for ECR-AVO data $(n=416)$. Sample size was determined using a formula for logistic regression on the website for MedCalc $\AA$, a statistical software package, (MedCalc $\AA$, n.d.; $N=\left[10^{*} k\right] / p$, where $p$ is the smallest of the proportions in the population and $k$ is the number of covariates or independent variables) and based on work by Peduzzi, Concato, Kemper, Holford, and Feinstein (1996). Using this formula, the minimum number of cases that was suggested for this study based on this calculation was $N=256$ (where $N=[10 * 4] / 0.156$ ). This was using $65 / 416$ as the smaller proportion and assuming that the model only included four independent variables (attachment, emotion regulation, PHQ-9, and GAD-7). While the total number of individuals who reported smoking increased to $n=87$ in the present data, the actual numbers used for the analyses were much lower $(n=17-18)$ since not all 87 had completed the necessary study measures. New calculations using the smallest proportion $(p=18 / 421=0.0428)$ result in $N=$ 935.6 (where $N=[10 * 4] / 0.0428$ ) using the ECR-AVO data. For the ECR-ANX data, $N=983.5$ (where $N=[10 * 4] / 0.0407)$. While MedCalc $®$ (n.d.) notes that sample size calculation for logistic regression is complex and that this number is a suggestion, it is clear that the current sample size is well below the suggested amount. Statistical power $(1-\beta)$ refers to how probable a statistical test will find an effect if it exists in a population (Field, 2013). It is the opposite of the Type II error rate or probability that a test will not find an effect if it exists (Field, 2013). Using G*Power Version 3.1 (G*Power, 2017) in a post-hoc analysis of power and setting the Type I error rate or 
probability of incorrect rejection of the null hypothesis (Field, 2013) at $\alpha=0.05$, and using the odds ratios found for the effects of emotion regulation scores on smoking $(O R=1.075, n=418$ for the ECR-ANX data and $O R=1.083, n=421$ for the ECR-AVO data), power for the ECRANX analysis was $11.4 \%$ and $12.8 \%$ for the ECR-AVO analysis. Since power is usually suggested at $80 \%$ (Field, 2013), the current sample sizes indicate that the analyses were underpowered. Interestingly, Field (2013) states that if one finds a significant effect in an analysis, then this means that there was enough power to detect such an effect. Indeed, even with such low calculated power, the unstandardized $b$ values or logit odds of smoking that were used to calculate the above odds ratios were found to be significant, in addition to the indices of moderated mediation.

Another related limitation is how smoking information was captured. Urinalysis is sometimes used when patients are suspected of smoking preoperatively but it is not used postoperatively since smoking is not an exclusion to the bariatric surgery program and is likely an unnecessary cost at this point. Thus, reports of postoperative smoking are restricted to self-report. Patients may not report smoking after surgery unless there are postsurgical complications. However, of the 272 patients in the entire research database who reported smoking at any time, only 22 reported having an ulcer at the same time or following the reports of smoking. This suggests that patients are forthcoming with their smoking regardless of whether or not they have ulcers, the most common smoking-related complication. In general, since bariatric patients are not removed from the program if they disclose postsurgical smoking, this behaviour is probably less likely to be kept undisclosed compared to presurgical smoking. Nonetheless, the number of patients who smoke but do not report it is unknown. Some patients may also report complications but do not disclose their smoking. The smoking data in the present analyses can only be generalized to patients who self-report smoking after bariatric surgery, as there are likely 
individuals who smoke but are not captured by the current data collection methods. Future prospective studies with a smaller subset of postoperative patients could rely on both self-reports and urinalysis for all patients to increase the validity of the smoking construct.

Methodological limitations. As discussed, one analysis could not be conducted due to lack of data. Since psychological disorders were not assessed at six months postsugery, this second stage moderated mediation could not be tested and compared to the second stage moderated mediation in Figure 2 using PHQ-9 and GAD-7 scores. The model using diagnoses was based on the existing study by Farris et al. (2015), which found that psychopathology as assessed by the SCID-I/NP moderated the effects of emotion regulation on smoking lapse. Since patients underwent psychological assessment in the present study annually, the model variables could have been shifted at a later time point (i.e., DERS and psychopathology measured at one-year postsurgery and smoking reported any time after one-year postsurgery). However, this would have resulted in even smaller sample sizes due to increasing non-adherence to follow-up appointments after bariatric surgery (Gourash et al., 2013; Lara et al., 2005). An alternative was to conduct a post-hoc first stage moderated mediation with psychological disorders. The results comparing first stage moderated mediation with psychological disorders and first stage moderated mediation with GAD-7 and PHQ-9 scores showed that Nagelkerke's $R^{2}$ was higher for the latter model (10.9\%$12.6 \%)$ compared to the former model (6.6\%-8.1\%). Furthermore, Nagelkerke's $R^{2}$ was $14.7 \%$ to $15.1 \%$ for the primary model of second stage moderated mediation with GAD-7 and PHQ-9 scores. While these values cannot be compared for statistically significant differences, they suggest that psychopathology in the form of diagnoses fit the data less well compared to using PHQ-9 and GAD-7 scores, and even more so when these measures are used in a second stage model. 
Another issue concerning lack of data was the missing demographics information for participants included in the analyses. While there is normally a lag of data entry for this information compared to the psychosocial questionnaire responses, demographics information was collected from electronic patient charts specifically for this study. Nonetheless, missing data ranged from $0 \%$ (BMI) to 54\% (household income) and is partially due to some patient records not being uploaded to the electronic repository following a switch from paper to electronic records in 2012-2013. This issue may also be due to nonresponse for privacy or recall reasons (e.g., keeping income private or not remembering one's income if it is inconsistent; Turrell, 2010).

Other improvements to data collection could be made. Reports of smoking were collected based on information from nursing appointments, which were mostly reported in a categorical way (e.g., patient is or is not smoking). Occasionally, there were reports of number of cigarettes smoked per day but this was not consistent. Since there are likely differences in health outcomes between individuals who smoke one cigarette per day to one pack per day for example, the collection of continuous measures would have indicated the nuance in this outcome behaviour. Nonetheless, guidelines set by the Ontario Bariatric Network (2015) require patients to quit smoking entirely after surgery, so there is still good external validity in measuring smoking in a binary fashion. In addition, this study does not examine self-reported reasons for smoking, unlike the study by Kassel et al. (2007), which asked participants how often they used substances in order to cope with stress or negative affect. This information may elucidate the reasons for smoking and potentially provide further support for the mediating role of emotion regulation from the individual's perspective. It may also support negative reinforcement models of addiction (e.g., Baker et al., 2004). The study by Kassel et al. (2007) also found significant mediating roles of dysfunctional attitudes about the self and low self-esteem within the relationship between insecure 
adult attachment style and substance use. Thus, another study could investigate these constructs and how they may fit into a model with emotion regulation and symptoms of depression and anxiety. Item six on the PHQ-9 asks about how often one feels bad about oneself (Kroenke et al., 2001; Spitzer et al., 1999) and likely taps into similar constructs.

Lastly, another limitation concerns the statistical analyses. In testing hypothesis five, it was determined that there were negative indices of moderated mediation, such that the logit odds of smoking decrease for every one unit increase on the GAD-7 measure. However, this mediation holds for low to average GAD-7 scores until it becomes non-significant at an unknown large GAD7 score. PROCESS has the option of using the Johnson-Neyman technique in order to determine a zone of significance in which the precise moderator values are given for when moderation is and is not significant (Field, 2013). While this would be helpful for the present study, this option is currently only available in PROCESS version two for moderation-only models (Models 1 and 3; Hayes, 2013). Hayes (n.d.) states that for the Johnson-Neyman zone of significance, it was previously assumed that the sampling distribution was normal for conditional indirect effects (Preacher, Rucker, \& Hayes, 2007). However, he has since stated that this was a faulty assumption and thus recommends using bootstrapping when interpreting indirect effects (Hayes, n.d.). Seeing where the linear functions in Figure 8 cross zero is also not reliable way to determine when the indirect effect is non-significant, since the value of GAD-7 $(W)$ is 5.938 when $y$ is zero for the function of ECR-ANX when PHQ-9 $(Z)$ is also zero $(0=0.038-0.0064 W+0.0002 Z)$. PROCESS results in Appendix A stated that the indirect effect is non-significant at a smaller value than this, when GAD-7 is 5.808 (one $S D$ above the mean), and so statistical significance cannot be determined from this visual inspection method. Thus, current statistical limitations prevent pinpointing when GAD-7 scores do and do not moderate the mediated effect in this study. 


\section{Clinical Implications, Future Research, and Conclusions}

As described in the introduction, cigarette smoking is a health risk generally (WHO, 2017), but there is an added risk of many surgical complications related to bariatric surgery, including death (Zhang et al., 2005), marginal ulcers (El-Hayek et al., 2012; Wilson et al., 2006), and respiratory issues (Gupta et al., 2010; Livingston et al., 2006). This has the potential for straining the health of patients and the resources of medical systems. Thus, surgical guidelines suggest and even require that bariatric surgery patients quit smoking before and after surgery (Mechanick et al., 2013; Ontario Bariatric Network, 2015). Programs such as the TWH-BSP sometimes use urinalysis to ensure that patients adhere to this policy. With such a great impetus for behavioural change, there is a need to understand why and under what conditions bariatric patients are likely to smoke in order to effectively promote such cessation. In other words, there is a need to understand the mediators and moderators of this process.

A moderated mediated effect was found in which anxiety symptoms moderated the indirect effect of emotion regulation on insecure attachment style and odds of smoking after bariatric surgery. Insecure (anxious and avoidant) attachment styles are positively associated with increased emotion dysregulation, which is in turn positively associated with increased likelihood of smoking after bariatric surgery. Anxiety symptoms were found to moderate this effect in an attenuating manner, but only at low and average levels of anxiety. Increasing anxious attachment at low levels of anxiety and high levels of depression was directly linked to decreasing odds of smoking, independent of the emotion regulation mediation. Knowing which factors are the "active ingredients" that promote and maintain smoking among bariatric surgery patients may help clinicians optimize the smoking cessation treatments they deliver, such as cognitive behavioural therapy (e.g., Brown et al., 2001; Farris et al., 2016). For example, emotion dysregulation may be 
an important target for treatment for those with "high" anxiety scores (GAD-7 = 5.81), while potentially amplifying the reduced likelihood for smoking for those with "low" (GAD-7 = 0) or "moderate" (GAD-7 = 2.27) anxiety scores. Since the majority of patients $(83.8 \%)$ scored below five on the GAD-7, most individuals will benefit from a reduced likelihood of smoking with low anxiety scores. Before it is suggested that anxiety is somehow promoted in individuals with low anxiety in order to confer a protective effect, it would be important to determine exactly which factors of anxiety are potentially adaptive. For example, increasing self-efficacy and goal-setting in an evaluative and stressful situation, as in a challenge state (Hase et al., 2018; Rossato et al., 2018), may increase anxiety in an adaptive way. This may be accomplished with techniques such as motivational interviewing, which supports self-efficacy and an exploration of goals (Center for Substance Abuse Treatment, 1999). Other possible protective aspects of anxiety, such as adaptive health anxiety should be explored in relation to physical symptoms (Taylor \& Asmundson, 2004). It should be noted that the "high" GAD-7 scores refer to one $S D$ above the mean which clinically fall within the mild symptom severity range (scores from 5-9), and so clinical interventions to treat anxiety symptoms in this range may not need to be intensive to achieve positive effects on smoking outcomes. Wu et al. (2015) found that one way to target emotion dysregulation for individuals who smoke is through cognitive reappraisal (i.e., altering one's emotion by changing one's interpretation of a situation). This may supplant maladaptive emotion regulation strategies in heavy smokers by reducing emotional arousal and cigarette craving (Wu et al., 2015). In terms of clinical significance, the odds ratios for increased likelihood of smoking based on increased DERS scores were modest $(O R=1.075-1.083)$, suggesting that other factors may need to be addressed to appreciably lower postsurgical smoking risks. Clinicians may also adjust their approaches in working with individuals with particular attachment styles in order to develop an effective 
therapeutic alliance (Hunter \& Maunder, 2001) and to obtain the best smoking cessation outcomes possible. In choosing from a variety of treatments, anxiously attached individuals may benefit more from interventions that revolve around interactions and which build self-esteem and communication skills, while individuals with more avoidant attachments may benefit more from self-directed interventions, such as pamphlets or online resources, as they do not require much collaboration and allow a sense of autonomy (Ahrens, Ciechanowski, \& Katon, 2012).

Future research can improve upon the present study by increasing the sample size of individuals who reported smoking, using more standardized collection of smoking data based on continuous measures (e.g., number of cigarettes per day), and assessing for psychological disorders at six-months postsurgery to compare second stage moderated mediation models with the ones tested in the present study. Future studies should also examine other related variables, such as dysfunctional attitudes about the self, self-esteem, and specific components of constructs such as anhedonia within depression and adaptive anxiety and health anxiety within generalized anxiety. Use of other statistical techniques that can pinpoint when the conditional indirect effects do and do not hold within these models would also be beneficial. Since it is not necessarily the smoking behaviour but rather the health risks that are relevant to clinicians and patients, future studies should determine whether or not smoking-related complications are more likely to occur in individuals who report smoking compared to those who do not report smoking. This will help validate the smoking cessation guidelines set by ASMBS (Mechanick, 2013) and the Ontario Bariatric Network (2015) in this sample. Among the 272 individuals who reported smoking at any time in the present total sample $(N=5,805)$, there were 22 cases of ulcers reported concurrently or after reports of smoking. Among individuals who reported smoking in the ECR-ANX dataset, two developed ulcers while 15 did not. For those in the ECR-AVO dataset, three developed ulcers 
while 15 did not. It is currently unknown how many non-smokers did or did not develop ulcers and these data are necessary for the appropriate chi-square tests.

The results of this study extend the findings by Shakory et al. (2015) and Taube-Schiff et al. (2015) which found that in bariatric surgery candidates, the effects of insecure attachment on binge eating and emotional eating are mediated by emotion regulation. This study built on this simple mediation model by also including two moderating factors and by using a prospective longitudinal design, enabling greater inference for causality (Lemmens et al., 2016). It also compared the primary analytic model to two other models to determine the greatest fit to the data. The results point to factors that not only increase the risk for smoking after bariatric surgery, but also protect against it. Further studies should focus on breaking down these factors into specific components, mitigating the risks, and promoting the protective factors in order to improve surgical outcomes for patients who may be at risk for smoking after bariatric surgery. 


\section{Table 1}

Descriptive statistics of continuous variables for the ECR-ANX/AVO datasets.

\begin{tabular}{lccccc}
\hline & \multicolumn{2}{c}{ ECR-ANX Data } & & \multicolumn{2}{c}{ ECR-AVO Data } \\
\cline { 2 - 3 } \cline { 5 - 6 } Variable & $M(S D)$ & $N$ & & $M(S D)$ & $N$ \\
& & $(\%$ of 418$)$ & & & \\
Pre-op BMI & $48.8(9.04)$ & $418(100 \%)$ & & $48.8(9.07)$ & $421(100 \%)$ \\
Pre-op age & $44.2(10.9)$ & $416(99 \%)$ & & $44.2(10.9)$ & $420(99 \%)$ \\
Pre-op household income & $\$ 82,865.29$ & $191(46 \%)$ & & $\$ 82,078.72$ & $194(46 \%)$ \\
& $(\$ 45,893.95)$ & & & $(\$ 46,021.41)$ & \\
\hline
\end{tabular}




\section{Table 2}

Descriptive statistics of categorical variables for the ECR-ANX/AVO datasets.

\begin{tabular}{|c|c|c|c|c|}
\hline \multirow[b]{2}{*}{ Variable } & \multicolumn{2}{|c|}{ ECR-ANX Data } & \multicolumn{2}{|c|}{ ECR-AVO Data } \\
\hline & Frequency & $\%$ of 418 & Frequency & $\%$ of 421 \\
\hline \multicolumn{5}{|l|}{ Gender } \\
\hline Female & 346 & $82.8 \%$ & 350 & $83.1 \%$ \\
\hline Male & 70 & $16.7 \%$ & 70 & $16.6 \%$ \\
\hline Missing & 2 & $0.5 \%$ & 1 & $0.2 \%$ \\
\hline \multicolumn{5}{|l|}{ Race / Ethnicity } \\
\hline White & 279 & $66.7 \%$ & 281 & $66.7 \%$ \\
\hline Black & 26 & $6.2 \%$ & 27 & $6.4 \%$ \\
\hline Latin / South American & 12 & $2.9 \%$ & 12 & $2.9 \%$ \\
\hline South East Asian & 8 & $1.9 \%$ & 8 & $1.9 \%$ \\
\hline Aboriginal & 5 & $1.2 \%$ & 5 & $1.2 \%$ \\
\hline Arab / West Asian & 1 & $0.2 \%$ & 1 & $0.2 \%$ \\
\hline Other & 3 & $0.7 \%$ & 3 & $0.7 \%$ \\
\hline Missing & 80 & $19.1 \%$ & 80 & $19.0 \%$ \\
\hline \multicolumn{5}{|c|}{ Presurgical relationship status } \\
\hline Married & 216 & $51.7 \%$ & 217 & $51.5 \%$ \\
\hline Common-law & 37 & $8.9 \%$ & 38 & $9.0 \%$ \\
\hline Divorced & 28 & $6.7 \%$ & 29 & $6.9 \%$ \\
\hline Separated & 19 & $4.5 \%$ & 19 & $4.5 \%$ \\
\hline Single, never married & 85 & 20.3 & 87 & $20.7 \%$ \\
\hline Widowed & 5 & $1.2 \%$ & 5 & $1.2 \%$ \\
\hline Missing & 28 & $6.7 \%$ & 26 & $6.2 \%$ \\
\hline \multicolumn{5}{|l|}{ Presurgical education } \\
\hline Some school & 25 & $6.0 \%$ & 26 & $6.2 \%$ \\
\hline Completed high school & 68 & $16.3 \%$ & 68 & $16.2 \%$ \\
\hline Some college & 36 & $8.6 \%$ & 36 & $8.6 \%$ \\
\hline Some university & 22 & $5.3 \%$ & 22 & $5.2 \%$ \\
\hline College diploma & 140 & $33.5 \%$ & 144 & $34.2 \%$ \\
\hline Bachelor's degree & 71 & $17.0 \%$ & 71 & $16.9 \%$ \\
\hline Graduate degree & 15 & $3.6 \%$ & 15 & $3.6 \%$ \\
\hline Missing & 41 & $9.8 \%$ & 39 & $9.3 \%$ \\
\hline \multicolumn{5}{|c|}{ Presurgical occupational status } \\
\hline Full-time & 260 & $62.2 \%$ & 262 & $62.2 \%$ \\
\hline Part-time & 31 & $7.4 \%$ & 32 & $7.6 \%$ \\
\hline Unemployed & 31 & $7.4 \%$ & 31 & $7.4 \%$ \\
\hline Retired & 22 & $5.3 \%$ & 22 & $5.2 \%$ \\
\hline Social assistance & 7 & $1.7 \%$ & 7 & $1.7 \%$ \\
\hline Disability & 31 & $7.4 \%$ & 33 & $7.8 \%$ \\
\hline Missing & 36 & $8.6 \%$ & 34 & $8.1 \%$ \\
\hline
\end{tabular}


Table 3a.

Descriptive statistics for model variables for ECR-ANX data.

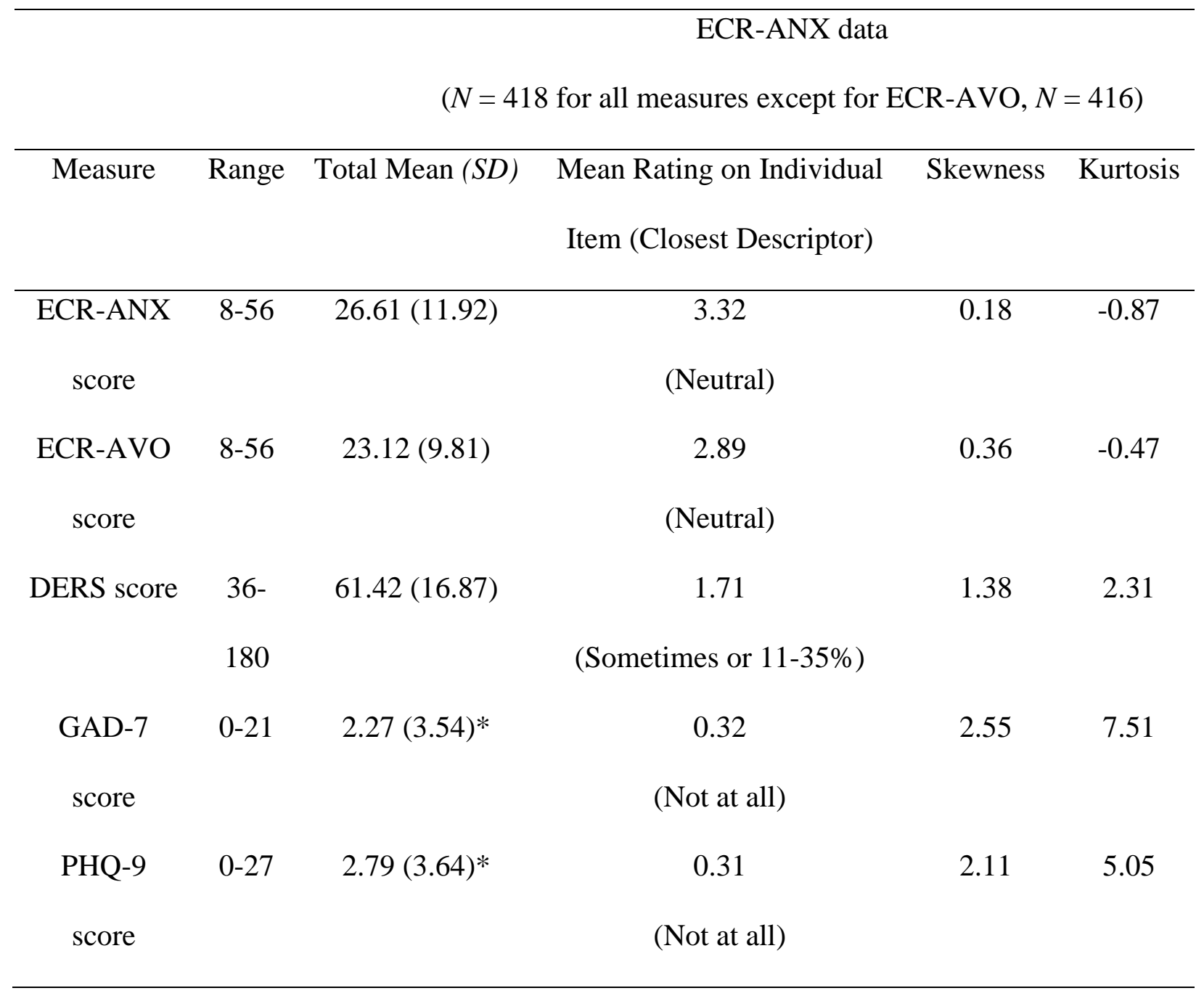

*Note: The total mean scores for GAD-7 and PHQ-9 fall below the clinical cut point of five for mild severity (Kroenke et al., 2001; Spitzer et al., 2006). 
Table 3b.

Descriptive statistics for model variables for ECR-AVO data.

\begin{tabular}{|c|c|c|c|c|c|}
\hline \multirow[b]{2}{*}{ Measure } & \multicolumn{5}{|c|}{$(N=421$ for all measures except for ECR-ANX, $N=416)$} \\
\hline & Range & Total Mean $(S D)$ & $\begin{array}{c}\text { Mean Rating on Individual } \\
\text { Item (Closest Category) }\end{array}$ & Skewness & Kurtosis \\
\hline $\begin{array}{l}\text { ECR-ANX } \\
\text { score }\end{array}$ & $8-56$ & $26.60(11.93)$ & $\begin{array}{c}3.35 \\
(\text { Neutral })\end{array}$ & 0.18 & -0.87 \\
\hline $\begin{array}{l}\text { ECR-AVO } \\
\text { score }\end{array}$ & $8-56$ & $23.18(9.80)$ & $\begin{array}{c}2.90 \\
\text { (Neutral) }\end{array}$ & 0.35 & -0.48 \\
\hline DERS score & $\begin{array}{l}36- \\
180\end{array}$ & $61.53(16.93)$ & $\begin{array}{c}1.71 \\
\text { (Sometimes or } 11-35 \%)\end{array}$ & 1.35 & 2.20 \\
\hline $\begin{array}{l}\text { GAD-7 } \\
\text { score }\end{array}$ & $0-21$ & $2.27(3.54)^{*}$ & $\begin{array}{c}0.32 \\
\text { (Not at all) }\end{array}$ & 2.55 & 7.51 \\
\hline $\begin{array}{l}\text { PHQ-9 } \\
\text { score }\end{array}$ & $0-27$ & $2.79(3.64) *$ & $\begin{array}{c}0.31 \\
\text { (Not at all) }\end{array}$ & 2.11 & 5.05 \\
\hline
\end{tabular}

*Note: The total mean scores for GAD-7 and PHQ-9 fall below the clinical cut point of five for mild severity (Kroenke et al., 2001; Spitzer et al., 2006). 


\section{Table 4}

Bivariate Pearson correlations (r) between model variables for ECR-ANX/AVO data.

\section{ECR-ANX data}

( $N=418$ for all correlations except those with ECR-AVO, $N=416$ )

\begin{tabular}{lccccc}
\hline Measure & 1. ECR-ANX & 2. ECR-AVO & 3. DERS & 4. GAD-7 & 5. PHQ-9 \\
1. ECR-ANX & 1 & $.41^{* *}$ & $.37^{* *}$ & $.20^{* *}$ & $.20^{* *}$ \\
2. ECR-AVO & $.41^{* *}$ & 1 & $.29^{* *}$ & .06 & .09 \\
3. DERS & $.37^{* *}$ & $.29^{* *}$ & 1 & $.54^{* *}$ & $.54^{* *}$ \\
4. GAD-7 & $.20^{* *}$ & .06 & $.54^{* *}$ & 1 & $.80^{* *}$ \\
5. PHQ-9 & $.20^{* *}$ & .09 & $.54^{* *}$ & $.80^{* *}$ & 1 \\
\hline
\end{tabular}

\section{ECR-AVO data}

$(N=421$ for all correlations except those with ECR-ANX, $N=416)$

\begin{tabular}{|c|c|c|c|c|c|}
\hline Measure & 1. ECR-ANX & 2. ECR-AVO & 3. DERS & 4. GAD-7 & 5. PHQ-9 \\
\hline 1. ECR-ANX & 1 & $.41^{* *}$ & $.37^{* *}$ & $.20^{* *}$ & $.20^{* *}$ \\
\hline 2. ECR-AVO & $.41^{* *}$ & 1 & $.30^{* *}$ & .07 & $.10^{*}$ \\
\hline 3. DERS & $.37^{* *}$ & $.30^{* *}$ & 1 & $.55^{* *}$ & $.55^{* *}$ \\
\hline 4. GAD-7 & $.20^{* *}$ & .07 & $.55^{* *}$ & 1 & $.81^{* *}$ \\
\hline 5. PHQ-9 & $.20^{* *}$ & $.10^{*}$ & $.55^{* *}$ & $.81^{* *}$ & 1 \\
\hline
\end{tabular}


Table 5a.

Collinearity statistics with smoking as the dependent variable.

\begin{tabular}{lcc}
\hline Measure & Tolerance & Variance Inflation Factor (VIF) \\
\hline ECR-ANX & .76 & 1.31 \\
ECR-AVO & .80 & 1.26 \\
DERS & .58 & 1.73 \\
GAD-7 & .33 & 3.01 \\
PHQ-9 & .34 & 2.95 \\
\hline
\end{tabular}

Table $5 b$.

Collinearity diagnostics with smoking as the dependent variable.

Variance Proportions

\begin{tabular}{|c|c|c|c|c|c|c|c|c|}
\hline Dimension & Eigenvalue & Condition & Constant & ECR- & ECR- & DERS & GAD- & PHQ- \\
\hline & & Index & & ANX & AVO & & 7 & 9 \\
\hline 1 & 4.76 & 1.00 & .00 & .00 & .00 & .00 & .01 & .01 \\
\hline 2 & .90 & 2.31 & .00 & .01 & .01 & .00 & .11 & .08 \\
\hline 3 & .13 & 6.03 & .00 & .01 & .00 & .00 & .80 & .88 \\
\hline 4 & .10 & 6.93 & .13 & .82 & .00 & .05 & .01 & .01 \\
\hline 5 & .09 & 7.29 & .06 & .14 & .98 & .03 & .03 & .00 \\
\hline 6 & .03 & 13.47 & .81 & .01 & .00 & .92 & .05 & .02 \\
\hline
\end{tabular}


Table 6.

Maximum likelihood estimates of regression coefficients using a second stage dual moderated mediation model using the ECR-ANX data.

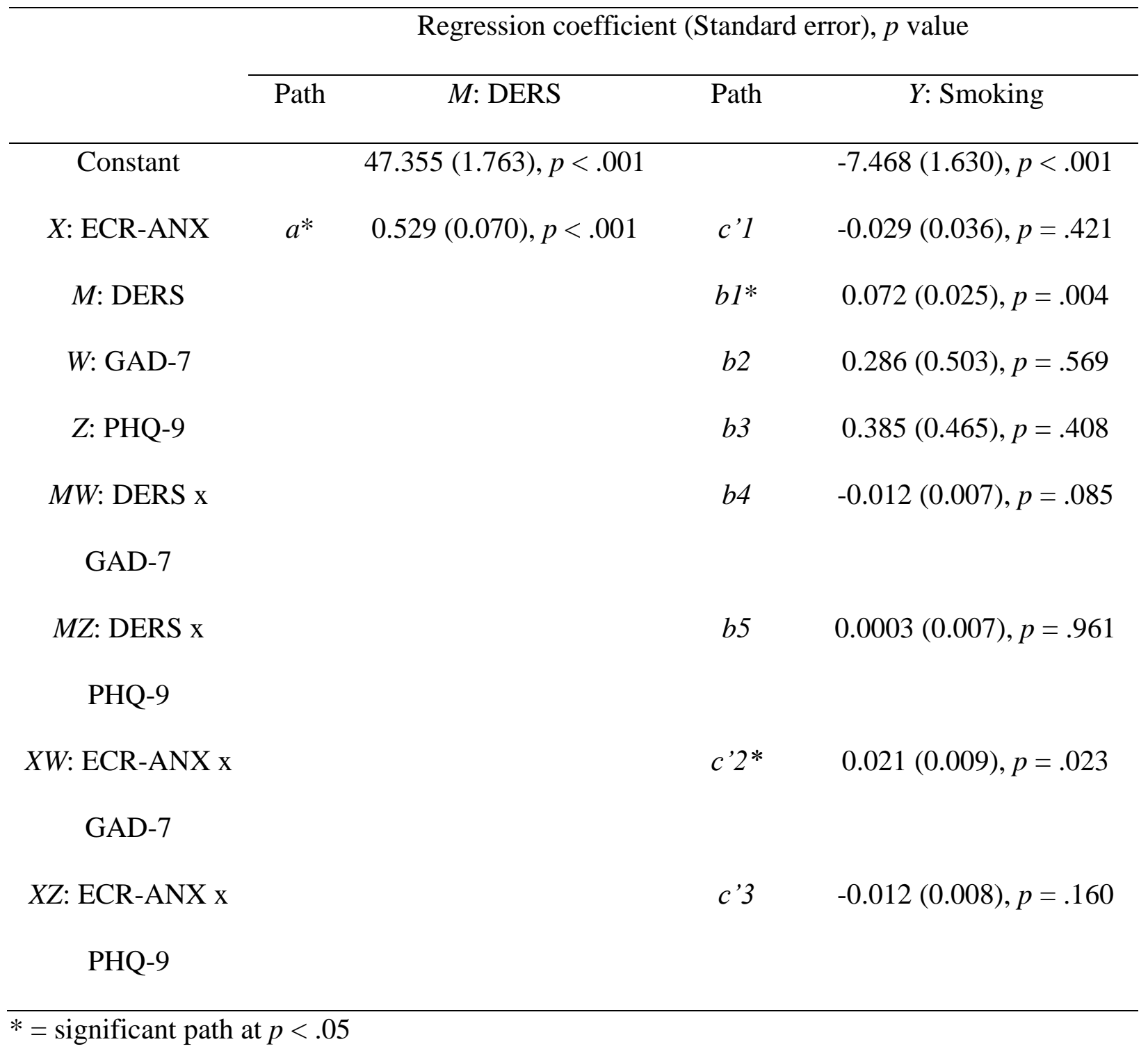

Note: The $a$ path coefficient from ECR-ANX to DERS is calculated using ordinary least squares since the DERS score is a continuous variable. 


\section{Table 7}

Maximum likelihood estimates of regression coefficients using a second stage dual moderated mediation model using the ECR-AVO data.

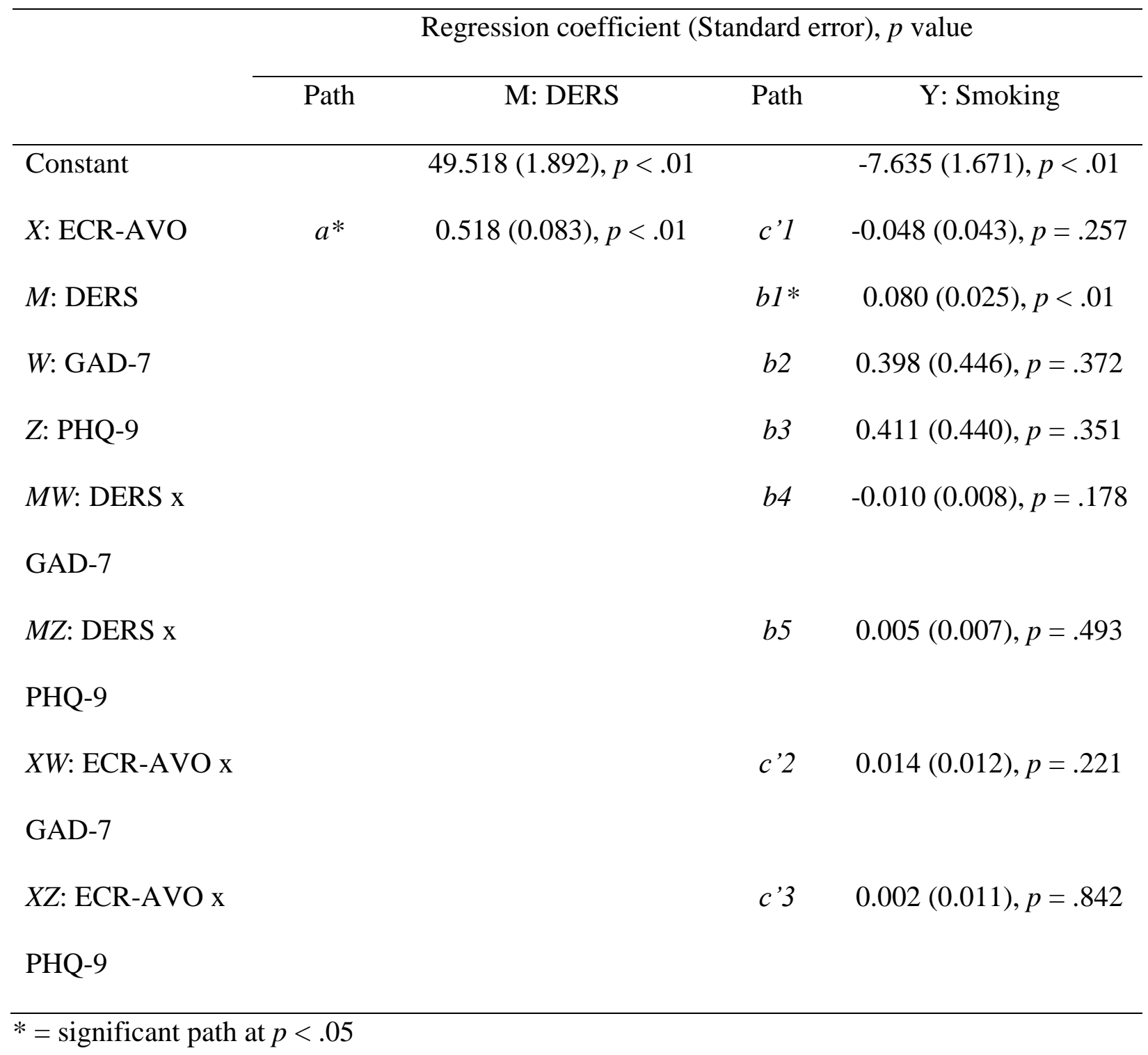

Note: The $a$ path coefficient from ECR-AVO to DERS is calculated using ordinary least squares since the DERS score is a continuous variable. 


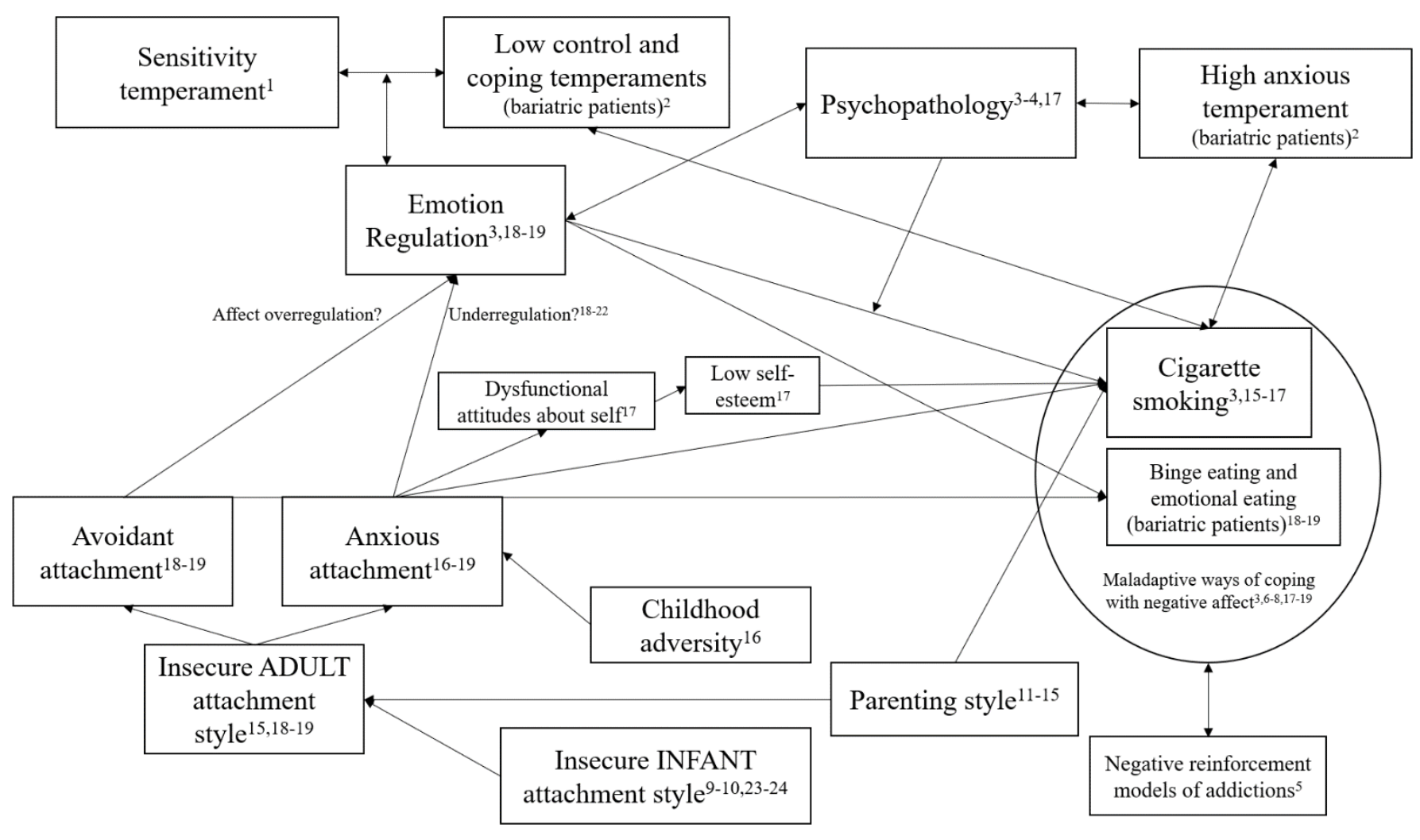

Figure 1. Visual representation of the concepts discussed in the articles described in the introduction. Double-sided arrows represent associations between concepts with no inference of causal direction. Single-sided arrows represent pathways of empirically supported causality or proposed causal relationships. Figure 1 references: (1) Lara et al. (2012); (2) Mombach et al. (2016); (3) Farris et al. (2016); (4) Mennin et al. (2007); (5) Baker et al. (2004); (6) Shiffman (2005); (7) Shiffman and Waters (2004); (8) Shiffman et al. (2007); (9) Hazan and Shaver (1987); (10) Waters et al. (2000); (11) Foxcroft and Geoff (1995); (12) Radziszewska et al. (1996); (13) Wang et al. (2015); (14) Wilhelm et al. (2016); (15) Csala et al. (2016); (16) Le et al. (2017); (17) Kassel et al. (2007); (18) Shakory et al. (2015); (19) Taube-Schiff et al. (2015); (20) Hunter and Maunder (2001); (21) Maunder and Hunter (2012); (22) Shaver et al. (2008); (23) Fraley (2002); (24) Fraley et al. (2011). 

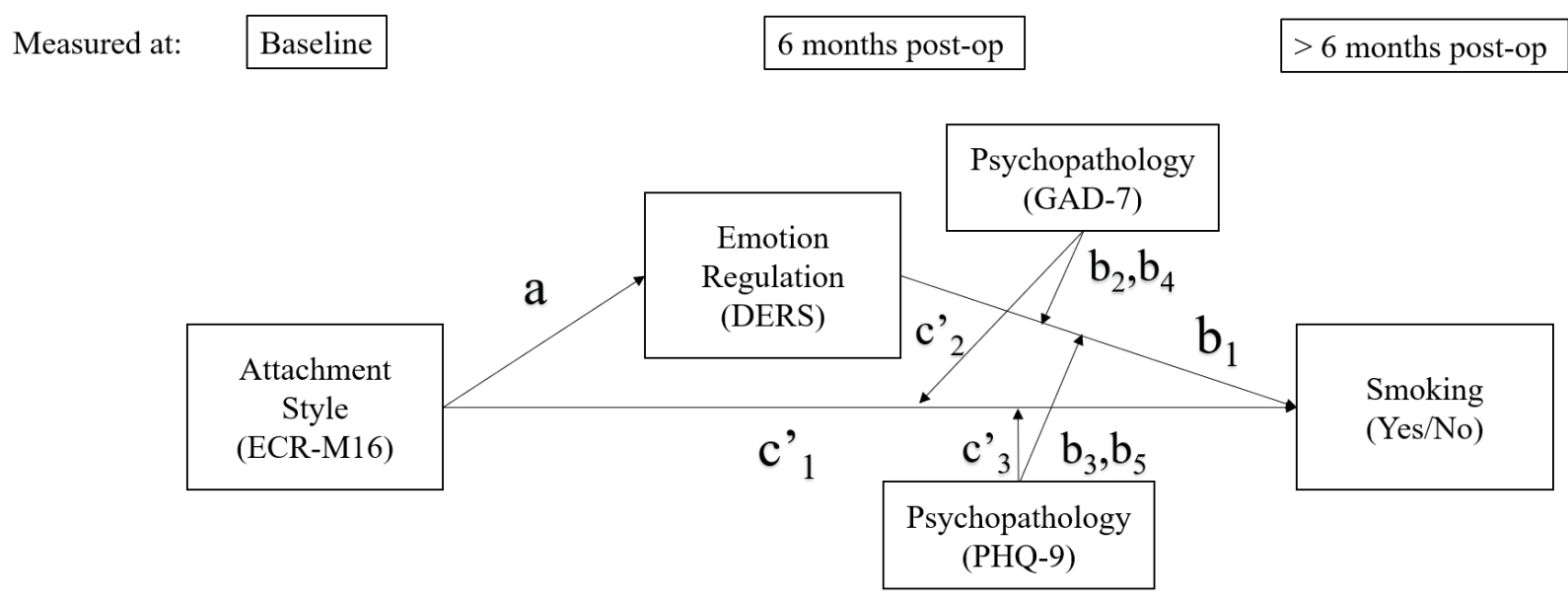

Figure 2. Second stage dual moderated mediation model of attachment style, emotional regulation, psychopathology, and cigarette smoking across three timepoints (Model 17 in Hayes, 2013). This is the primary model tested in the present study. Psychopathology is based on the two separate scores of the PHQ-9 and GAD-7 measured at six months postsurgery. Path notations are based on Figure 7 (reproduced from Hayes, 2018). 
Measured at:

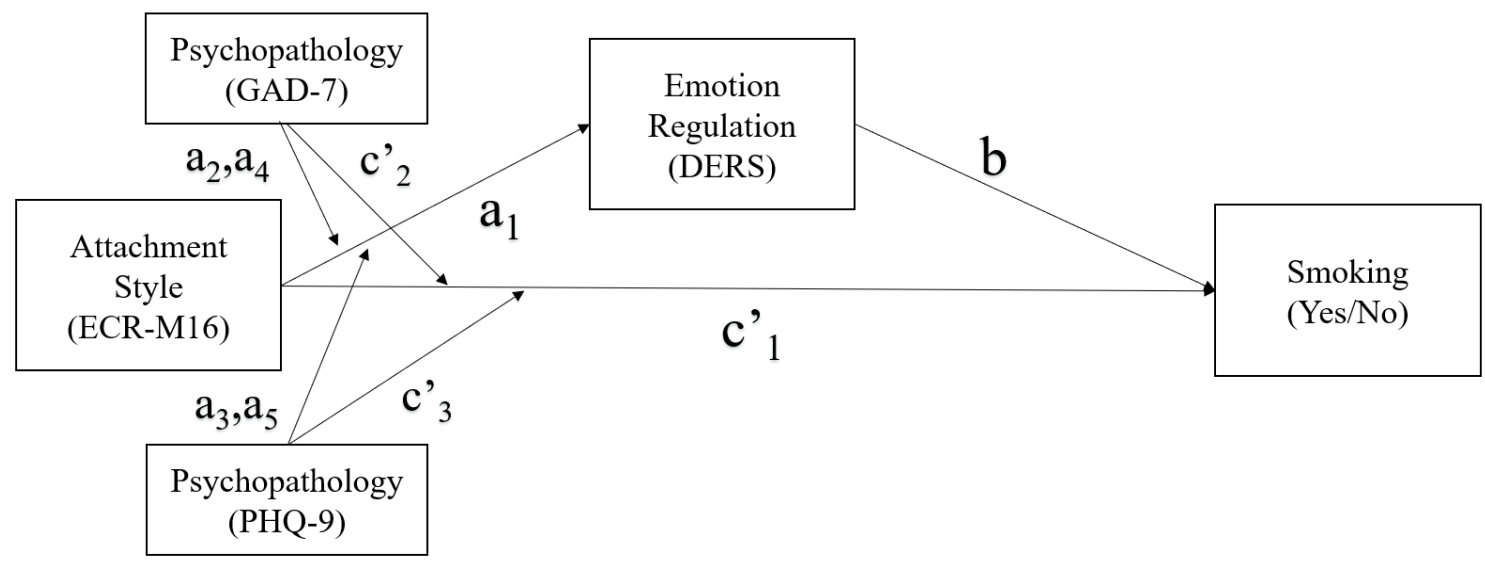

Figure 3. First stage dual moderated mediation model of attachment style, emotion regulation, psychopathology, and cigarette smoking across three timepoints (Model 10 in Hayes, 2013). Psychopathology is based on the two separate scores of the PHQ-9 and GAD-7 measured at presurgery. This is an alternative model tested in a post-hoc analysis. Path notations are based on Hayes (2018). 

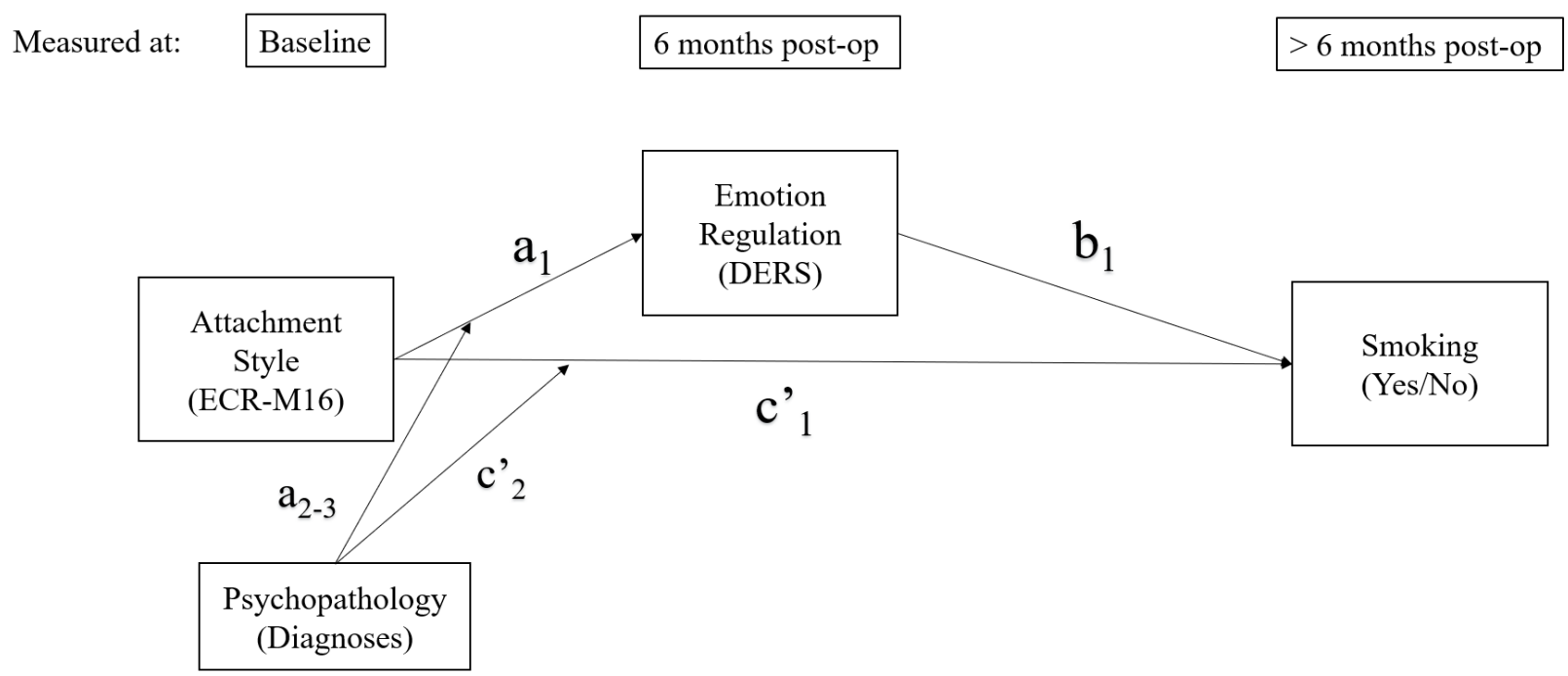

Figure 4. First stage moderated mediation model of attachment style, emotion regulation, psychopathology, and cigarette smoking across three timepoints (Model 8 in Hayes, 2013). Psychopathology is based on presurgical MINI psychological disorder diagnoses. This is an alternative model tested in a post-hoc analysis. Path notations are based on Hayes (2015). 


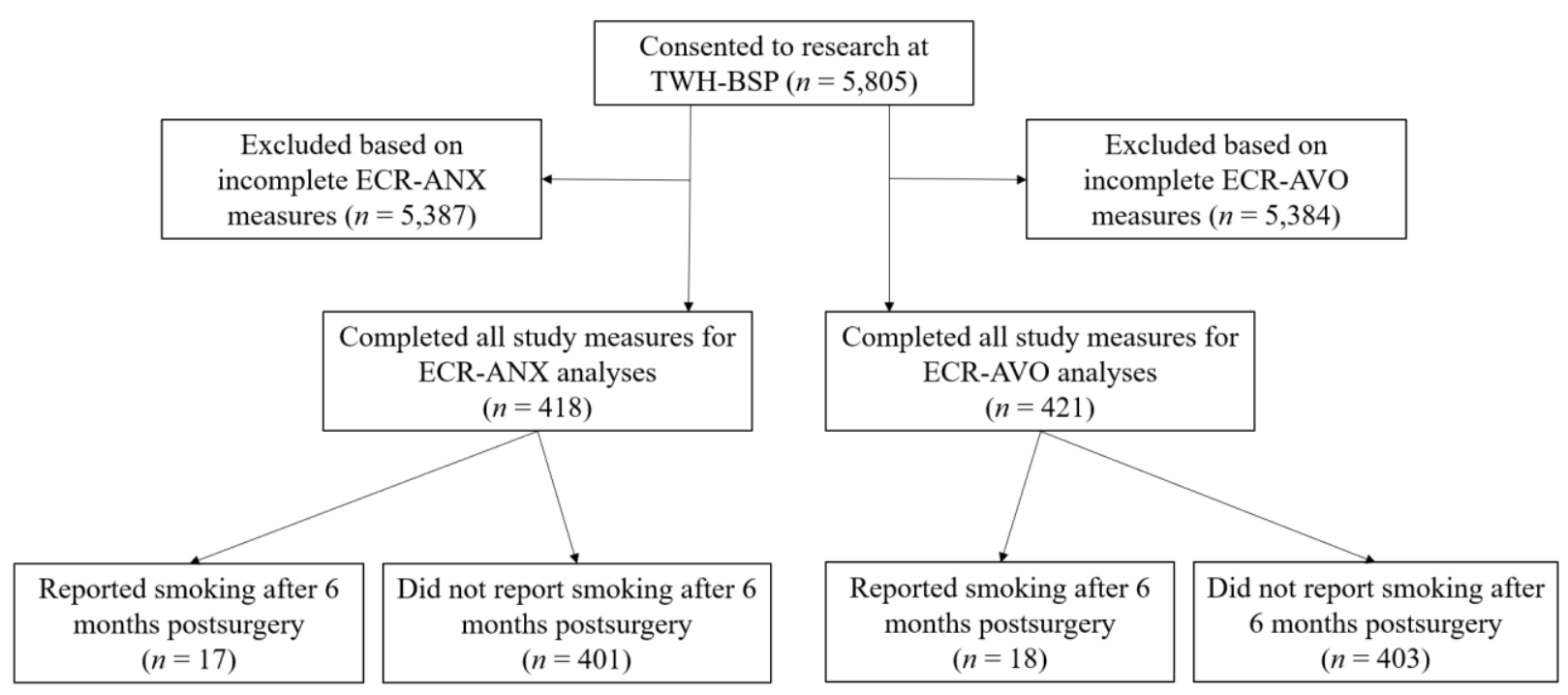

Figure 5. Study participant flow, where ECR-ANX measures include the presurgical ECR-M16 anxious attachment subscale and six-month postsurgical DERS, GAD-7, and PHQ-9 scales. ECR-AVO measures are the same except for the use of the presurgical ECR-M16 avoidant attachment subscale instead of the anxious attachment subscale. Reports of smoking were not used to exclude participants. All measures were present since the beginning of data collection for the larger psychosocial study (June 2010), except for smoking data, which has been collected both retrospectively and prospectively since around June-August 2016. Two participants were unique to the ECR-ANX dataset and five participants were unique to the ECR-AVO dataset, for a total analysed sample size of $N=423$. 

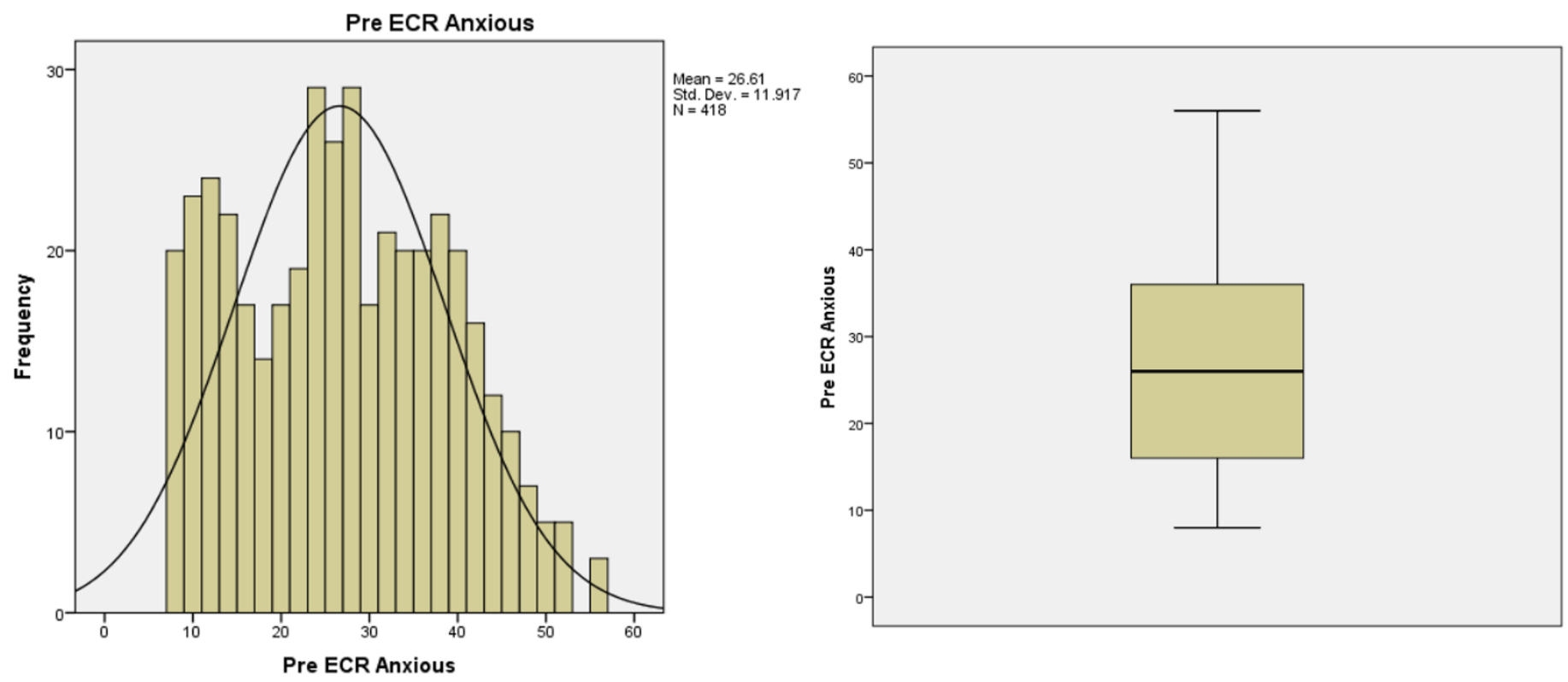

Figure 6a. Histogram (left) and boxplot (right) of presurgical ECR-Anxious scores for ECR-ANX data. The centre of the boxplot is the median, the top and bottom of the box represent the interquartile range (middle 50\% of scores), and the two whiskers represent the top and bottom $25 \%$ of scores (Field, 2013). 

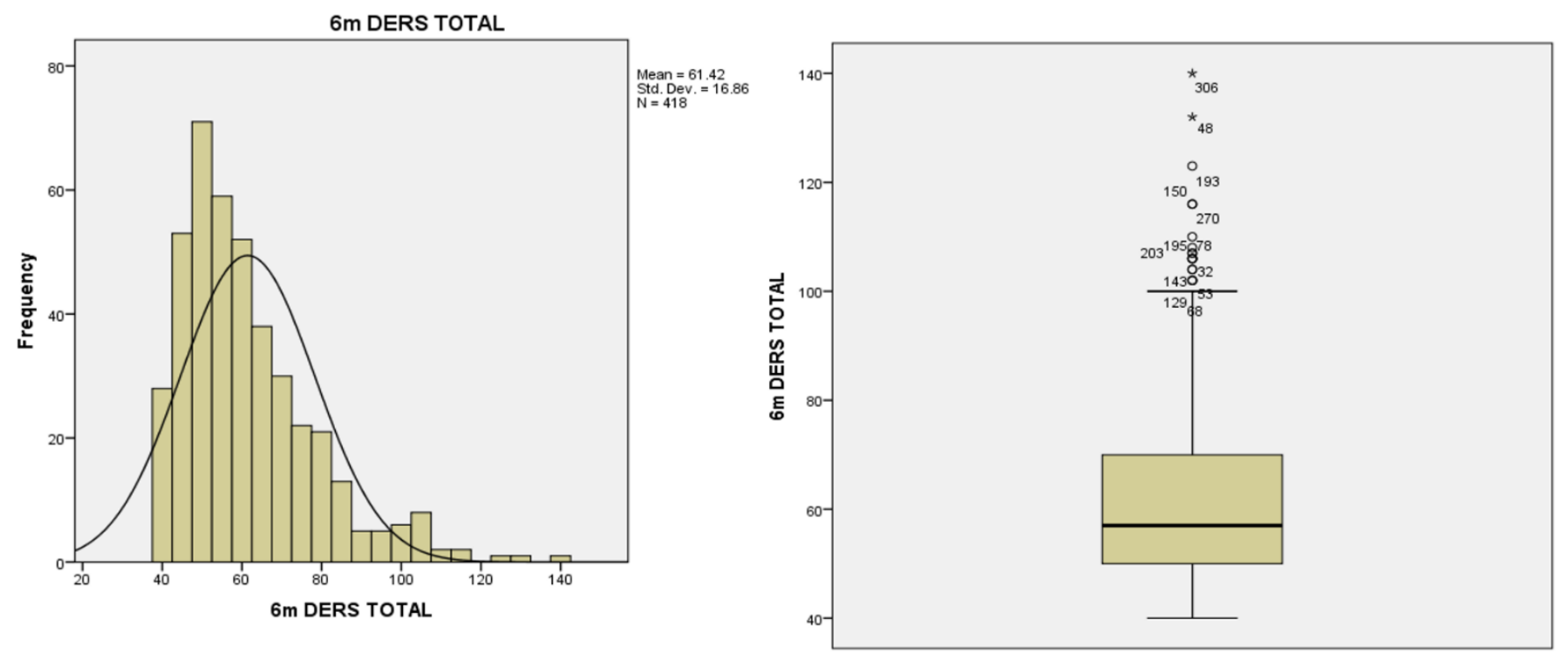

Figure 6b. Histogram (left) and boxplot (right) of six-month postsurgical DERS scores for ECRANX data. Outliers are represented by circles in the boxplots and indicate scores larger than the upper quartile plus 1.5 times the interquartile range. Asterisks represent extreme cases larger than the upper quartile plus 3 times the interquartile range (Field, 2013). The numbers in the boxplot refer to individual cases. 

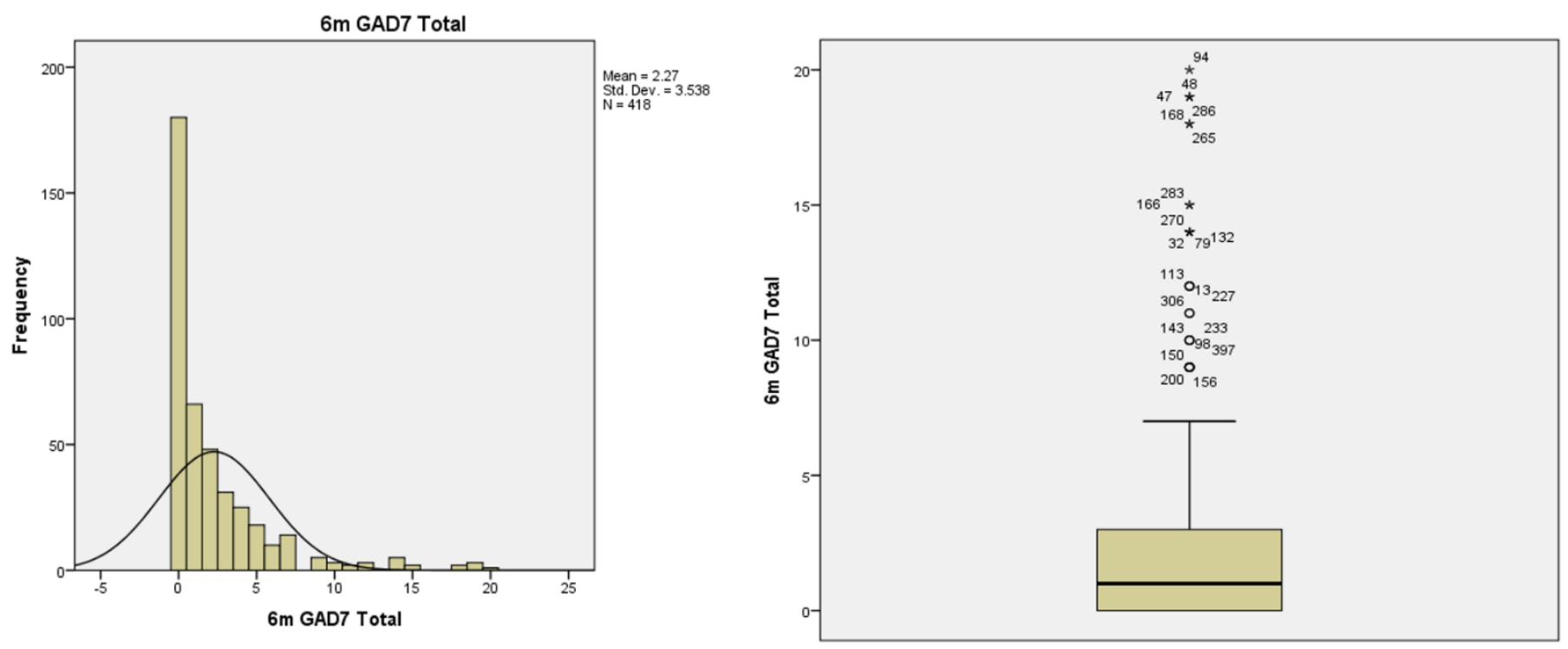

Figure 6c. Histogram (left) and boxplot (right) of six-month postsurgical GAD-7 scores for ECRANX data.
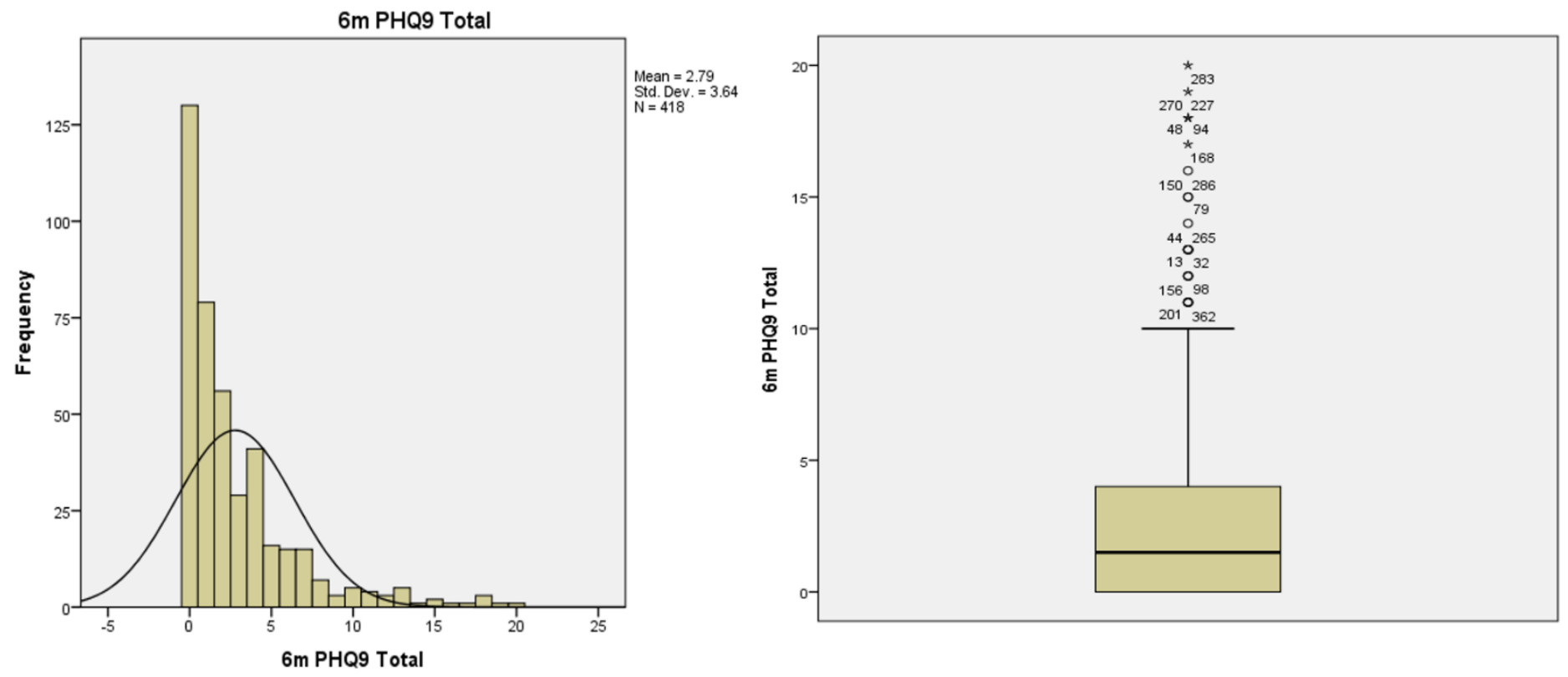

Figure 6d. Histogram (left) and boxplot (right) of six-month postsurgical PHQ-9 scores for ECRANX data. 


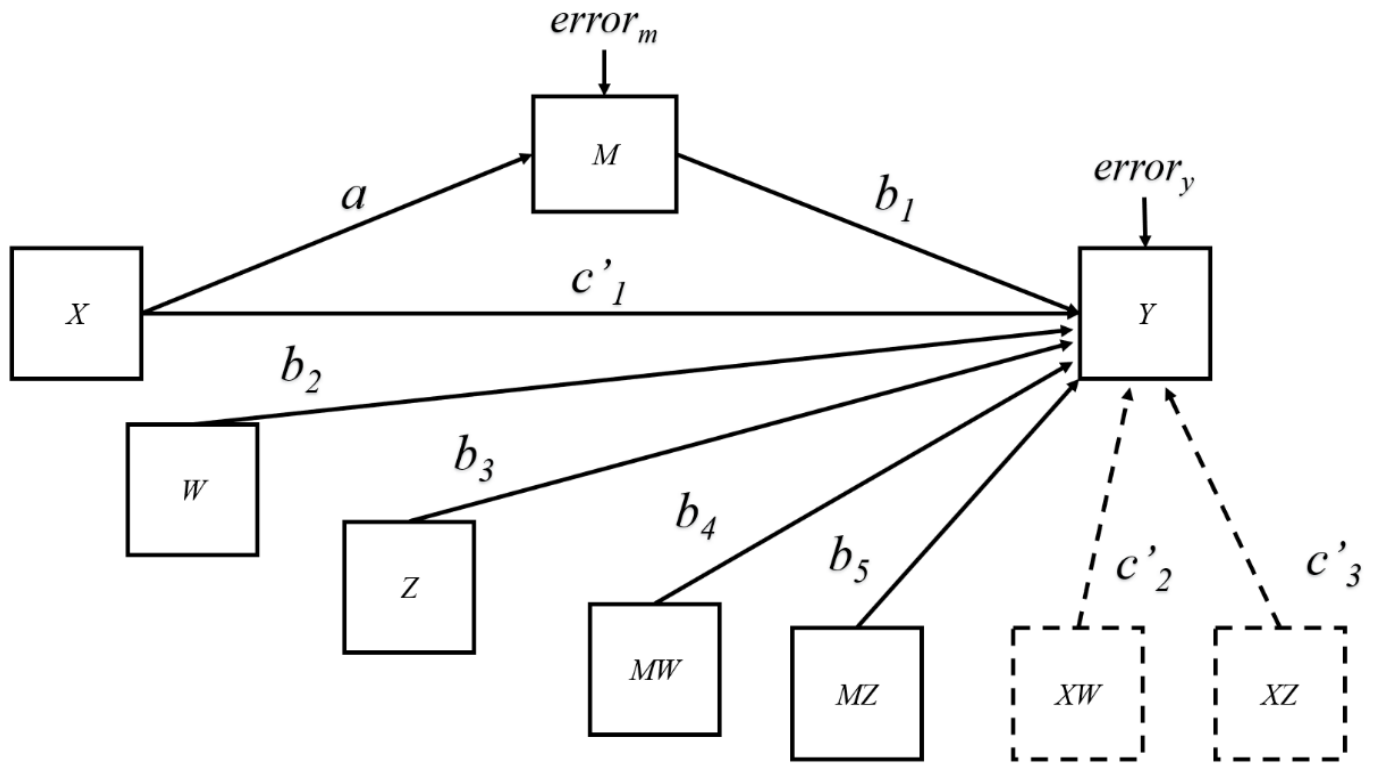

Figure 7. Statistical path diagram of the second stage dual moderated mediation model. Moderation of the direct effect of $\mathrm{X}$ is optional and is denoted by the dashed lines. Reproduced from Hayes (2018), p. 11. 


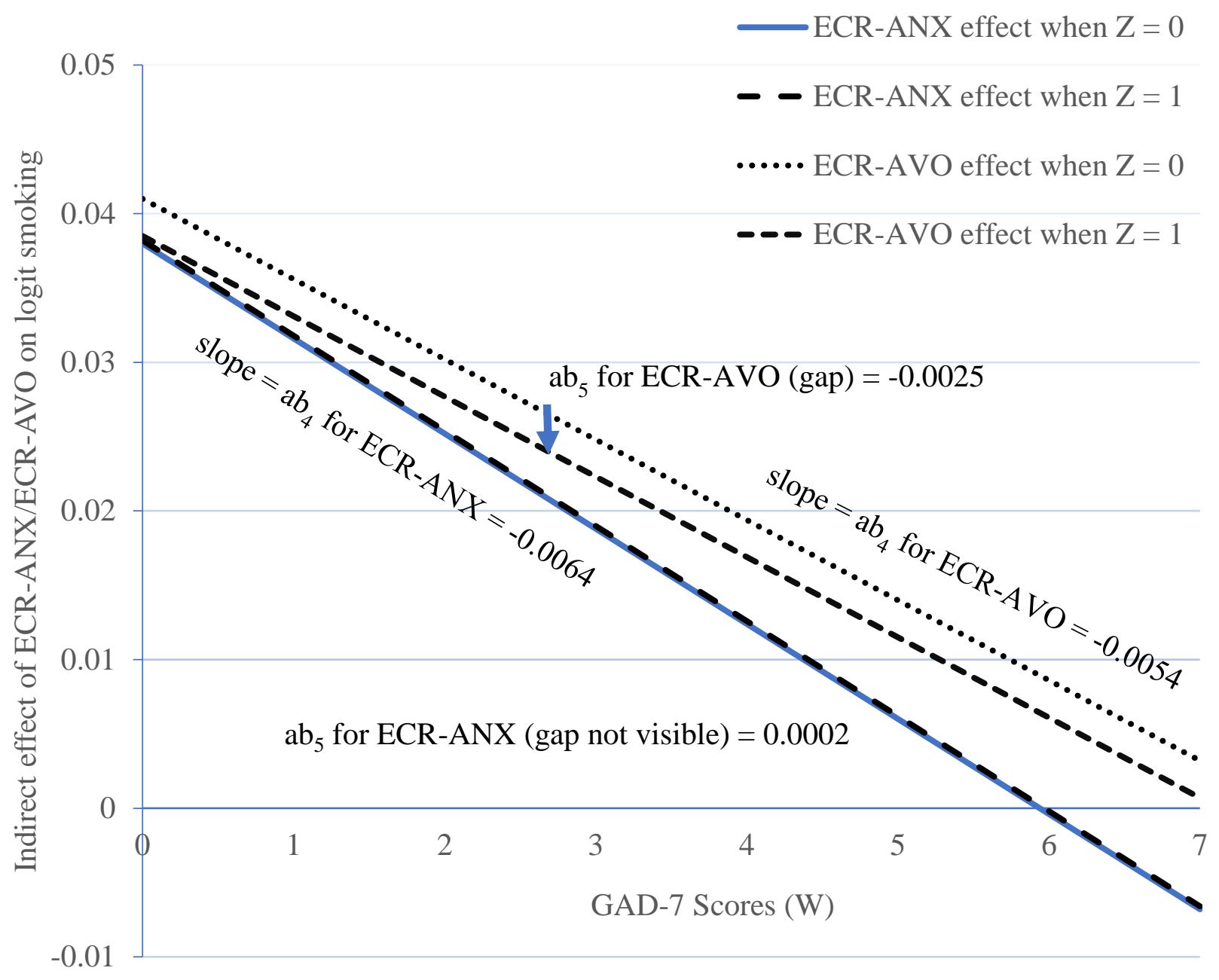

Figure 8. Indirect effect of ECR-ANX and ECR-AVO scores on logit smoking through DERS scores as a function of GAD-7 $(W)$ and PHQ-9 scores $(Z)$. The two overlapping bottom solid and dashed lines represent the linear function $a b_{1}+a b_{4} W+a b_{5} Z=0.038-0.0064(W)+0.0002(Z)$ for the ECR-ANX data. The two top dotted and dashed lines represent $0.041-0.0054(W)-0.0025(Z)$ for the ECR-AVO data. The indices of moderated mediation for $W$ and $Z$ are represented by the noted slopes and gaps, respectively. 


\section{Appendices}

Appendix A

\section{PROCESS output from SPSS for ECR-ANX data using the second stage dual moderated mediation model using GAD-7 and PHQ-9 scores and direct path moderation (Figure 2).}

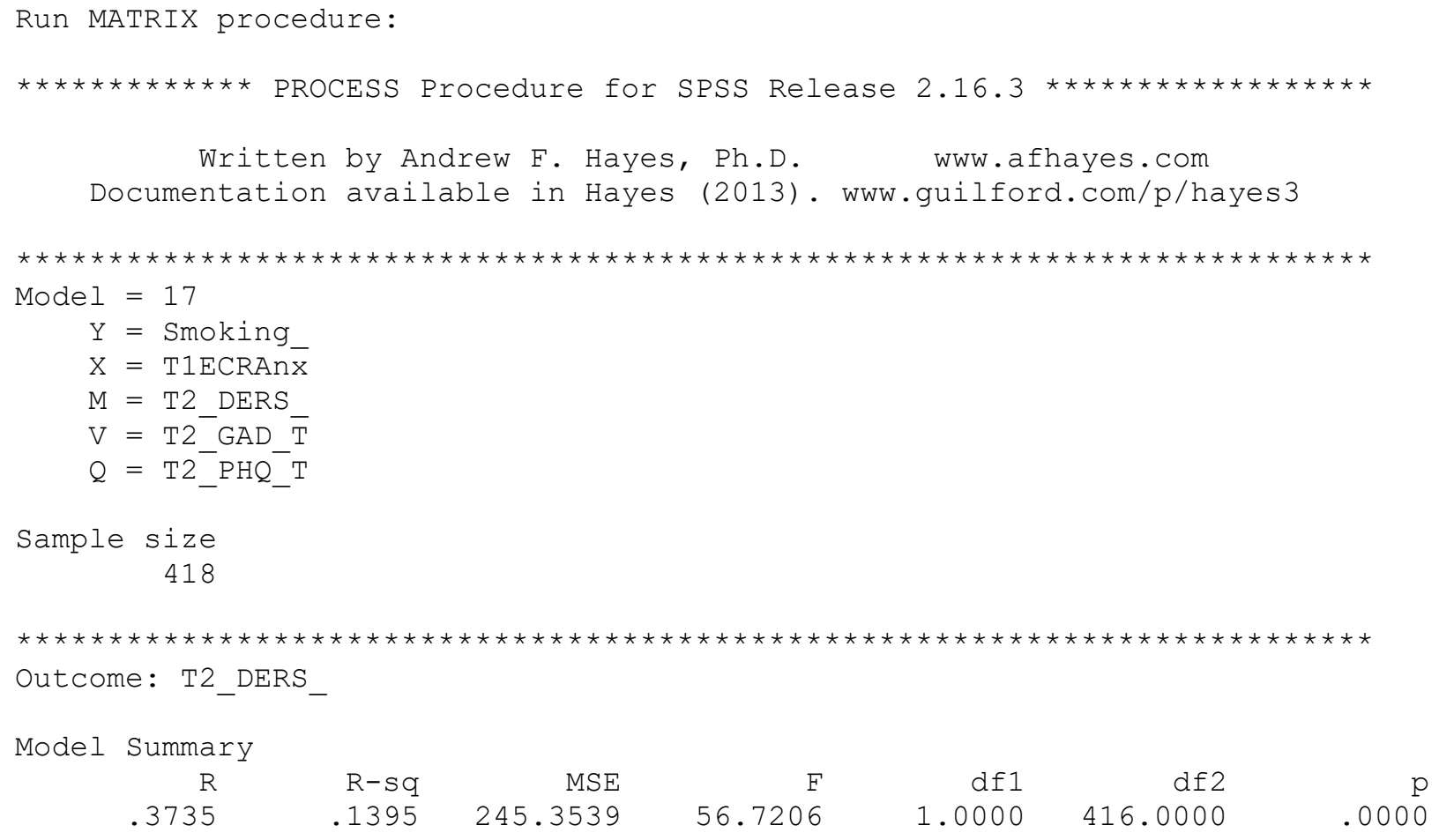

$\begin{array}{rrrrrrr} & \text { coeff } & \text { se } & t & p & \text { LLCI } & \text { ULCI } \\ \text { Constant } & 47.3549 & 1.7631 & 26.8585 & .0000 & 43.8892 & 50.8207 \\ \text { TlECRAnx } & .5285 & .0702 & 7.5313 & .0000 & .3906 & .6664\end{array}$




\begin{tabular}{|c|c|c|c|c|c|c|}
\hline T1ECRAnx & -.0290 & .0361 & -.8042 & .4213 & -.0997 & .0417 \\
\hline T2_GAD_T & .2864 & .5032 & .5691 & .5693 & -.6999 & 1.2728 \\
\hline $\mathrm{T}^{-} \mathrm{PHQ}^{-} \mathrm{T}$ & .3854 & .4653 & .8283 & .4075 & -.5266 & 1.2974 \\
\hline int $1-$ & -.0121 & .0071 & -1.7201 & .0854 & -.0260 & .0017 \\
\hline int_2 & .0003 & .0067 & .0490 & .9609 & -.0127 & .0134 \\
\hline int_3 & .0211 & .0093 & 2.2712 & .0231 & .0029 & .0392 \\
\hline int 4 & -.0119 & .0085 & -1.4036 & .1604 & -.0286 & .0047 \\
\hline
\end{tabular}

Product terms key:

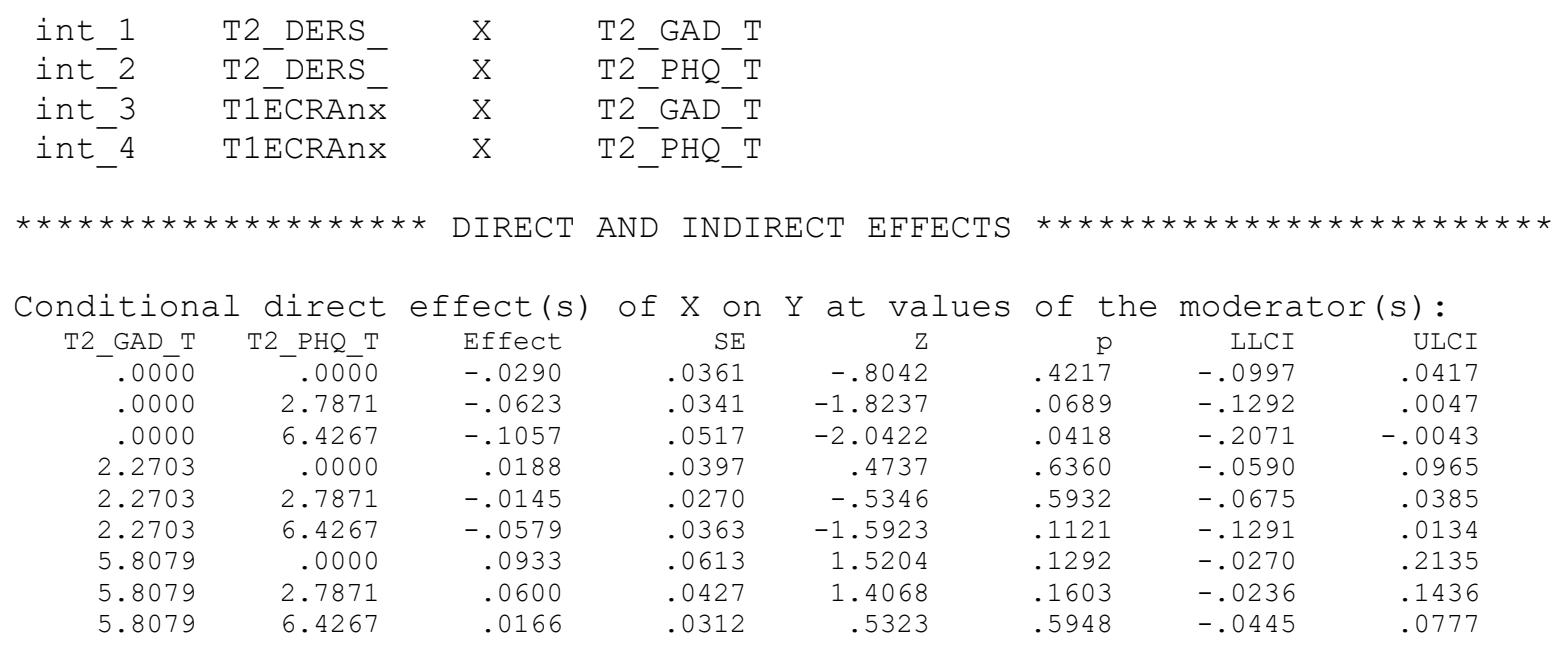

Conditional indirect effect(s) of $\mathrm{X}$ on $\mathrm{Y}$ at values of the moderator(s):

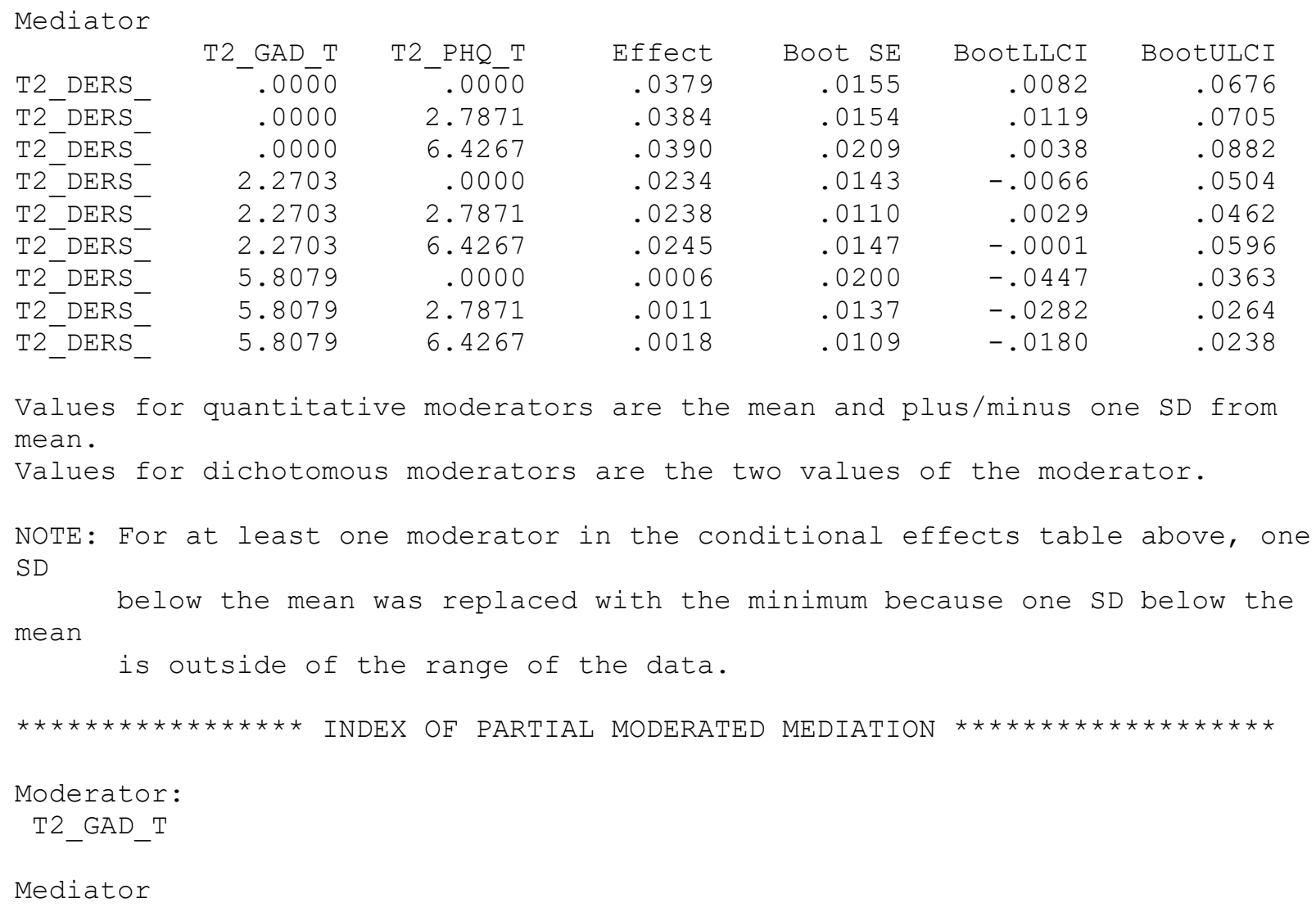




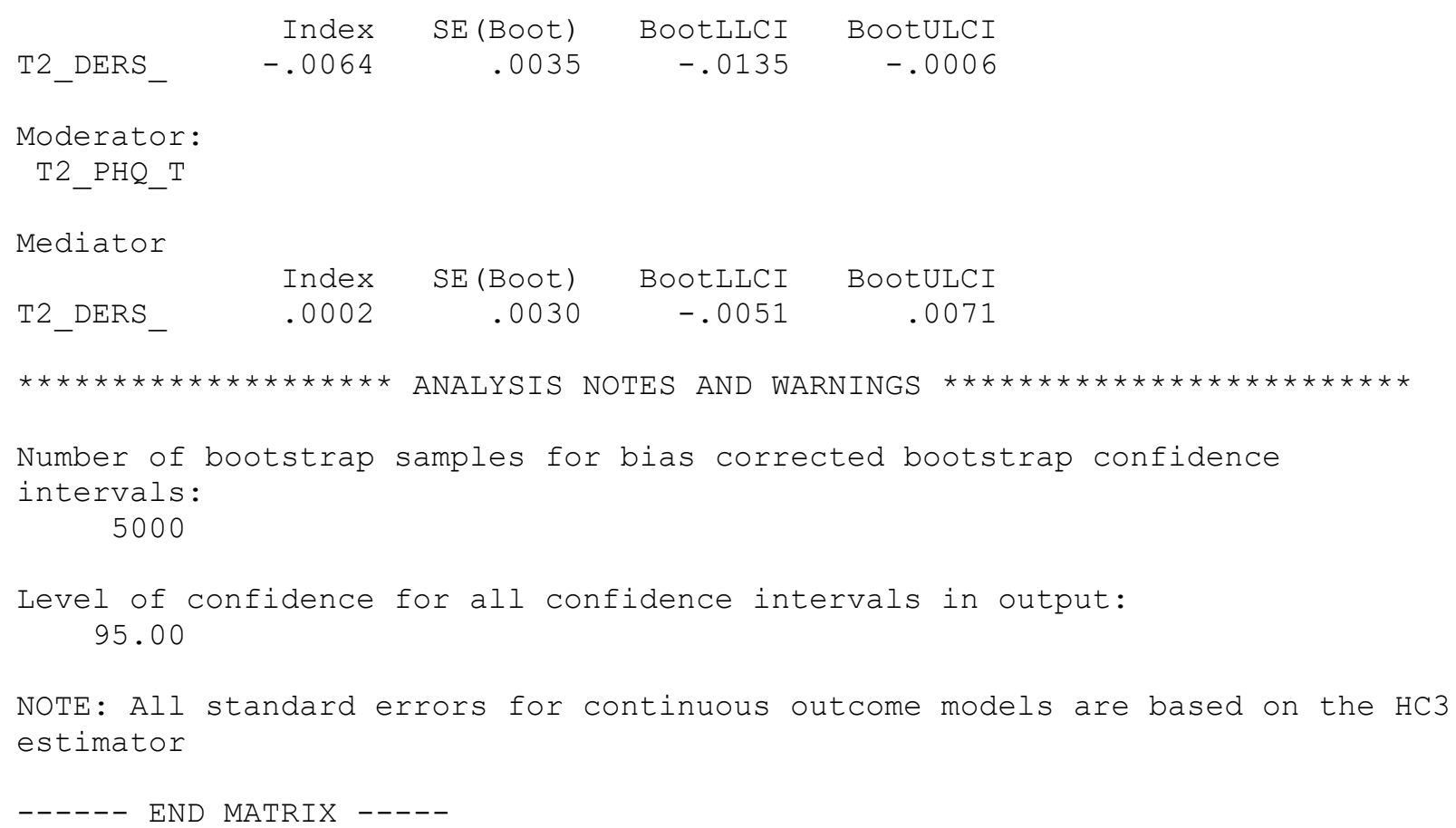




\section{Appendix B}

\section{PROCESS output from SPSS for ECR-AVO data using the second stage dual moderated mediation model using GAD-7 and PHQ-9 scores and direct path moderation (Figure 2).}

Run MATRIX procedure:

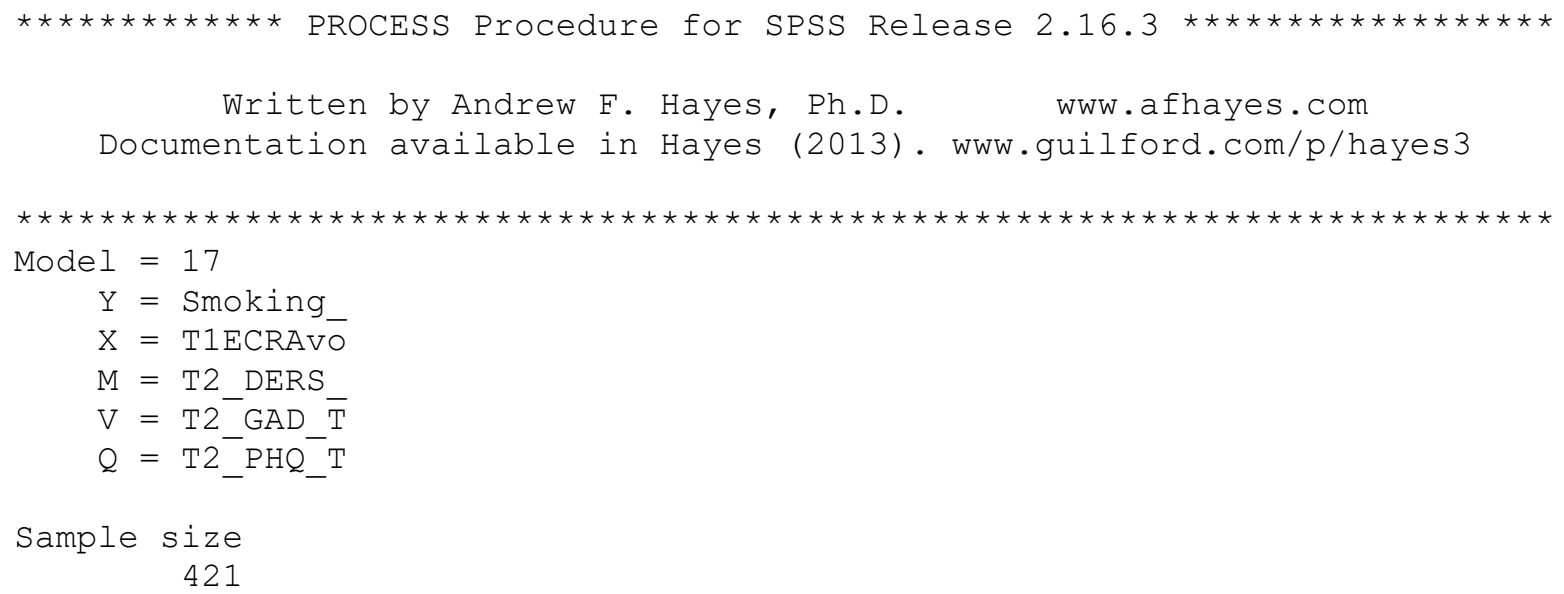

$\begin{array}{lrrrrrr} & \text { coeff } & \text { se } & \mathrm{z} & \mathrm{p} & \text { LLCI } & \text { ULCI } \\ \text { Constant } & -7.6345 & 1.6711 & -4.5687 & .0000 & -10.9097 & -4.3593 \\ \text { T2_DERS_ } & .0797 & .0246 & 3.2379 & .0012 & .0315 & .1280 \\ \text { T1ECRAvo } & -.0482 & .0425 & -1.1342 & .2567 & -.1314 & .0351 \\ \text { T2_GAD_T } & .3983 & .4464 & .8923 & .3722 & -.4766 & 1.2733\end{array}$




\begin{tabular}{|c|c|c|c|c|c|c|}
\hline T2 PHQ T & .4108 & .4400 & .9335 & .3506 & -.4517 & 1.2732 \\
\hline int $1-$ & -.0104 & .0078 & -1.3476 & .1778 & -.0256 & .0047 \\
\hline int 2 & -.0049 & .0071 & -.6861 & .4926 & -.0188 & .0091 \\
\hline int ${ }_{-3}$ & .0144 & .0118 & 1.2234 & .2212 & -.0087 & .037 \\
\hline int_4 & .0022 & .0108 & .1999 & .8416 & -.0190 & 0233 \\
\hline
\end{tabular}

Product terms key:

\begin{tabular}{|c|c|c|c|c|c|c|c|c|}
\hline int 1 & T2 DERS & $\mathrm{X}$ & T2 & GAD T & & & & \\
\hline int 2 & $\mathrm{~T} 2^{-} \mathrm{DERS}{ }^{-}$ & $\mathrm{X}$ & $\mathrm{T} 2$ & $\mathrm{PHQ}^{-} \mathrm{T}$ & & & & \\
\hline int 3 & T1ĒERAvo & $\mathrm{X}$ & $\mathrm{T} 2$ & GAD_T & & & & \\
\hline int ${ }^{-} 4$ & T1ECRAvo & $\mathrm{X}$ & $\mathrm{T} 2$ & $\mathrm{PHQ}_{-}^{-} \mathrm{T}$ & & & & \\
\hline 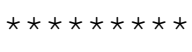 & 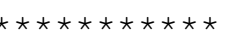 & DIRECT & AND & INDIREC? & CT EFFECTS & 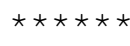 & 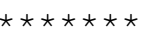 & 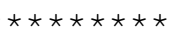 \\
\hline Condition & al direct ef & ffect (s) & of & $X$ on $Y$ & at values & of the & modera & s) : \\
\hline T2 GAD $\mathrm{T}$ & T2 PHQ T & Effect & & SE & Z & $\mathrm{p}$ & LLCI & ULCI \\
\hline$-.00 \overline{0} 0$ & $-.00 \overline{0} 0$ & -.0482 & & .0425 & -1.1342 & .2574 & -.1314 & .0351 \\
\hline .0000 & 2.8242 & -.0421 & & .0408 & -1.0305 & .3034 & -.1222 & .0380 \\
\hline .0000 & 6.4923 & -.0342 & & .0652 & -.5244 & .6003 & -.1620 & .0936 \\
\hline 2.2684 & .0000 & -.0154 & & .0463 & -.3330 & .7393 & -.1061 & .0752 \\
\hline 2.2684 & 2.8242 & -.0093 & & .0296 & -.3152 & .7528 & -.0673 & .0487 \\
\hline 2.2684 & 6.4923 & -.0014 & & .0447 & -.0320 & .9745 & -.0890 & .0861 \\
\hline 5.8001 & .0000 & .0356 & & .0743 & .4794 & .6319 & -.1100 & .1812 \\
\hline 5.8001 & 2.8242 & .0417 & & .0500 & .8343 & .4046 & -.0562 & .1396 \\
\hline 5.8001 & 6.4923 & .0496 & & .0365 & 1.3576 & .1753 & -.0220 & .1212 \\
\hline
\end{tabular}

Conditional indirect effect(s) of $X$ on $Y$ at values of the moderator(s):

Mediator

$\begin{array}{lrrrrrr} & \text { T2_GAD T } & \text { T2_PHQ T } & \text { Effect } & \text { Boot SE } & \text { BootLLCI } & \text { BootULCI } \\ \text { T2_DERS_ } & .0000 & .0000 & .0413 & .0159 & .0141 & .0725 \\ \text { T2_DERS- } & .0000 & 2.8242 & .0342 & .0148 & .0101 & .0665 \\ \text { T2_DERS- } & .0000 & 6.4923 & .0249 & .0201 & -.0080 & .0728 \\ \text { T2_DERS- } & 2.2684 & .0000 & .0290 & .0144 & .0034 & .0588 \\ \text { T2_DERS- } & 2.2684 & 2.8242 & .0219 & .0101 & .0030 & .0419 \\ \text { T2_DERS- } & 2.2684 & 6.4923 & .0126 & .0139 & -.0115 & .0446 \\ \text { T2_DERS- } & 5.8001 & .0000 & .0099 & .0188 & -.0284 & .0472 \\ \text { T2_DERS_ } & 5.8001 & 2.8242 & .0028 & .0116 & -.0200 & .0257 \\ \text { T2_DERS_ } & 5.8001 & 6.4923 & -.0065 & .0091 & -.0217 & .0142\end{array}$

Values for quantitative moderators are the mean and plus/minus one SD from mean .

Values for dichotomous moderators are the two values of the moderator.

NOTE: For at least one moderator in the conditional effects table above, one SD mean below the mean was replaced with the minimum because one SD below the is outside of the range of the data.

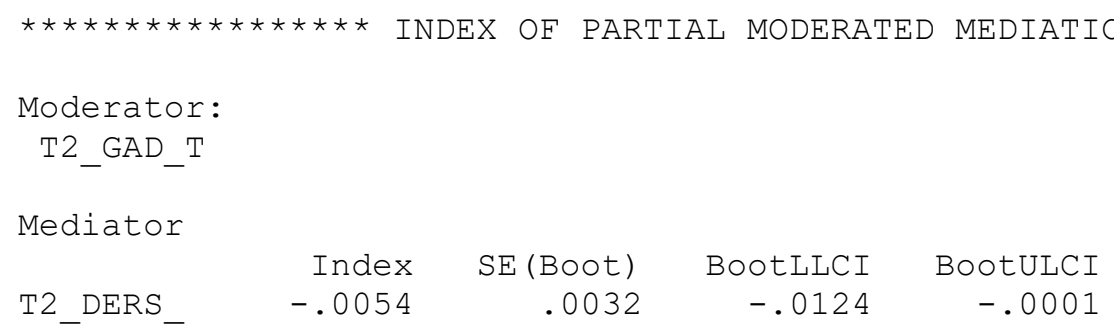


Moderator:

T2_PHQ_T

Mediator

T2 DERS

Index

SE (Boot)

BootLLCI

.0031

$-.0089$

BootULCI

.0036

$\star * * * * * * * * * * * * * * * * * * *$ ANALYSIS NOTES AND WARNINGS

Number of bootstrap samples for bias corrected bootstrap confidence intervals:

5000

Level of confidence for all confidence intervals in output: 95.00

NOTE: All standard errors for continuous outcome models are based on the HC3 estimator

----- END MATRIX ----- 


\section{Appendix C}

PROCESS output from SPSS for ECR-ANX data using the first stage dual moderated mediation model using GAD-7 and PHQ-9 scores and direct path moderation (Figure 3). From $n=418$ in total ECR-ANX data (including $n=418$ for ECR-anxious and DERS scores), 410 patients had baseline GAD-7 scores and 403 patients had baseline PHQ-9 scores. Using listwise exclusion for patients who did not complete all of these measures, $n=398$ in this analysis.

Run MATRIX procedure:

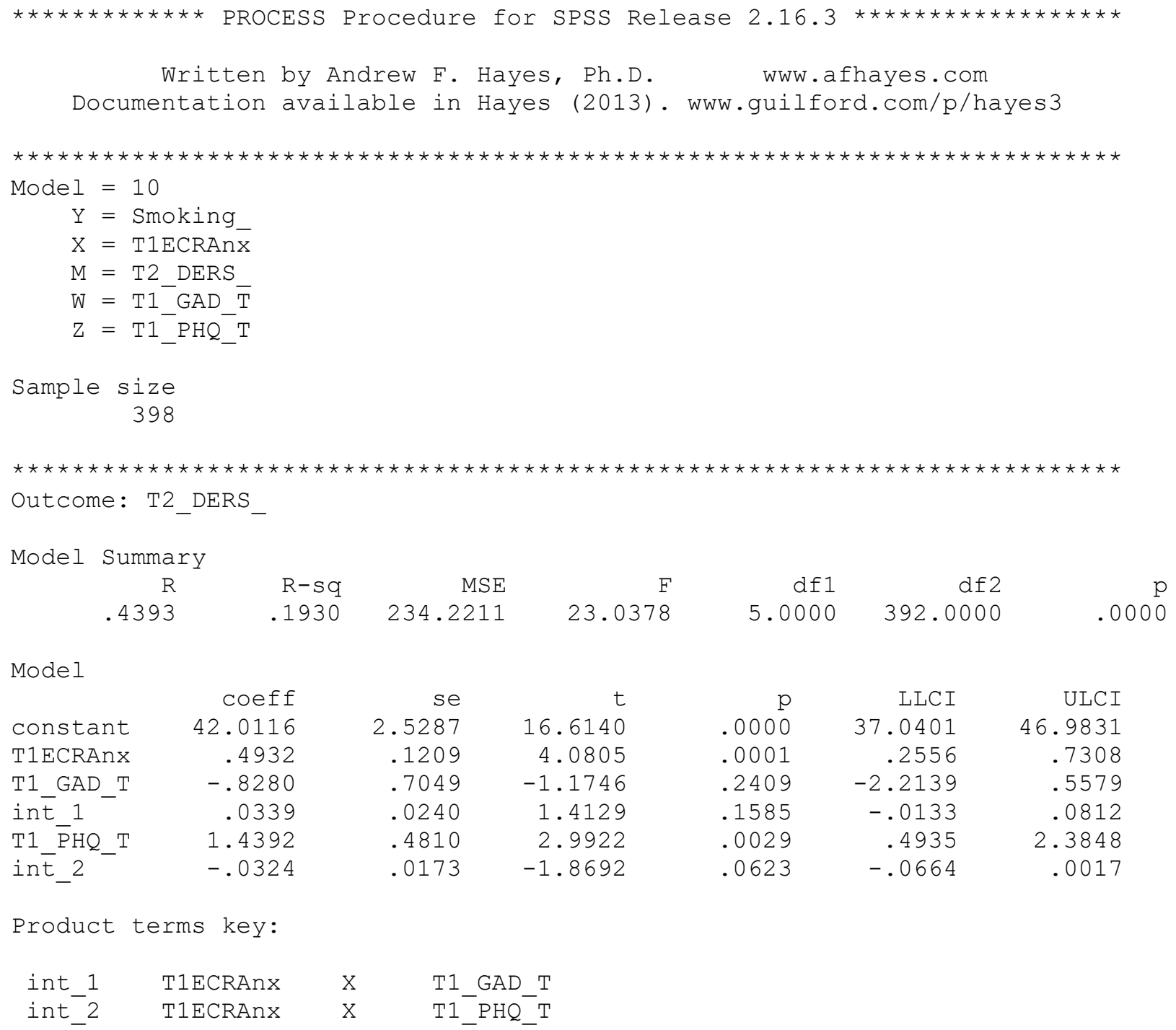




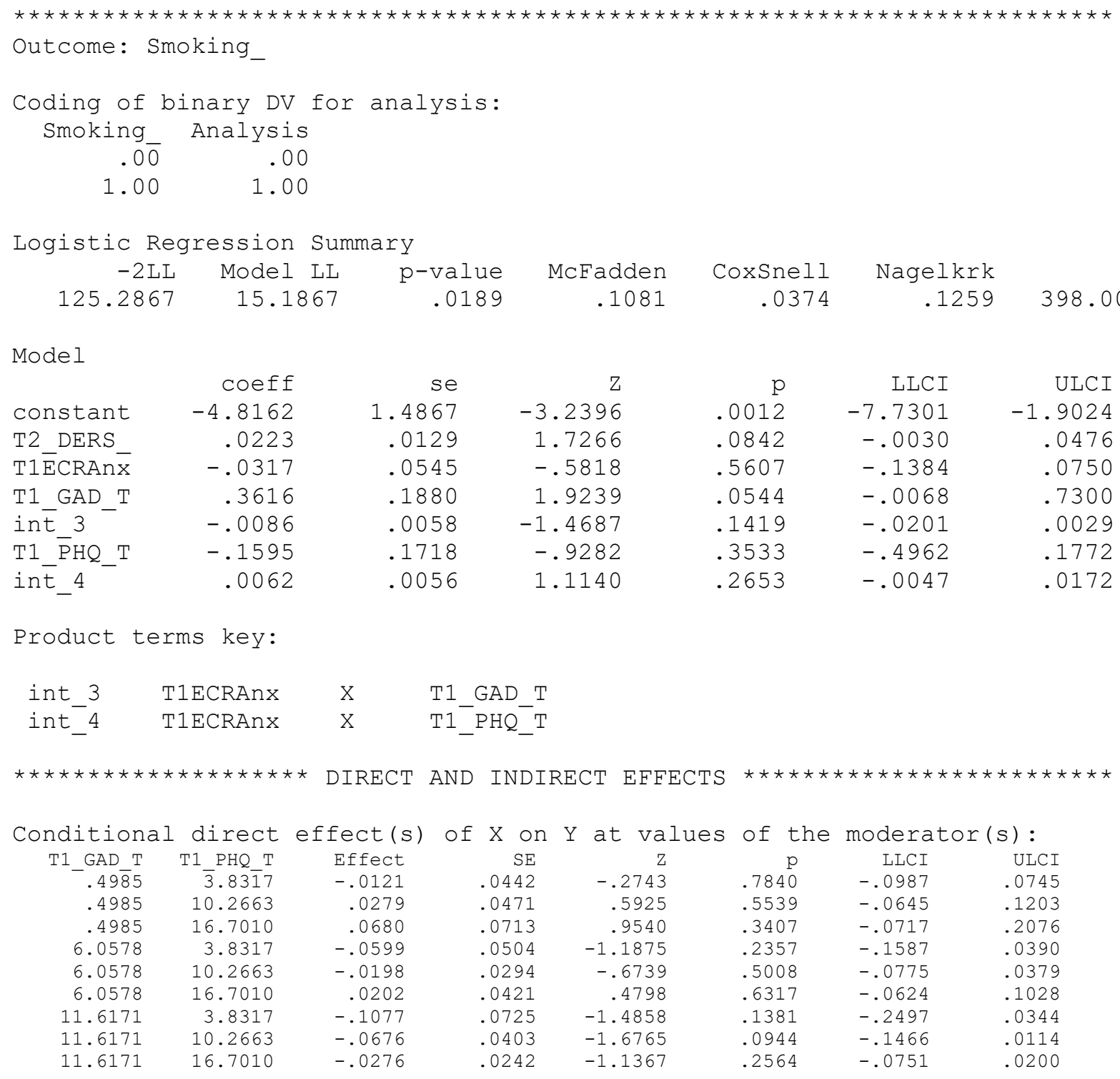

Conditional indirect effect(s) of $X$ on $Y$ at values of the moderator(s):

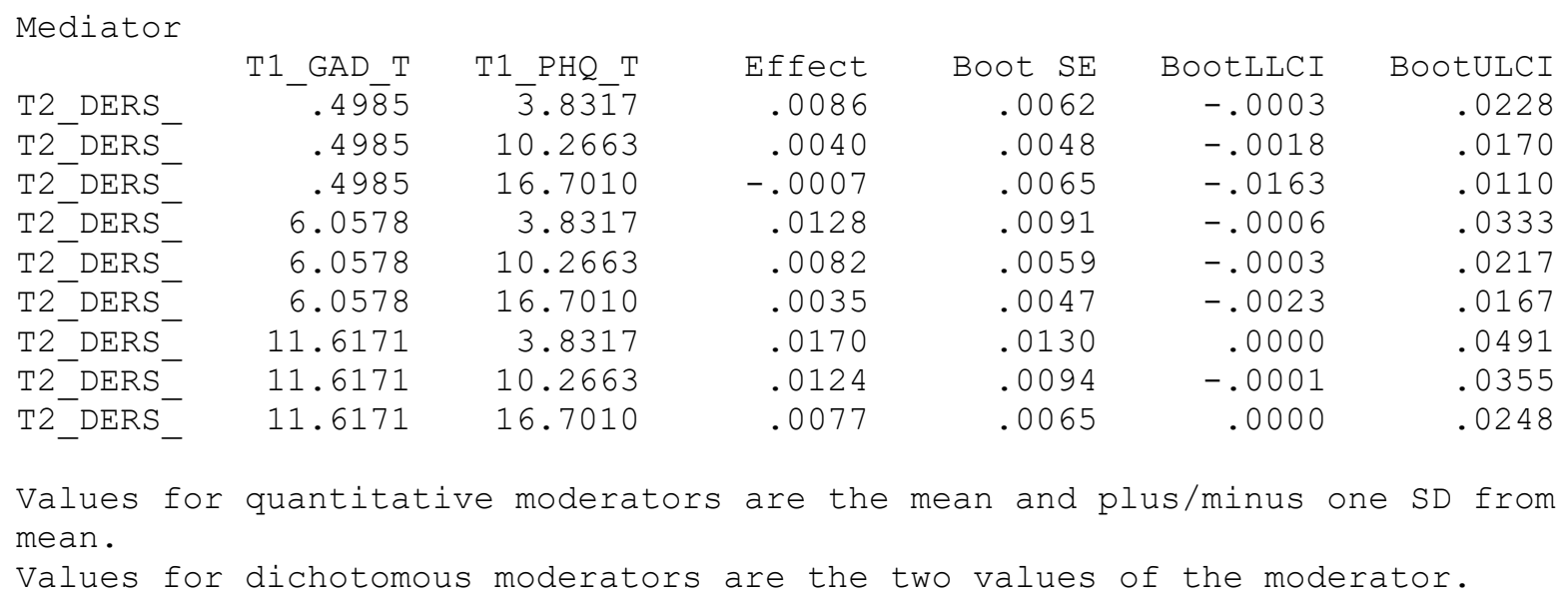




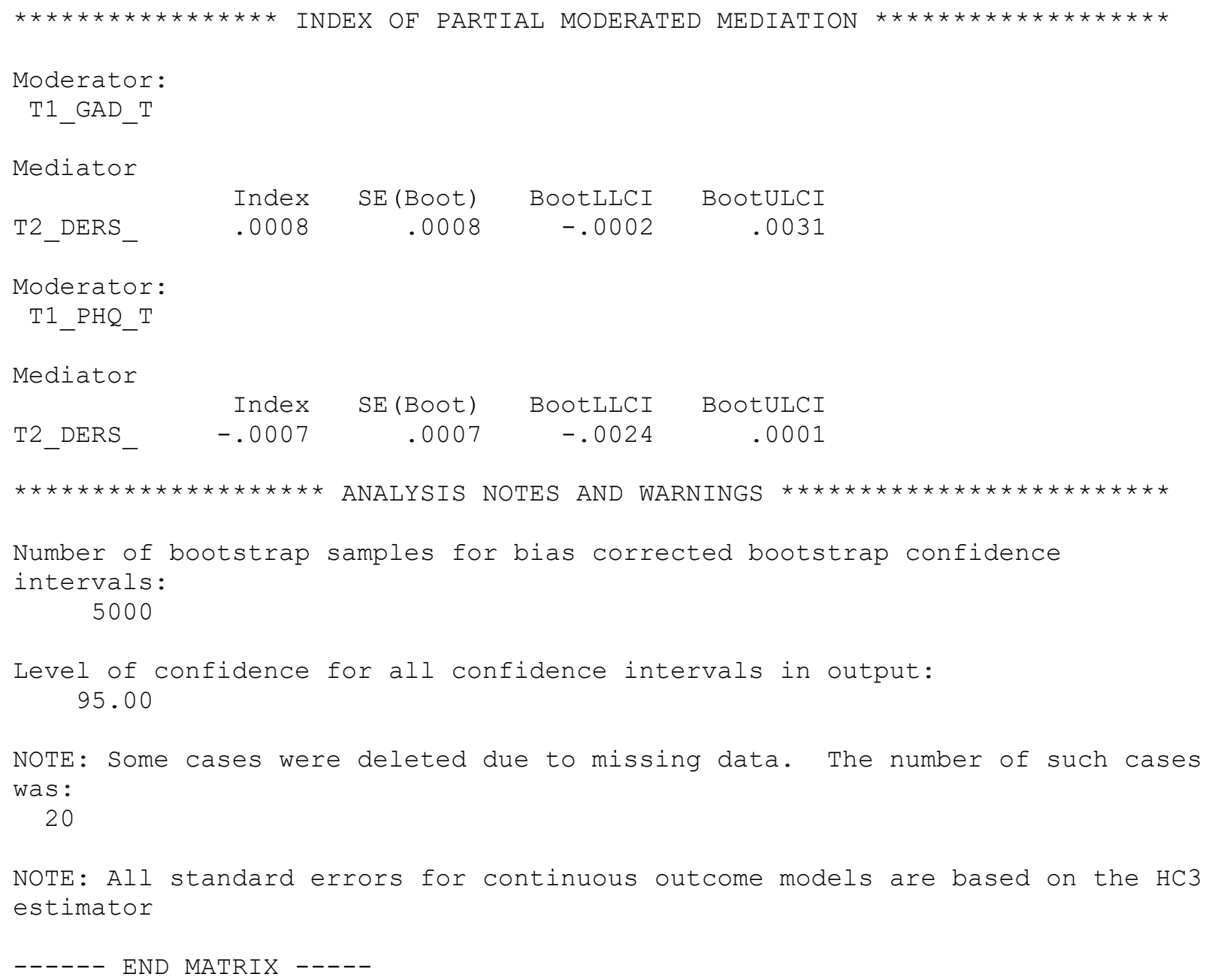




\section{Appendix D}

PROCESS output from SPSS for ECR-AVO data using the first stage dual moderated mediation model using GAD-7 and PHQ-9 scores and direct path moderation (Figure 3). From $n=421$ in total ECR-AVO data (including $n=421$ for ECR-anxious and DERS scores), 413 patients had baseline GAD-7 scores and 406 patients had baseline PHQ-9 scores. Using listwise exclusion for patients who did not complete all of these measures, $n=401$ in this analysis.

Run MATRIX procedure:

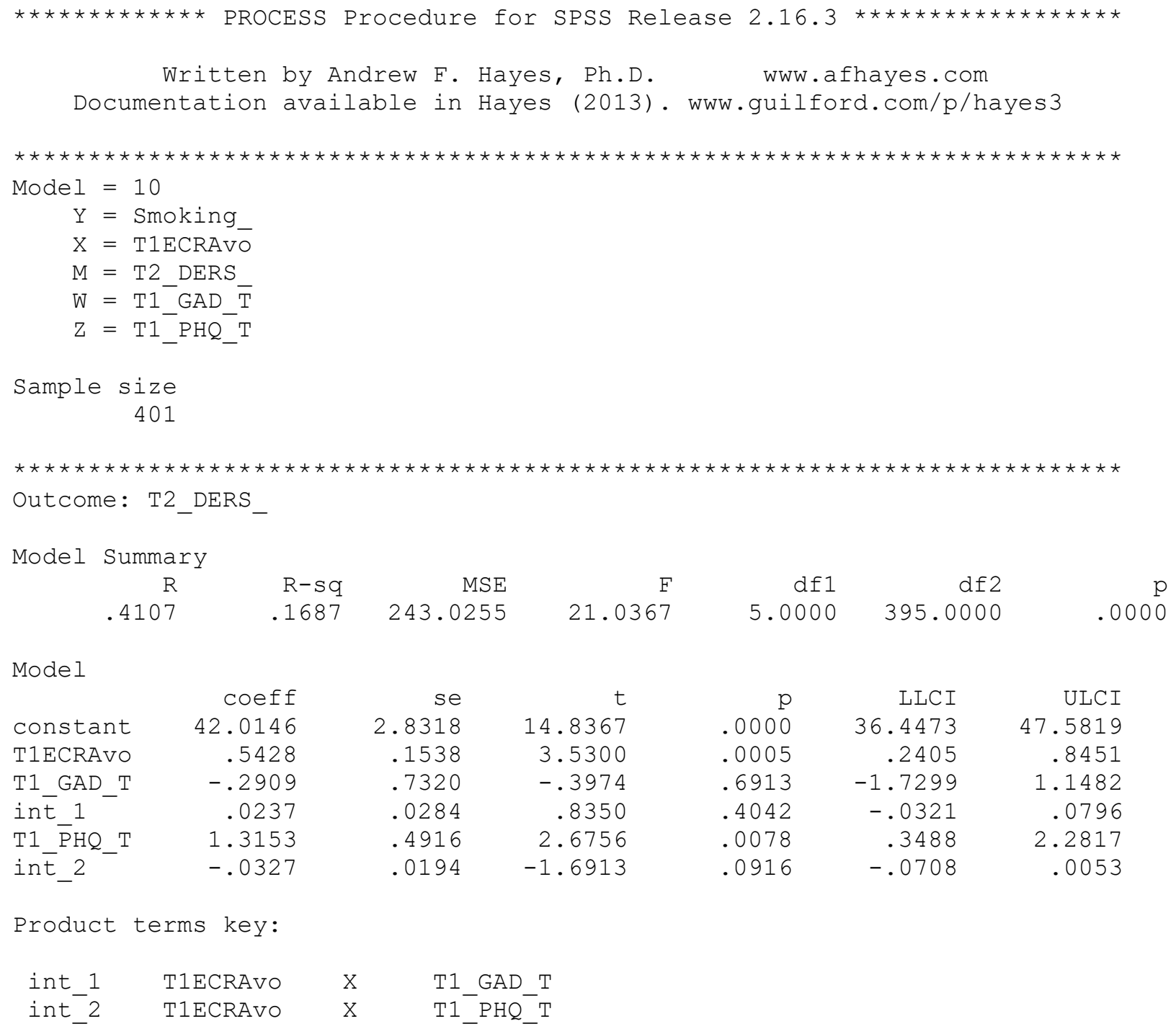




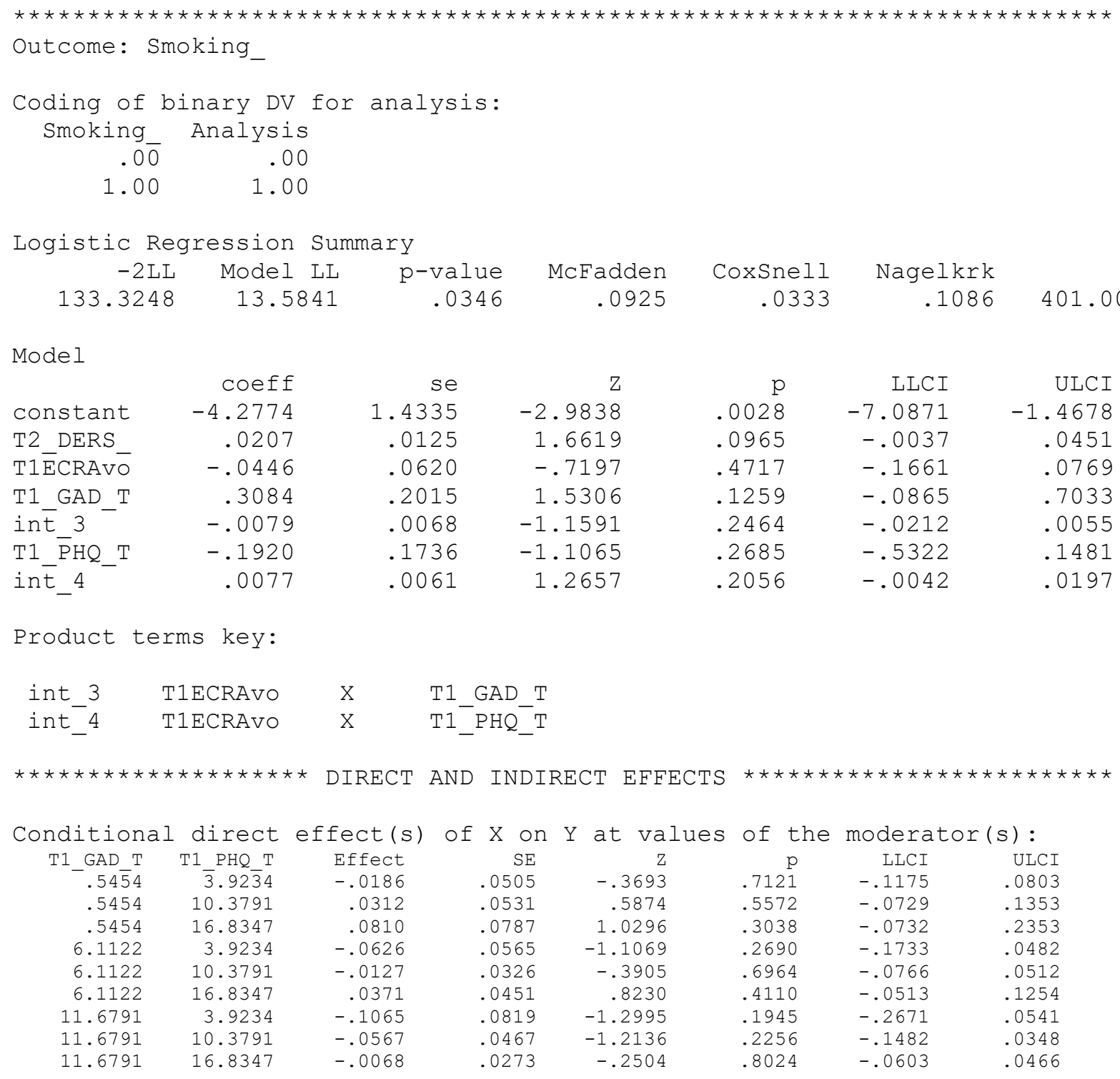

Conditional indirect effect(s) of $X$ on $Y$ at values of the moderator(s):

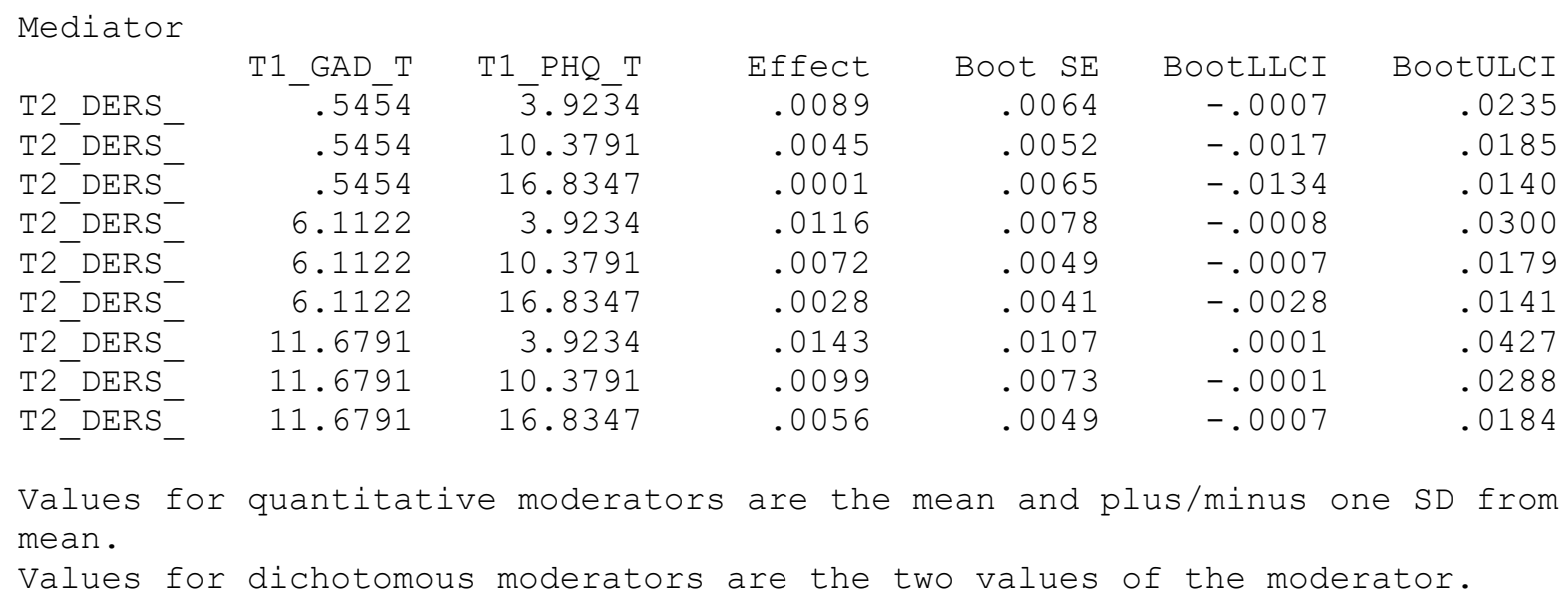




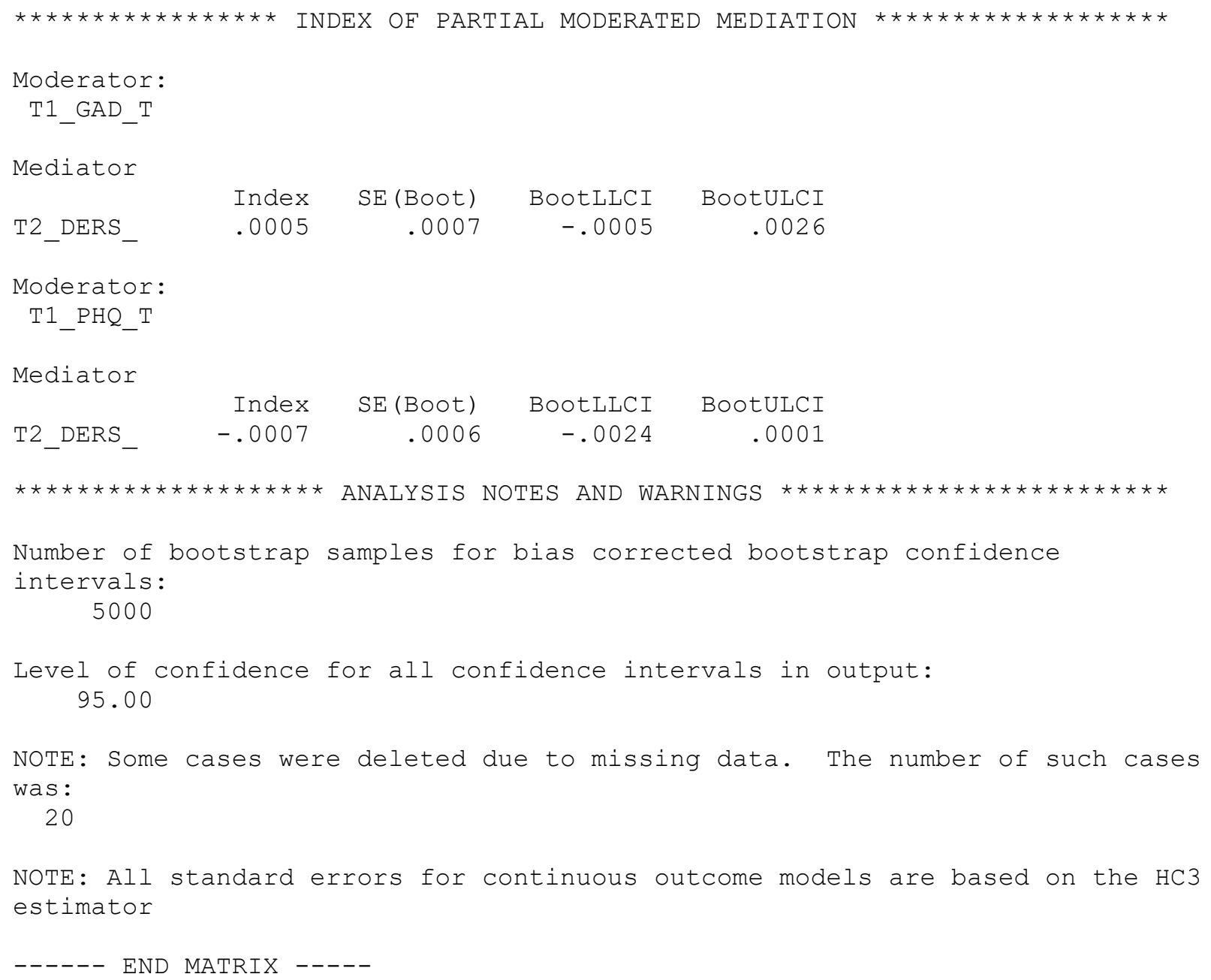




\section{Appendix E}

PROCESS output from SPSS for ECR-ANX data using the first stage moderated mediation model using psychological disorders and direct path moderation (Figure 4). From $n=418$ in total ECR-ANX data, 93 patients were missing diagnosis information, 45 had at least one current Axis I diagnosis, and 280 did not have a current Axis I diagnosis. Thus, excluding patients with missing information, $n=325$ in this analysis.

Run MATRIX procedure:

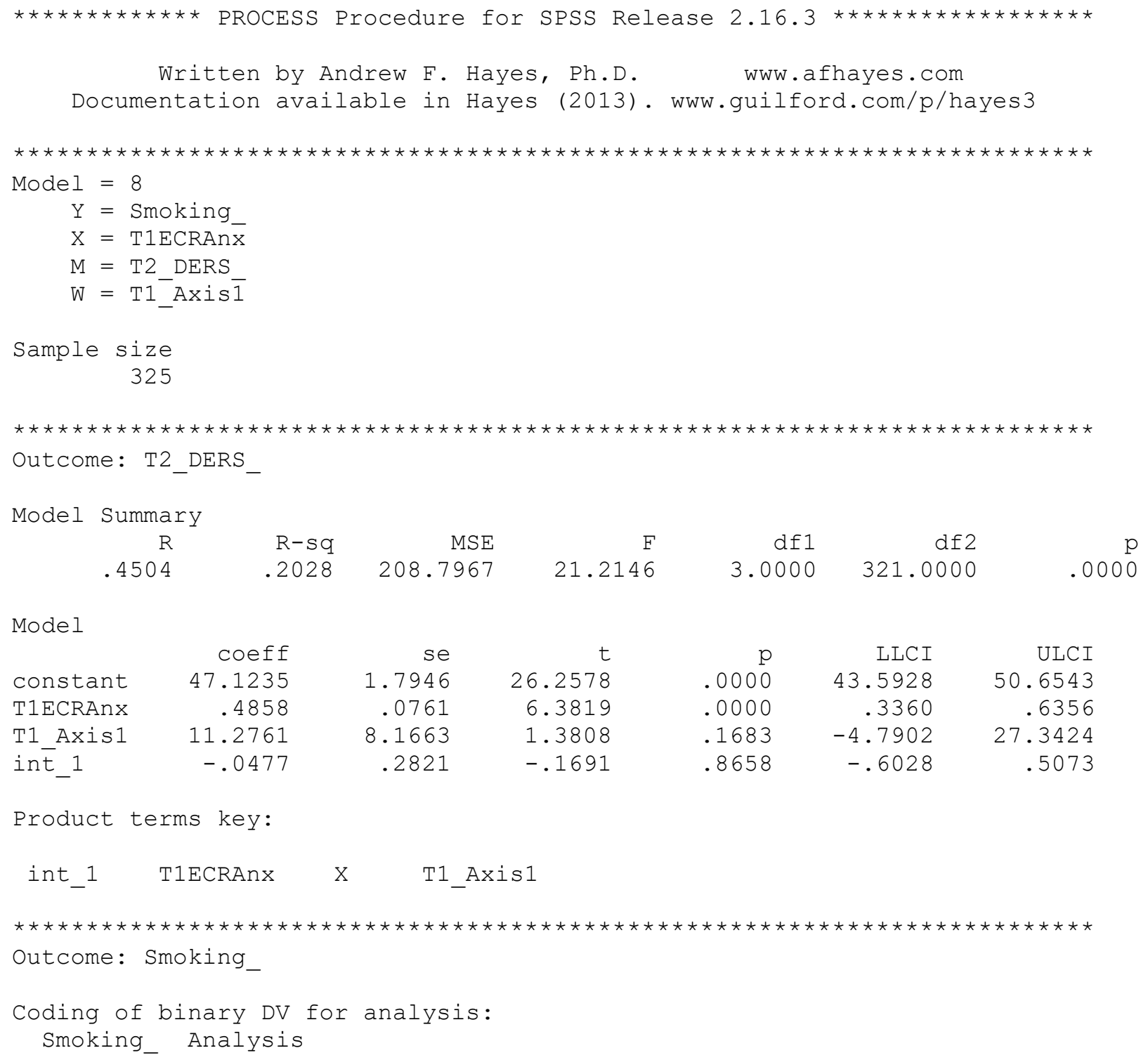




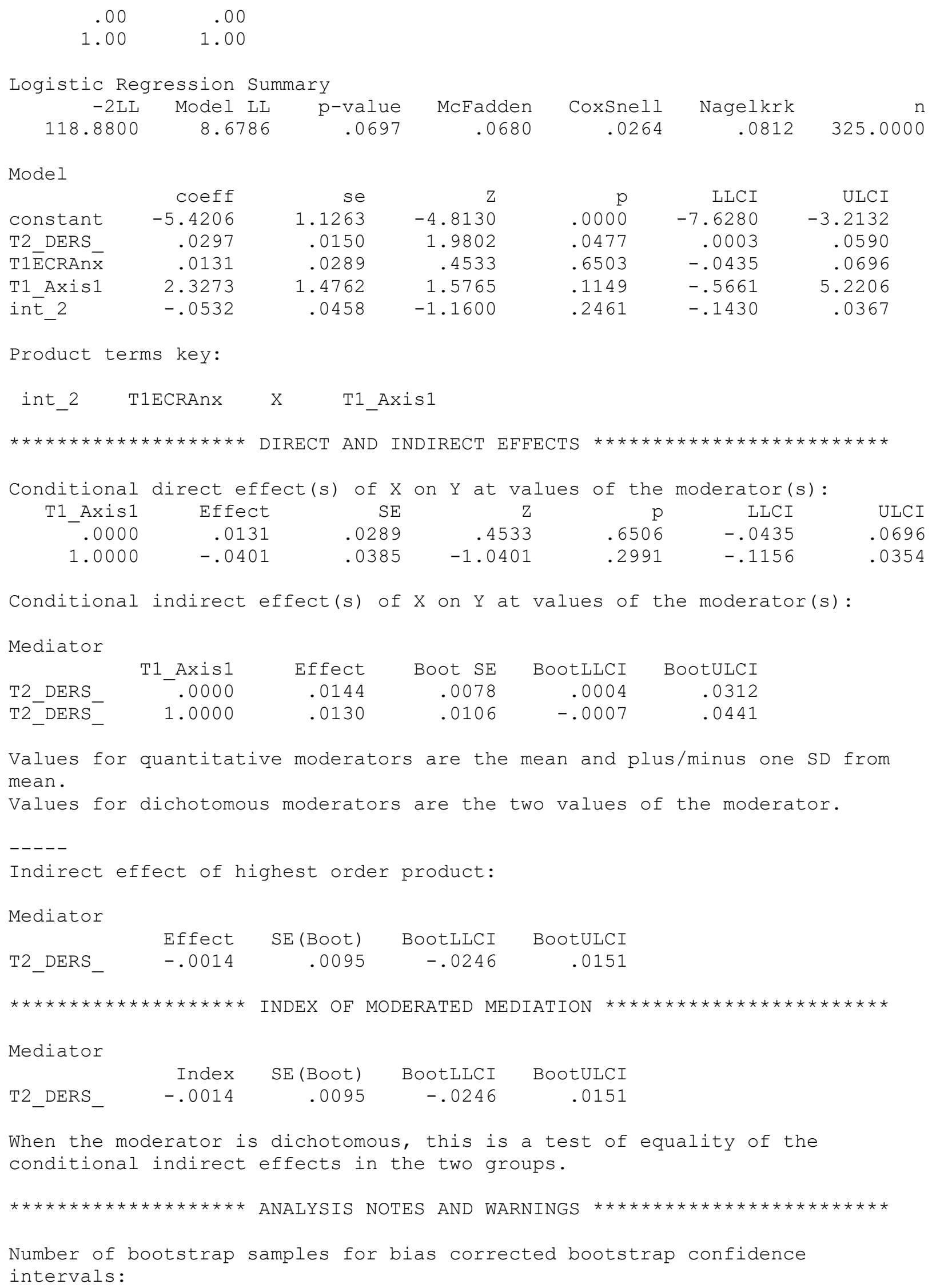


5000

Level of confidence for all confidence intervals in output: 95.00

NOTE: Some cases were deleted due to missing data. The number of such cases was:

93

NOTE: All standard errors for continuous outcome models are based on the HC3 estimator

----- END MATRIX ----- 


\section{Appendix F}

PROCESS output from SPSS for ECR-AVO data using the first stage moderated mediation model using psychological disorders and direct path moderation (Figure 4). From $n=421$ in total ECR-AVO data, 95 patients were missing diagnosis information, 46 had at least one current Axis I diagnosis, and 280 did not have a current Axis I diagnosis. Thus, excluding patients with missing information, $n=326$ in this analysis.

Run MATRIX procedure:

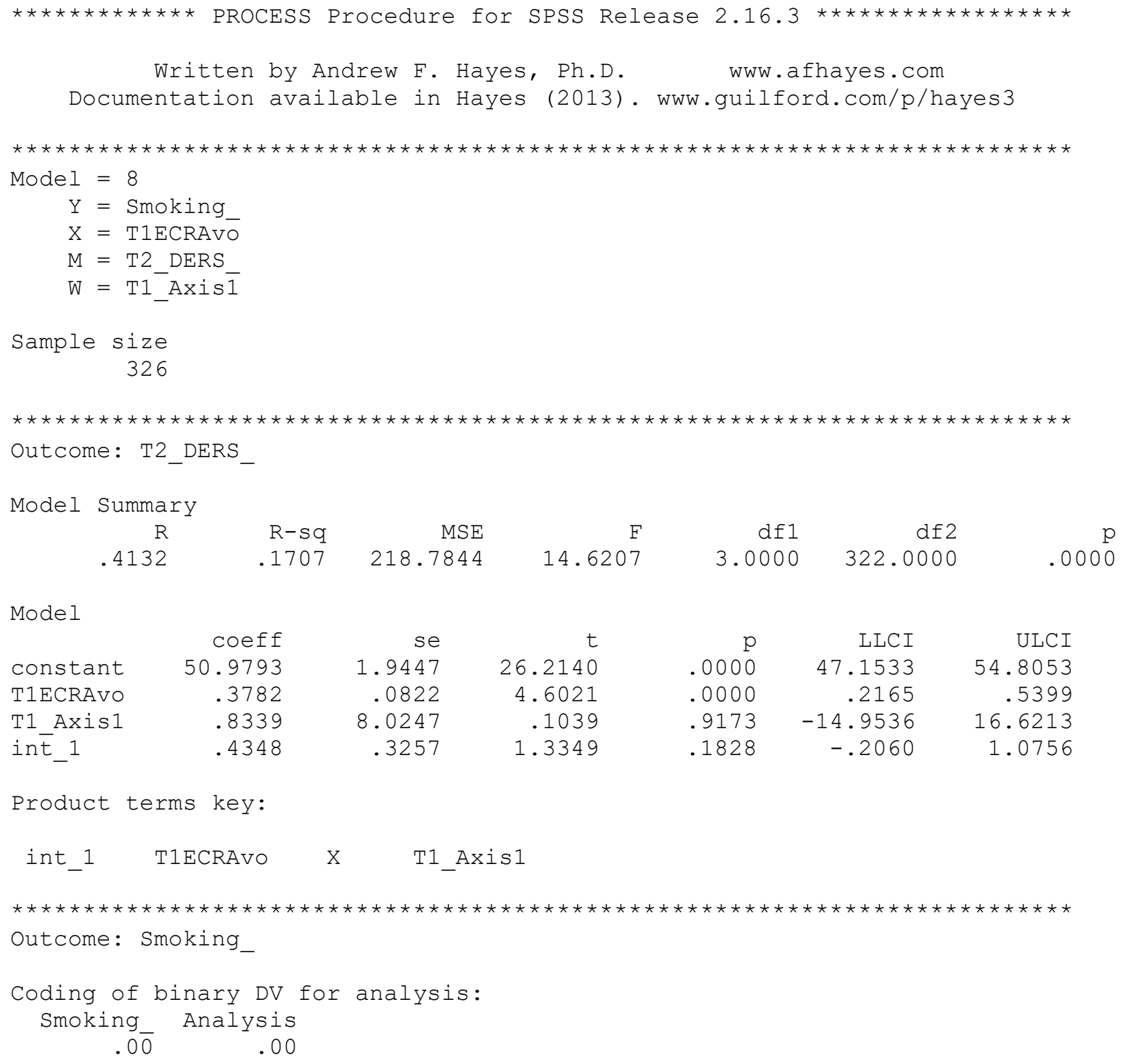




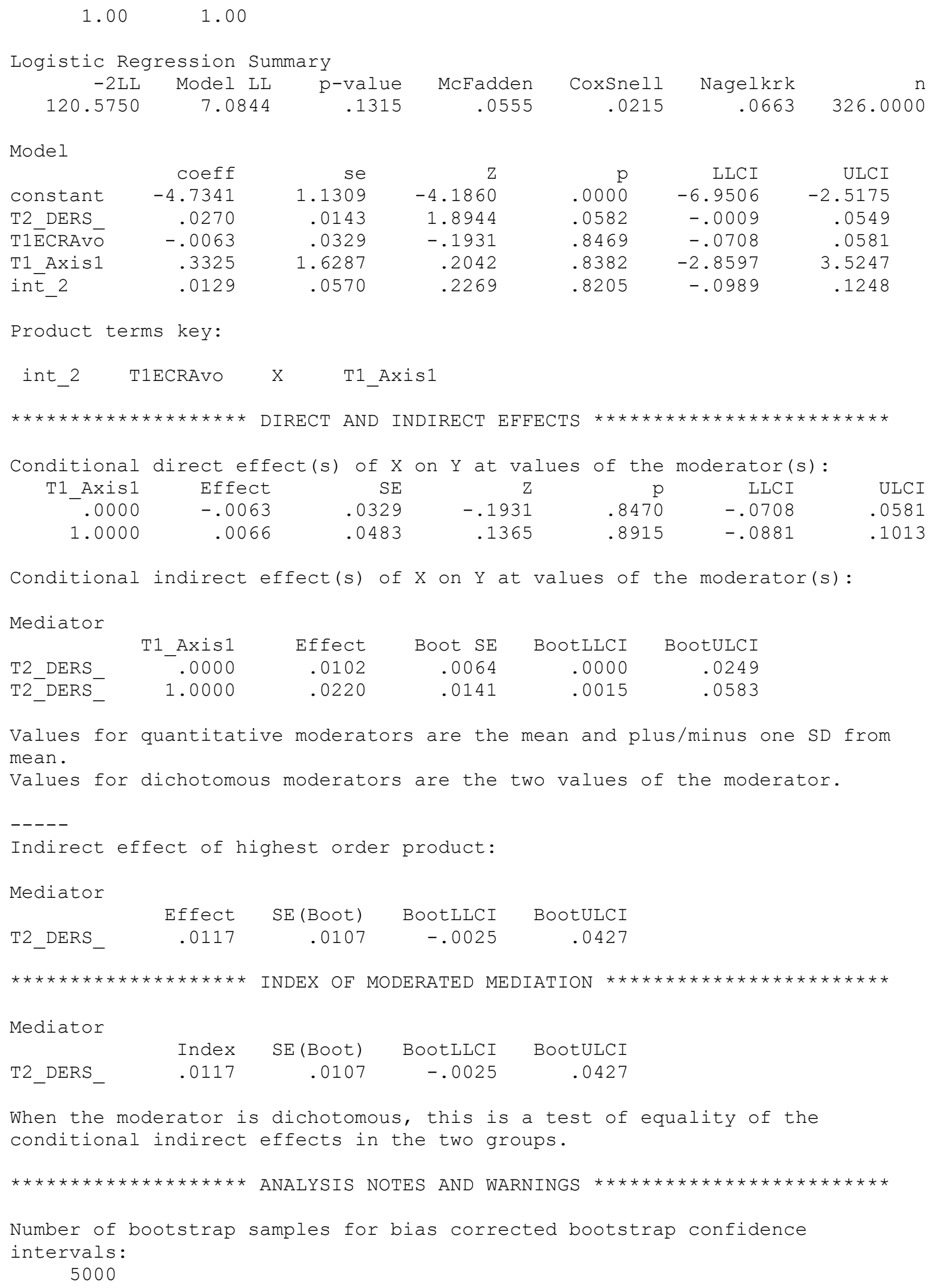


Level of confidence for all confidence intervals in output:

95.00

NOTE: Some cases were deleted due to missing data. The number of such cases was:

95

NOTE: All standard errors for continuous outcome models are based on the HC3 estimator

----- END MATRIX ----- 


\section{Appendix G}

Experiences in Close Relationships-Modified scale (ECR-M16)

The following statements concern how you feel in close relationships with others. In the following statements the term 'other people' refers to people with whom you feel close. Using the rating scale, indicate how much you agree or disagree with each statement by circling one number per line.

1. I get uncomfortable when other people want to be very close to me.

\begin{tabular}{ccccccc} 
Disagree & \multicolumn{3}{c}{ Neutral } & Agree \\
1 & 2 & 3 & 4 & 5 & 6 & 7
\end{tabular}

2. I worry about being abandoned.

Disagree

Neutral

Agree

1

2

3

4

5

6

7

3. I tell people with whom I feel close just about everything.

Disagree

1

2

3

Neutral

Agree

4

5

6

7

4. I need a lot of reassurance that I am loved by people with whom I feel close.

Disagree

1
2

3
Neutral

4

5
Agree

7

5. I don't feel comfortable opening up to other people.

Disagree

1
2
Neutral

4
5
Agree

7 
6. I worry a lot about my relationships.

\begin{tabular}{ccccccc} 
Disagree & \multicolumn{3}{c}{ Neutral } & Agree \\
1 & 2 & 3 & 4 & 5 & 6 & 7
\end{tabular}

7. I usually discuss my problems and concerns with people with whom I feel close.

Disagree

1

2

3

Neutral

Agree

4

5

6

7

8. I find that other people don't want to get as close as I would like.

Disagree

Neutral

Agree

1

2

3

4

5

6

7

9. I try to avoid getting too close to other people.

Disagree

1

2

3

4

5

6

Agree

7

10. I worry that other people won't care about me as much as I care about them.

Disagree

$$
1
$$

2

Neutral

Agree

3

4

5

6

7

11. I don't mind asking other people for comfort, advice, or help.

Disagree

Neutral

Agree

1

2

3

4

5

6

7 
12. I get frustrated when other people are not around as much as I would like.

Disagree

1

2

3

Neutral

Agree

13. I prefer not to be too close to other people.

Disagree

1

2

3

Neutral

Agree

4

5

6

7

14. I worry a fair amount about losing people with whom I feel close.

Disagree

1
2

Neutral

Agree

4

5

6

7

15. It helps to turn to other people in times of need.

Disagree

Neutral

Agree

1

2

3

4

5

6

7

16. I resent it when people with whom I feel close spend time away from me.

Disagree

1

2

3

5

6
Agree

7

Even-numbered items measure attachment anxiety.

Odd-numbered items measure avoidance.

Items 3, 7, 11, and 15 are reverse-scored.

(Lo et al., 2009) 


\section{Appendix H}

Difficulties in Emotion Regulation Scale (DERS)

Please indicate how often these statements apply to you by circling the appropriate number.

\begin{tabular}{|c|c|c|c|c|c|}
\hline & $\begin{array}{c}\text { Almost } \\
\text { never } \\
(0-10 \%)\end{array}$ & $\begin{array}{l}\text { Sometimes } \\
(11-35 \%)\end{array}$ & $\begin{array}{l}\text { About half } \\
\text { the time } \\
(36-65 \%)\end{array}$ & $\begin{array}{c}\text { Most of } \\
\text { the time } \\
(66-90 \%)\end{array}$ & $\begin{array}{c}\text { Almost } \\
\text { always } \\
(91-100 \%) \\
\end{array}$ \\
\hline 1. I am clear about my feelings. & 1 & 2 & 3 & 4 & 5 \\
\hline 2. I pay attention to how I feel. & 1 & 2 & 3 & 4 & 5 \\
\hline $\begin{array}{l}\text { 3. I experience my emotions as overwhelming and } \\
\text { out of control. }\end{array}$ & 1 & 2 & 3 & 4 & 5 \\
\hline 4. I have no idea how I am feeling. & 1 & 2 & 3 & 4 & 5 \\
\hline 5. I have difficulty making sense of my feelings. & 1 & 2 & 3 & 4 & 5 \\
\hline 6. I am attentive to my feelings. & 1 & 2 & 3 & 4 & 5 \\
\hline 7. I know exactly how I am feeling. & 1 & 2 & 3 & 4 & 5 \\
\hline 8. I care about what I am feeling. & 1 & 2 & 3 & 4 & 5 \\
\hline 9. I am confused about how I feel. & 1 & 2 & 3 & 4 & 5 \\
\hline 10. When I'm upset, I acknowledge my emotions. & 1 & 2 & 3 & 4 & 5 \\
\hline $\begin{array}{l}\text { 11. When I'm upset, I become angry with myself for } \\
\text { feeling that way. }\end{array}$ & 1 & 2 & 3 & 4 & 5 \\
\hline $\begin{array}{l}\text { 12. When I'm upset, I become embarrassed for } \\
\text { feeling that way. }\end{array}$ & 1 & 2 & 3 & 4 & 5 \\
\hline $\begin{array}{l}\text { 13. When I'm upset, I have difficulty getting work } \\
\text { done. }\end{array}$ & 1 & 2 & 3 & 4 & 5 \\
\hline 14. When I'm upset, I become out of control. & 1 & 2 & 3 & 4 & 5 \\
\hline $\begin{array}{l}\text { 15. When I'm upset, I believe that I will remain that } \\
\text { way for a long time. }\end{array}$ & 1 & 2 & 3 & 4 & 5 \\
\hline $\begin{array}{l}\text { 16. When I'm upset, I believe that I'll end up feeling } \\
\text { very depressed. }\end{array}$ & 1 & 2 & 3 & 4 & 5 \\
\hline $\begin{array}{l}\text { 17. When I'm upset, I believe that my feelings are } \\
\text { valid and important. }\end{array}$ & 1 & 2 & 3 & 4 & 5 \\
\hline
\end{tabular}




\begin{tabular}{|c|c|c|c|c|c|c|}
\hline & & $\begin{array}{l}\text { Almost } \\
\text { never } \\
(0-10 \%)\end{array}$ & $\begin{array}{c}\text { Sometimes } \\
(11-35 \%)\end{array}$ & $\begin{array}{l}\text { About half } \\
\text { the time } \\
(36-65 \%)\end{array}$ & $\begin{array}{l}\text { Most of } \\
\text { the time } \\
(66-90 \%)\end{array}$ & $\begin{array}{l}\text { Almost } \\
\text { always } \\
(91-100 \%)\end{array}$ \\
\hline 18. & $\begin{array}{l}\text { When I'm upset, I have difficulty focusing on other } \\
\text { things. }\end{array}$ & 1 & 2 & 3 & 4 & 5 \\
\hline 19. & When I'm upset, I feel out of control. & 1 & 2 & 3 & 4 & 5 \\
\hline 20. & When I'm upset, I can still get things done. & 1 & 2 & 3 & 4 & 5 \\
\hline 21. & $\begin{array}{l}\text { When I'm upset, I feel ashamed of myself for } \\
\text { feeling that way. }\end{array}$ & 1 & 2 & 3 & 4 & 5 \\
\hline 22. & $\begin{array}{l}\text { When I'm upset, I know I can find a way to } \\
\text { eventually feel better. }\end{array}$ & 1 & 2 & 3 & 4 & 5 \\
\hline 23. & When I'm upset, I feel like I am weak. & 1 & 2 & 3 & 4 & 5 \\
\hline 24. & $\begin{array}{l}\text { When I'm upset, I feel like I can remain in control } \\
\text { of my behaviors. }\end{array}$ & 1 & 2 & 3 & 4 & 5 \\
\hline 25. & When I'm upset, I feel guilty for feeling that way. & 1 & 2 & 3 & 4 & 5 \\
\hline 26. & When I'm upset, I have difficulty concentrating. & 1 & 2 & 3 & 4 & 5 \\
\hline 27. & $\begin{array}{l}\text { When I'm upset, I have difficulty controlling my } \\
\text { behaviors. }\end{array}$ & 1 & 2 & 3 & 4 & 5 \\
\hline 28. & $\begin{array}{l}\text { When I'm upset, I believe there is nothing I can do } \\
\text { to make myself feel better. }\end{array}$ & 1 & 2 & 3 & 4 & 5 \\
\hline 29. & $\begin{array}{l}\text { When I'm upset, I become irritated with myself for } \\
\text { feeling that way. }\end{array}$ & 1 & 2 & 3 & 4 & 5 \\
\hline 30. & $\begin{array}{l}\text { When I'm upset, I start to feel very bad about } \\
\text { myself. }\end{array}$ & 1 & 2 & 3 & 4 & 5 \\
\hline & $\begin{array}{l}\text { When I'm upset, I believe that wallowing is all I } \\
\text { can do. }\end{array}$ & 1 & 2 & 3 & 4 & 5 \\
\hline 32. & When I'm upset, I lose control over my behaviors. & 1 & 2 & 3 & 4 & 5 \\
\hline & $\begin{array}{l}\text { When I'm upset, I have difficulty thinking about } \\
\text { anything else. }\end{array}$ & 1 & 2 & 3 & 4 & 5 \\
\hline & $\begin{array}{l}\text { When I'm upset, I take time to figure out what I'm } \\
\text { really feeling. }\end{array}$ & 1 & 2 & 3 & 4 & 5 \\
\hline
\end{tabular}




\begin{tabular}{llcccc}
\hline & $\begin{array}{c}\text { Almost } \\
\text { never } \\
(0-10 \%)\end{array}$ & $\begin{array}{c}\text { Sometimes } \\
(11-35 \%)\end{array}$ & $\begin{array}{c}\text { About half } \\
\text { the time } \\
(36-65 \%)\end{array}$ & $\begin{array}{c}\text { Most of } \\
\text { the time } \\
(66-90 \%)\end{array}$ & $\begin{array}{c}\text { Almost } \\
\text { always } \\
(91-100 \%)\end{array}$ \\
\hline $\begin{array}{l}\text { 35. When l'm upset, it takes me a long time to feel } \\
\text { better. }\end{array}$ & 1 & 2 & 3 & 4 \\
\hline 36. When l'm upset, my emotions feel overwhelming. & 1 & 2 & 3 & 4 \\
\hline
\end{tabular}

(Gratz \& Roemer, 2004) 


\section{Appendix I}

Patient Health Questionnaire-9 (PHQ-9)

Over the last 2 weeks, how often have you been bothered by any of the following problems? Please circle the appropriate number.

\begin{tabular}{|c|c|c|c|c|}
\hline & $\begin{array}{l}\text { Not at } \\
\text { all }\end{array}$ & $\begin{array}{c}\text { Several } \\
\text { days }\end{array}$ & $\begin{array}{l}\text { More than } \\
\text { half the } \\
\text { days }\end{array}$ & $\begin{array}{l}\text { Nearly } \\
\text { every } \\
\text { day }\end{array}$ \\
\hline 1. Little interest or pleasure in doing things & 0 & 1 & 2 & 3 \\
\hline 2. Feeling down, depressed, or hopeless & 0 & 1 & 2 & 3 \\
\hline $\begin{array}{l}\text { 3. Trouble falling or staying asleep, or } \\
\text { sleeping too much }\end{array}$ & 0 & 1 & 2 & 3 \\
\hline 4. Feeling tired or having little energy & 0 & 1 & 2 & 3 \\
\hline 5. Poor appetite or overeating & 0 & 1 & 2 & 3 \\
\hline $\begin{array}{l}\text { 6. Feeling bad about yourself }- \text { or that you } \\
\text { are a failure or have let yourself or your } \\
\text { family down }\end{array}$ & 0 & 1 & 2 & 3 \\
\hline $\begin{array}{l}\text { 7. Trouble concentrating on things, such as } \\
\text { reading the newspaper or watching } \\
\text { television }\end{array}$ & 0 & 1 & 2 & 3 \\
\hline $\begin{array}{l}\text { 8. Moving or speaking so slowly that other } \\
\text { people could have noticed. Or the } \\
\text { opposite - being so fidgety or restless that } \\
\text { you have been moving around a lot more } \\
\text { than usual }\end{array}$ & 0 & 1 & 2 & 3 \\
\hline $\begin{array}{l}\text { 9. Thoughts that you would be better off dead } \\
\text { or of hurting yourself in some way }\end{array}$ & 0 & 1 & 2 & 3 \\
\hline (For staff coding: Total Score & $=$ & + & + & ( ) \\
\hline PHQ 9 & $=$ & & Reviewed by: & 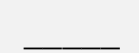 \\
\hline
\end{tabular}

If you check off any of these problems, how difficult have these problems made it for you to do your work, take care of things at home, or get along with other people?

Not at all difficult Somewhat difficult $\quad$ Very difficult $\quad$ Extremely difficult 


\section{Appendix J}

Generalized Anxiety Disorder-7 scale (GAD-7)

Over the last 2 weeks, how often have you been bothered by any of the following problems? Please circle the appropriate number.

\begin{tabular}{lcccc}
\hline & $\begin{array}{c}\text { Not at } \\
\text { all }\end{array}$ & $\begin{array}{c}\text { Several } \\
\text { days }\end{array}$ & $\begin{array}{c}\text { More than } \\
\text { half the } \\
\text { days }\end{array}$ & $\begin{array}{c}\text { Nearly } \\
\text { every } \\
\text { day }\end{array}$ \\
\hline Feeling nervous, anxious or on edge & 0 & 1 & 2 & 3 \\
Not being able to stop or control worrying & 0 & 1 & 2 & 3 \\
Worrying too much about different things & 0 & 1 & 2 & 3 \\
Trouble relaxing & 0 & 1 & 2 & 3 \\
Being so restless that it is hard to sit still & 0 & 1 & 2 & 3 \\
Becoming easily annoyed or irritable & 0 & 1 & 2 & 3 \\
$\begin{array}{l}\text { Feeling afraid as if something awful might } \\
\text { happen }\end{array}$ & 0 & 1 & 2 & 3 \\
\hline (Spitzer et & & & &
\end{tabular}

(Spitzer et al., 2006) 


\section{References}

Adams, C. E., Gabriele, J. M., Baillie, L. E., \& Dubbert, P. M. (2012). Tobacco use and substance use disorders as predictors of postoperative weight loss 2 years after bariatric surgery. The Journal of Behavioral Health Services \& Research, 39(4), 462-471.

Ahrens, K. R., Ciechanowski, P., \& Katon, W. (2012). Associations between adult attachment style and health risk behaviors in an adult female primary care population. Journal of Psychosomatic Research, 72(5), 364-370.

Ainsworth, M. D. S., Blehar, M. C., Waters, E., \& Wall, S. (1978). Patterns of attachment: A psychological study of the strange situation. Oxford, UK: Lawrence Erlbaum.

Akiskal, H. S., Mendlowicz, M. V., Jean-Louis, G., Rapaport, M. H., Kelsoe, J. R., Gillin, J. C., \& Smith, T. L. (2005). TEMPS-A: Validation of a short version of a self-rated instrument designed to measure variations in temperament. Journal of Affective Disorders, 85(1), 4552.

Amann, B., Mergl, R., Torrent, C., Perugi, G., Padberg, F., El-Gjamal, N., \& Laakmann, G. (2009). Abnormal temperament in patients with morbid obesity seeking surgical treatment. Journal of Affective Disorders, 118(1), 155-160.

American Heart Association. (2017). What is venous thromboembolism (VTE)? Retrieved from: http://www.heart.org/HEARTORG/Conditions/More/What-is-VenousThromboembolism-VTE_UCM_479052_Article.jsp\#.WRKX3tLytPY

American Psychiatric Association [APA]. (1994). Diagnostic and statistical manual of mental disorders (4th ed.). Washington, DC: Author.

American Psychiatric Association [APA]. (2013). Diagnostic and statistical manual of mental disorders (5th ed.). Arlington, VA: Author. 
Arnow, B., Kenardy, J., \& Agras,W.S. (1995). The Emotional Eating Scale: The development of a measure to assess coping with negative affect by eating. International Journal of Eating Disorders, 18(1), 79-90.

Asmundson, G. J., Abramowitz, J. S., Richter, A. A., \& Whedon, M. (2010). Health anxiety: Current perspectives and future directions. Current Psychiatry Reports, 12(4), 306-312.

Azin, A., Zhou, C., Jackson, T., Cassin, S., Sockalingam, S., \& Hawa, R. (2014). Body contouring surgery after bariatric surgery: a study of cost as a barrier and impact on psychological well-being. Plastic and Reconstructive Surgery, 133(6), 776e-782e.

Baker, T. B., Piper, M. E., McCarthy, D. E., Majeskie, M. R., \& Fiore, M. C. (2004). Addiction motivation reformulated: An affective processing model of negative reinforcement. Psychological Review, 111(1), 33-51.

Bartholomew, K., \& Horowitz, L. M. (1991). Attachment styles among young adults: A test of a four-category model. Journal of Personality and Social Psychology, 61, 226-244.

Beck, A. T. (1987). Cognitive models of depression. Journal of Cognitive Psychotherapy, 1, $5-37$.

Beck, A. T., Epstein, N., Brown, G., \& Steer, R. A. (1988). An inventory for measuring clinical anxiety: Psychometric properties. Journal of Consulting and Clinical Psychology, 56(6), 893.

Beck, A.T., Steer, R.A., \& Brown, G.K. (1996). Manual for the Beck Depression Inventory-II. San Antonio, TX: Psychological Corporation.

Bisol, L. W., Soldado, F., Albuquerque, C., Lorenzi, T. M., \& Lara, D. R. (2010). Emotional and affective temperaments and cigarette smoking in a large sample. Journal of Affective Disorders, 127(1), 89-95. 
Black, C.M., \& Wilson, G.T. (1996). Assessment of eating disorders: Interview versus questionnaire. International Journal of Eating Disorders, 20(1), 43-50.

Black, D. W., Goldstein, R. B., \& Mason, E. E. (2003). Psychiatric diagnosis and weight loss following gastric surgery for obesity. Obesity Surgery, 13(5), 746-751.

Bowlby, J. (1969). Attachment and loss: Vol. 1. Attachment. New York, NY: Basic Books.

Boyett, D., Magnuson, T., Schweitzer, M. (2016). Metabolic changes following bariatric surgery. In J. L. Cameron and A. M. Cameron (Eds.). Current surgical therapy (12 ${ }^{\text {th }}$ ed., pp. 802806). E-book: Elsevier Health Sciences.

Brennan, K., Clark, C., \& Shaver, P. (1998). Self-report measures of adult romantic attachment. In J. Simpson, \& W. Rholes (Eds.), Attachment theory and close relationships. New York, NY: Guilford Press.

Brethauer, S., Kashyup, S., Schauer, P. (2013). Obesity. Retrieved from: http://www.clevelandclinicmeded.com/medicalpubs/diseasemanagement/endocrinology/o besity/

Brown, R. A., Kahler, C. W., Niaura, R., Abrams, D. B., Sales, S. D., Ramsey, S. E., ... \& Miller, I. W. (2001). Cognitive-behavioral treatment for depression in smoking cessation. Journal of Consulting and Clinical Psychology, 69, 471-480.

Buchwald, H., Estok, R., Fahrbach, K., Banel, D., \& Sledge, I. (2007). Trends in mortality in bariatric surgery: A systematic review and meta-analysis. Surgery, 142(4), 621-635.

Campos, J. J., Barrett, K., Lamb, M. E., Goldsmith, H. E., \& Stenberg, C. (1983). Socioemotional development. In P. H. Mussen (Series Ed.) \& M. M. Haith \& J. J. Campos (Vol. Eds.), Handbook of child psychology: Vol. 2. Infancy and developmental psychobiology (pp. 783-915). New York, NY: Wiley. 
Canadian Institute for Health Information. (2014). Bariatric surgery in Canada. Ottawa, ON: Canadian Institute for Health Information.

Carvalho, A. F., Hyphantis, T. N., Taunay, T. C., Macêdo, D. S., Floros, G. D., Ottoni, G. L., ... \& Lara, D. R. (2013). The relationship between affective temperaments, defensive styles and depressive symptoms in a large sample. Journal of Affective Disorders, 146(1), 5865.

Cassin, S., Sockalingam, S., Hawa, R., Wnuk, S., Royal, S., Taube-Schiff, M., et al. (2013). Psychometric properties of the Patient Health Questionnaire (PHQ-9) as a depression screening tool for bariatric surgery candidates. Psychosomatics, 54(4), 352-358.

Catanzaro, S. J., \& Mearns, J. (1990). Measuring generalized expectancies for negative mood regulation: Initial scale development and implications. Journal of Personality Assessment, 54(3-4), 546-563.

Center for Behavioral Health Statistics and Quality. (2016). Key substance use and mental health indicators in the United States: Results from the 2015 National Survey on Drug Use and Health (HHS Publication No. SMA 16-4984, NSDUH Series H-51). Retrieved from https://www.samhsa.gov/data/sites/default/files/NSDUH-FFR1-2015/NSDUH-FFR12015/NSDUH-FFR1-2015.pdf

Center for Substance Abuse Treatment. (1999). Chapter 3-Motivational interviewing as a counseling style. Enhancing Motivation for Change in Substance Abuse Treatment. Rockville, MD: Substance Abuse and Mental Health Services Administration (US). Centers for Disease Control and Prevention [CDCP]. (2017). Cigarette smoking and tobacco use among people of low socioeconomic status [Fact sheet]. Retrieved from: https://www.cdc.gov/tobacco/disparities/low-ses/index.htm 
Centers for Disease Control and Prevention [CDCP]. (2018). Current cigarette smoking among adults in the United States [Fact sheet]. Retrieved from: https://www.cdc.gov/tobacco/data_statistics/fact_sheets/adult_data/cig_smoking/index.ht $\underline{\mathrm{m}}$

Chatkin, R., Mottin, C. C., \& Chatkin, J. M. (2010). Smoking among morbidly obese patients. BMC Pulmonary Medicine, 10(1), 61.

Cloninger, C. R., Svrakic, D. M., \& Przybeck, T. R. (1993). A psychobiological model of temperament and character. Archives of General Psychiatry, 50(12), 975-990.

Collins, N. L., \& Read, S. J. (1990). Adult attachment, working models, and relationship quality in dating couples. Journal of Personality and Social Psychology, 58, 644-663.

Conason, A., Teixeira, J., Hsu, C. H., Puma, L., Knafo, D., \& Geliebter, A. (2013). Substance use following bariatric weight loss surgery. Journal of the American Medical Association Surgery, 148(2), 145-150.

Corey, B. L., \& Stahl, R. D. (2016). Glycemic control and cardiovascular disease reduction after bariatric surgery. In J. L. Cameron and A. M. Cameron (Eds.). Current surgical therapy (12 ${ }^{\text {th }}$ ed., pp. 806-813). E-book: Elsevier Health Sciences.

Csala, I., Elemery, M., Martinovszky, F., Dome, P., Dome, B., Faludi, G., ... \& Lazary, J. (2016). Maternal bonding styles in smokers and non-smokers: A comparative study. Annals of General Psychiatry, 15(1), 32.

de Zwaan, M., Georgiadou, E., Stroh, C. E., Teufel, M., Köhler, H., Tengler, M., \& Müller, A. (2014). Body image and quality of life in patients with and without body contouring surgery following bariatric surgery: a comparison of pre-and post-surgery groups. Frontiers in Psychology, 5, 1310. 
Derogatis, L. R., Lipman, R. S., Rickels, K., Uhlenhuth, E. H., \& Covi, L. (1974). The Hopkins Symptom Checklist (HSCL): A self-report symptom inventory. Behavioral Science, $19(1), 1-15$.

Eastern Health (2017). Bariatric Surgery Booking Form. http://www.easternhealth.ca/Professionals.aspx?d=1\&id=320\&p=81

El-Hayek, K., Timratana, P., Shimizu, H., \& Chand, B. (2012). Marginal ulcer after Roux-en-Y gastric bypass: What have we really learned? Surgical Endoscopy, 26, 2789-2796.

Ertelt, T. W., Mitchell, J. E., Lancaster, K., Crosby, R. D., Steffen, K. J., \& Marino, J. M. (2008). Alcohol abuse and dependence before and after bariatric surgery: A review of the literature and report of a new data set. Surgery for Obesity and Related Diseases, 4(5), 647-650.

Fairburn, C. G., \& Beglin, S. J. (1994). Assessment of eating disorders: Interview or self-report questionnaire? International Journal of Eating Disorders, 16(4), 363-370.

Farris, S. G., Zvolensky, M. J., \& Schmidt, N. B. (2016). Difficulties with emotion regulation and psychopathology interact to predict early smoking cessation lapse. Cognitive Therapy and Research, 40(3), 357-367.

Field, A. (2013). Discovering statistics using IBM SPSS statistics. London, Sage Publications Ltd.

First, M. B., Spitzer, R. L., Gibbon, M., \& Williams, J. B. (2007). Structured Clinical Interview for DSM-IV-TR Axis I disorders, research version, non-patient edition (SCIDI/NP). New York, NY: Biometrics Research, New York State Psychiatric Institute.

Foxcroft, D. R., \& Lowe, G. (1995). Adolescent drinking, smoking and other substance use involvement: Links with perceived family life. Journal of Adolescence, 18(2), 159-177. 
Fraley, R. C. (2002). Attachment stability from infancy to adulthood: Meta-analysis and dynamic modeling of developmental mechanisms. Personality and Social Psychology Review, 6(2), 123-151.

Fraley, R. C., Vicary, A. M., Brumbaugh, C. C., \& Roisman, G. I. (2011). Patterns of stability in adult attachment: an empirical test of two models of continuity and change. Journal of Personality and Social Psychology, 101(5), 974.

Franken, I. H. A., Zijlstra, C., \& Muris, P. (2006). Are nonpharmacological induced rewards related to anhedonia? A study among skydivers. Progress in Neuro-Psychopharmacology and Biological Psychiatry, 30, 297-300.

Gangemi, A., Russel, S., Patel, K., Khalaf, H., Masrur, M., \& Hassan, C. (2018). Conversion to laparoscopic sleeve gastrectomy after failure of laparoscopic gastric band: A systematic review of the literature and cost considerations. Obesity Research \& Clinical Practice. doi: 10.1016/j.orcp.2017.12.004.

Gianini, L. M., White, M. A., \& Masheb, R. M. (2013). Eating pathology, emotion regulation, and emotional overeating in obese adults with binge eating disorder. Eating Behaviors, 14, 309-313.

Gonzalez, R., Haines, K., Nelson, L. G., Gallagher, S. F., \& Murr, M. M. (2006). Predictive factors of thromboembolic events in patients undergoing Roux-en-Y gastric bypass. Surgery for Obesity and Related Diseases, 2(1), 30-35.

Gormally, J., Black, S., Daston, S., \& Rardin, D. (1982). The assessment of binge eating severity among obese persons. Addictive Behaviors, 7(1), 47-55. 
Gourash, W. F., Ebel, F., Lancaster, K., Adeniji, A., Iacono, L. K., Eagleton, J. K., ... \& Wolfe, B. M. (2013). Longitudinal Assessment of Bariatric Surgery (LABS): retention strategy and results at 24 months. Surgery for Obesity and Related Diseases, 9(4), 514-519.

Grace, D. M., Pederson, L., Speechley, K. N., \& McAlpine, D. (1990). A longitudinal study of smoking status and weight loss following gastroplasty in a group of morbidly obese patients. International Journal of Obesity, 14, 311-317.

Grace-Martin, K. (n.d.). Missing Data Mechanisms: A Primer. Retrieved from: http://www.theanalysisfactor.com/causes-of-missing-data/

Gratz, K. L., \& Roemer, L. (2004). Multidimensional assessment of emotion regulation and dysregulation: Development, factor structure, and initial validation of the difficulties in emotion regulation scale. Journal of Psychopathology and Behavioral Assessment, 26(1), $41-54$.

Griffin-Shelley, E., Sandler, K. R., \& Lees, C. (1990). Sex-role perceptions in chemically dependent subjects: Adults versus adolescents. International Journal of the Addictions, $25,1383-1391$.

Gupta, P. K., Gupta, H., Kaushik, M., Fang, X., Miller, W. J., Morrow, L. E., \& Armour-Forse, R. (2012). Predictors of pulmonary complications after bariatric surgery. Surgery for Obesity and Related Diseases, 8(5), 574-581.

Hallion, L. S., Steinman, S. A., Tolin, D. F., \& Diefenbach, G. J. (2018). Psychometric properties of the Difficulties in Emotion Regulation Scale (DERS) and its short forms in adults with emotional disorders. Frontiers in Psychology, 9, 539. 
Hase, A., O'Brien, J., Moore, L. J., \& Freeman, P. (2018). The relationship between challenge and threat states and performance: A systematic review. Sport, Exercise, and Performance Psychology. Advance online publication. http://dx.doi.org/10.1037/spy0000132

Hayes, A. F. (2013). Introduction to mediation, moderation, and conditional process analysis: A regression-based approach. Guilford Press. [Note: For model templates, see also http://www.personal.psu.edu/jxb14/M554/specreg/templates.pdf].

Hayes, A. F. (2015). An index and test of linear moderated mediation. Multivariate Behavioral Research, 50(1), 1-22.

Hayes, A. F. (2018). Partial, conditional, and moderated moderated mediation: Quantification, inference, and interpretation. Communication Monographs, 85(1), 4-40.

Hayes, A. F. (n.d.). The PROCESS macro for SPSS and SAS (FAQ). Retrieved from: http://www.processmacro.org/faq.html

Hayes, S. C., Strosahl, K., Wilson, K. G., Bissett, R. T., Pistorello, J., Toarmino, D., ... \& Stewart, S. H. (2004). Measuring experiential avoidance: A preliminary test of a working model. The Psychological Record, 54(4), 553-578.

Hazan, C., \& Shaver, P. (1987). Romantic love conceptualized as an attachment process. Journal of Personality and Social Psychology, 52(3), 511.

Hintsanen, M., Jokela, M., Cloninger, C. R., Pulkki-Råback, L., Hintsa, T., Elovainio, M., ... \& Keltikangas-Järvinen, L. (2012). Temperament and character predict body-mass index: A population-based prospective cohort study. Journal of Psychosomatic Research, 73(5), 391-397.

Hintsanen, M., Jokela, M., Cloninger, C. R., Pulkki-Råback, L., Hintsa, T., Elovainio, M., ... \& Keltikangas-Järvinen, L. (2012). Temperament and character predict body-mass index: a 
population-based prospective cohort study. Journal of Psychosomatic Research, 73(5), 391-397.

Hunter, J. J., \& Maunder, R. G. (2001). Using attachment theory to understand illness behavior. General hospital psychiatry, 23(4), 177-182.

Kagan, J. (1996). Three pleasing ideas. American Psychologist, 51, 901-908. doi:10.1037/0003066X.51.9.901

Kalarchian, M. A., King, W. C., Devlin, M. J., Marcus, M. D., Garcia, L., Chen, J. Y., ... \& Mitchell, J. E. (2016). Psychiatric disorders and weight change in a prospective study of bariatric surgery patients: a 3-year follow-up. Psychosomatic Medicine, 78(3), 373-381.

Kassel, J. D., Wardle, M., \& Roberts, J. E. (2007). Adult attachment security and college student substance use. Addictive Behaviors, 32(6), 1164-1176.

King, W. C., Chen, J. Y., Mitchell, J. E., Kalarchian, M. A., Steffen, K. J., Engel, S. G., ... \& Yanovski, S. Z. (2012b). Prevalence of alcohol use disorders before and after bariatric surgery. Journal of the American Medical Association, 307(23), 2516-2525.

King, W. C., Engel, S. G., Elder, K. A., Chapman, W. H., Eid, G. M., Wolfe, B. M., \& Belle, S. H. (2012). Walking capacity of bariatric surgery candidates. Surgery for Obesity and Related Diseases, 8(1), 48-59.

Kökönyei, G., Urbán, R., Reinhardt, M., Józan, A., \& Demetrovics, Z. (2014). The Difficulties in Emotion Regulation Scale: Factor structure in chronic pain patients. Journal of Clinical Psychology, 70(6), 589-600.

Kring, A. M., Smith, D. A., \& Neale, J. M. (1994). Individual differences in dispositional expressiveness: development and validation of the Emotional Expressivity Scale. Journal of Personality and Social Psychology, 66(5), 934. 
Kroenke, K., Spitzer, R. L., \& Williams, J. B. (2001). The PHQ-9. Journal of General Internal Medicine, 16(9), 606-613.

Lara, D. R., Bisol, L. W., Brunstein, M. G., Reppold, C. T., de Carvalho, H. W., \& Ottoni, G. L. (2012). The Affective and Emotional Composite Temperament (AFECT) model and scale: A system-based integrative approach. Journal of Affective Disorders, 140(1), 1437.

Lara, M. D., Baker, M. T., Larson, C. J., Mathiason, M. A., Lambert, P. J., \& Kothari, S. N. (2005). Travel distance, age, and sex as factors in follow-up visit compliance in the postgastric bypass population. Surgery for Obesity and Related Diseases, 1(1), 17-21.

Larjani, S., Spivak, I., Guo, M. H., Aliarzadeh, B., Wang, W., Robinson, S., ... \& Aarts, M. A. (2016). Preoperative predictors of adherence to multidisciplinary follow-up care postbariatric surgery. Surgery for Obesity and Related Diseases, 12(2), 350-356.

Lautz, D. B., Jackson, T. D., Clancy, K. A., Escareno, C. E., Schifftner, T., Henderson, W. G., ... \& Khuri, S. (2007). Bariatric operations in Veterans Affairs and selected university medical centers: Results of the patient safety in surgery study. Journal of the American College of Surgeons, 204(6), 1261-1272.

Le, T. L., Mann, R. E., Levitan, R. D., George, T. P., \& Maunder, R. G. (2017). Sex differences in the relationships between childhood adversity, attachment anxiety and current smoking. Addiction Research \& Theory, 25(2), 146-153.

Leary, M. R., Schreindorfer, L. S., \& Haupt, A. L. (1995). The role of low self-esteem in emotional and behavioral problems: Why is low self-esteem dysfunctional? Journal of Social and Clinical Psychology, 14, 297-314. 
Leite, L., Machado, L. N., \& Lara, D. R. (2014). Emotional traits and affective temperaments in alcohol users, abusers and dependents in a national sample. Journal of Affective Disorders, 163, 65-69.

Lemmens, L. H., Müller, V. N., Arntz, A., \& Huibers, M. J. (2016). Mechanisms of change in psychotherapy for depression: An empirical update and evaluation of research aimed at identifying psychological mediators. Clinical Psychology Review, 50, 95-107.

Lent, M. R., Hayes, S. M., Wood, G. C., Napolitano, M. A., Argyropoulos, G., Gerhard, G. S., ... \& Still, C. D. (2013). Smoking and alcohol use in gastric bypass patients. Eating Behaviors, 14, 460-463.

Leventhal, A. M., \& Zvolensky, M. J. (2015). Anxiety, depression, and cigarette smoking: A transdiagnostic vulnerability framework to understanding emotion-smoking comorbidity. Psychological Bulletin, 141(1), 176.

Levine, M. D., Kalarchian, M. A., Courcoulas, A. P., Wisinski, M. S., \& Marcus, M. D. (2007). History of smoking and postcessation weight gain among weight loss surgery candidates. Addictive behaviors, 32(10), 2365-2371.

Lewis, M. (1997). Altering fate: Why the past does not predict the future. New York, NY: Guilford Press.

Lewis, M. (1999). On the development of personality. In L. A. Pervin \& O. P. John (Eds.), Handbook of personality: Theory and research ( $2^{\text {nd }}$ ed., pp. 327-346). New York, NY: Guilford Press.

Lewis, M., Feiring, C., \& Rosenthal, S. (2000). Attachment over time. Child Development, 71, 707-720. doi:10.1111/1467-8624.00180 
Lier, H. Ø., Biringer, E., Stubhaug, B., \& Tangen, T. (2013). Prevalence of psychiatric disorders before and 1 year after bariatric surgery: the role of shame in maintenance of psychiatric disorders in patients undergoing bariatric surgery. Nordic Journal of Psychiatry, 67(2), 89-96.

Livingston, E. H., Arterburn, D., Schifftner, T. L., Henderson, W. G., \& DePalma, R. G. (2006). National Surgical Quality Improvement Program analysis of bariatric operations: Modifiable risk factors contribute to bariatric surgical adverse outcomes. Journal of the American College of Surgeons, 203(5), 625-633.

Lo, C., Walsh, A., Mikulincer, M., Gagliese, L., Zimmermann, C., \& Rodin, G. (2009). Measuring attachment security in patients with advanced cancer: Psychometric properties of a modified and brief Experiences in Close Relationships scale. PsychoOncology, 18(5), 490-499.

Ma, I. T., \& Madura, J. A. (2015). Gastrointestinal complications after bariatric surgery. Gastroenterology \& Hepatology, 11(8), 526.

Malik, S., Mitchell, J. E., Engel, S., Crosby, R., \& Wonderlich, S. (2014). Psychopathology in bariatric surgery candidates: A review of studies using structured diagnostic interviews. Comprehensive Psychiatry, 55(2), 248-259.

Marek, R. J., Heinberg, L. J., Lavery, M., Merrell Rish, J., \& Ashton, K. (2016). A review of psychological assessment instruments for use in bariatric surgery evaluations. Psychological Assessment, 28(9), 1142.

Martin, M., Beekley, A., Kjorstad, R., \& Sebesta, J. (2010). Socioeconomic disparities in eligibility and access to bariatric surgery: A national population-based analysis. Surgery for Obesity and Related Diseases, 6(1), 8-15. 
Maunder, R. G., \& Hunter, J. J. (2016). Can patients be 'attached' to healthcare providers? An observational study to measure attachment phenomena in patient-provider relationships. BMJ Open, 6(5), e011068.

Maunder, R.G., \& Hunter, J.J. (2012). A prototype-based model of adult attachment for clinicians. Psychodynamic Psychiatry, 40(4), 549-573.

Mauri, M., Rucci, P., Calderone, A., Santini, F., Oppo, A., Romano, A., ... \& Cassano, G. B. (2008). Axis I and II disorders and quality of life in bariatric surgery candidates. Journal of Clinical Psychiatry, 69(2), 295-301.

Mayo Clinic Staff. (2016). Guide to types of weight-loss surgery. Retrieved from: http://www.mayoclinic.org/tests-procedures/bariatric-surgery/in-depth/weight-losssurgery/art-20045334?pg=1

McCrae, R. R., \& Costa, P. T. (1987). Validation of the five-factor model of personality across instruments and observers. Journal of personality and social psychology, 52(1), 81-90.

Mechanick, J. I., Youdim, A., Jones, D. B., Garvey, W. T., Hurley, D. L., McMahon, M. M., ... \& Brethauer, S. (2013). Clinical practice guidelines for the perioperative nutritional, metabolic, and nonsurgical support of the bariatric surgery patient - 2013 update: Cosponsored by American Association of Clinical Endocrinologists, the Obesity Society, and American Society for Metabolic \& Bariatric Surgery. Obesity, 21, S1-27.

MedCalc®. (n.d.). Logistic regression. Retrieved from: https://www.medcalc.org/manual/logistic_regression.php

Mennin, D. S., Holaway, R. M., Fresco, D. M., Moore, M. T., \& Heimberg, R. G. (2007). Delineating components of emotion and its dysregulation in anxiety and mood psychopathology. Behavior Therapy, 38(3), 284-302. 
Mitchell, J. E., Steffen, K., Engel, S., King, W. C., Chen, J. Y., Winters, K., ... \& Elder, K. (2015). Addictive disorders after Roux-en-Y gastric bypass. Surgery for Obesity and Related Diseases, 11(4), 897-905.

Mombach, K. D., de Souza Brito, C. L., Padoin, A. V., Casagrande, D. S., \& Mottin, C. C. (2016). Emotional and affective temperaments in smoking candidates for bariatric surgery. PLOS ONE, 11(3), e0150722.

Mühlhans, B., Horbach, T., \& de Zwaan, M. (2009). Psychiatric disorders in bariatric surgery candidates: a review of the literature and results of a German prebariatric surgery sample. General Hospital Psychiatry, 31(5), 414-421.

Myers, K., Hajek, P., Hinds, C., \& McRobbie, H. (2011). Stopping smoking shortly before surgery and postoperative complications: A systematic review and metaanalysis. Archives of Internal Medicine, 171(11), 983-989.

National Cancer Institute. (n.d.). Pack year. Retrieved from: https://www.cancer.gov/publications/dictionaries/cancer-terms?cdrid=306510 National Institute for Clinical Excellence [NICE]. (2014). Obesity: Identification, assessment and management (Clinical Guideline CG189). Retrieved from: https://www.nice.org.uk/guidance/cg189/chapter/1-recommendations\#surgical$\underline{\text { interventions }}$

Ontario Bariatric Network. (2015). Surgical program. FAQ. Retrieved from: http://www.ontariobariatricnetwork.ca/our-programs/surgical-program

Padwal, R. S., Chang, H. J., Klarenbach, S., Sharma, A. M., \& Majumdar, S. R. (2012). Characteristics of the population eligible for and receiving publicly funded bariatric surgery in Canada. International Journal for Equity in Health, 11(1), 54. 
Pandolfino, J. E., Krishnamoorthy, B., \& Lee, T. J. (2004). Gastrointestinal complications of obesity surgery. Medscape General Medicine, 6(2).

Peduzzi, P., Concato, J., Kemper, E., Holford, T. R., \& Feinstein, A. R. (1996). A simulation study of the number of events per variable in logistic regression analysis. Journal of Clinical Epidemiology, 49(12), 1373-1379.

Pitzul, K. B., Jackson, T., Crawford, S., Kwong, J. C., Sockalingam, S., Hawa, R., et al. (2014). Understanding disposition after referral for bariatric surgery. When and why patients referred do not undergo surgery. Obesity Surgery, 24(1), 134-140.

Preacher, K. J., \& Hayes, A. F. (2004). SPSS and SAS procedures for estimating indirect effects in simple mediation models. Behavior Research Methods, Instruments, \& Computers, 36, $717-731$.

Preacher, K. J., \& Hayes, A. F. (2008). Asymptotic and resampling strategies for assessing and comparing indirect effects in multiple mediator models. Behavior Research Methods, 40, 879-891.

Prospective Studies Collaboration. (2009). Body-mass index and cause-specific mortality in 900 000 adults: collaborative analyses of 57 prospective studies. The Lancet, 373(9669), 1083-1096.

Radziszewska, B., Richardson, J. L., Dent, C. W., \& Flay, B. R. (1996). Parenting style and adolescent depressive symptoms, smoking, and academic achievement: Ethnic, gender, and SES differences. Journal of Behavioral Medicine, 19(3), 289-305.

Romo-Nava, F., Fresán-Orellana, A., Barragán, V., Saracco-Álvarez, R., Becerra-Palars, C., Osorio, Y., ... \& Lara, D. R. (2015). The Affective and Emotional Composite Temperament Scale (AFECTS): Psychometric properties of the Spanish version in a 
community sample from Mexico City and comparison between remitted psychiatric patients. Journal of Affective Disorders, 172, 251-258.

Rosenberg, M. (1979). Conceiving the self. New York, NY: Basic Books.

Rosenberger, P. H., Henderson, K. E., \& Grilo, C. M. (2006). Psychiatric disorder comorbidity and association with eating disorders in bariatric surgery patients: A cross-sectional study using structured interview-based diagnosis. Journal of Clinical Psychiatry, 67(7), 10801085.

Rossato, C. J., Uphill, M. A., Swain, J., \& Coleman, D. A. (2018). The development and preliminary validation of the Challenge and Threat in Sport (CAT-Sport) Scale. International Journal of Sport and Exercise Psychology, 16(2), 164-177.

Sakata, R., McGale, P., Grant, E. J., Ozasa, K., Peto, R., \& Darby, S. C. (2012). Impact of smoking on mortality and life expectancy in Japanese smokers: A prospective cohort study. BMJ, 345, e7093.

Santiago, V. A., Warwick, K., Ratnakumarasuriyar, S., Oyewumi, A., Robinson, S., \& Sockalingam, S. (in press). Evaluation of a Patient Care Planning Intervention to Improve Appointment Attendance in Adults Following Bariatric Surgery, a Treatment for Obesity and Type 2 Diabetes. Canadian Journal of Diabetes. DOI: https://doi.org/10.1016/j.jcjd.2018.05.003

SAS Institute Inc. (2017). The MI Procedure. Retrieved from: http://go.documentation.sas.com/?docsetId=statug\&docsetVersion=14.3\&docsetTarget=s $\underline{\text { tatug_mi_overview.htm\&locale=en }}$ 
Shakory, S., Van Exan, J., Mills, J. S., Sockalingam, S., Keating, L., \& Taube-Schiff, M. (2015). Binge eating in bariatric surgery candidates: The role of insecure attachment and emotion regulation. Appetite, 91, 69-75.

Shaver, P. R., Mikulincer, M., \& Chun, D. S. (2008). Adult attachment theory, emotion regulation, and prosocial behavior. In M. Vandekerckhove, C. von Sheve, S. Ismer, S. Jung, \& S. Kronast (Eds.), Regulating emotions. Culture, social necessity, and biological inheritance (pp. 121-145). Malden, MA: Blackwell Publishing.

Sheehan, D. V., Lecrubier, Y., Sheehan, K. H., Amorim, P., Janavs, J., Weiller, E., ... \& Dunbar, G. (1998). The Mini-International Neuropsychiatric Interview (M.I.N.I.): The development and validation of a structured diagnostic psychiatric interview for DSM-IV and ICD-10. Journal of Clinical Psychiatry, 59, Suppl. 20:22-33; quiz 34-57.

Sherbourne, C. D., \& Stewart, A. L. (1991). The MOS social support survey. Social Science \& Medicine, 32(6), 705-714.

Shiffman, S. (2005). Dynamic influences on smoking relapse process. Journal of Personality, 73(6), 1715-1748.

Shiffman, S., \& Waters, A. J. (2004). Negative affect and smoking lapses: A prospective analysis. Journal of Consulting and Clinical Psychology, 72(2), 192-201.

Shiffman, S., Balabanis, M. H., Gwaltney, C. J., Paty, J. A., Gnys, M., Kassel, J. D., ... \& Paton, S. M. (2007). Prediction of lapse from associations between smoking and situational antecedents assessed by ecological momentary assessment. Drug and Alcohol Dependence, 91(2), 159-168. 
Sjöström, L., Narbro, K., Sjöström, C. D., Karason, K., Larsson, B., Wedel, H., ... \& Carlsson, L. M. (2007). Effects of bariatric surgery on mortality in Swedish obese subjects. New England Journal of Medicine, 357(8), 741-752.

Sockalingam, S., Cassin, S., Crawford, S. A., Pitzul, K., Khan, A., Hawa, R., et al. (2013). Psychiatric predictors of surgery non-completion following suitability assessment for bariatric surgery. Obesity Surgery, 23(2), 205-211.

Sockalingam, S., Hawa, R., Wnuk, S., Santiago, V., Kowgier, M., Jackson, T., ... \& Cassin, S. (2017). Psychosocial predictors of quality of life and weight loss two years after bariatric surgery: Results from the Toronto Bari-PSYCH study. General Hospital Psychiatry, 47, 7-13.

Sockalingam, S., Wnuk, S., Strimas, R., Hawa, R., \& Okrainec, A. (2011). The association between attachment avoidance and quality of life in bariatric surgery candidates. Obesity Facts, 4, 456-460.

Spitzer, R. L., Kroenke, K., Williams, J. B., \& Löwe, B. (2006). A brief measure for assessing generalized anxiety disorder: The GAD-7. Archives of Internal Medicine, 166(10), 10921097.

Spitzer, R.L., Kroenke, K., \& Williams, J.B. (1999). Validation and utility of a self-report version of PRIME-MD: The PHQ primary care study. Primary Care Evaluation of Mental Disorders. Patient Health Questionnaire. Journal of the American Medical Association, 282(18), 1737-1744.

Statistics Canada. (2018). Smoking, 2017 [Fact Sheet]. Retrieved from: https://www150.statcan.gc.ca/n1/pub/82-625-x/2018001/article/54974-eng.htm 
Steele, K. E., Schweitzer, M. A., Prokopowicz, G., Shore, A. D., Eaton, L. C., Lidor, A. O., ... \& Magnuson, T. H. (2011). The long-term risk of venous thromboembolism following bariatric surgery. Obesity Surgery, 21(9), 1371-1376.

Stewart, A. L., Hays, R. D., \& Ware, J. E. (1988). The MOS short-form general health survey: reliability and validity in a patient population. Medical Care, 26(7), 724-735.

Sullivan, S., Cloninger, C. R., Przybeck, T. R., \& Klein, S. (2007). Personality characteristics in obesity and relationship with successful weight loss. International Journal of Obesity, 31(4), 669-674.

Sunil, S., Santiago, V. A., Gougeon, L., Warwick, K., Okrainec, A., Hawa, R., \& Sockalingam, S. (2017). Predictors of vitamin adherence after bariatric surgery. Obesity Surgery, 27(2), 416-423.

Svaldi, J., Griepenstroh, J., Tuschen-Caffier, B., \& Ehring, T. (2012). Emotion regulation deficits in eating disorders. A marker of eating pathology or general psychopathology? Psychiatry Research, 197, 103-111.

Tae, B., Pelaggi, E. R., Moreira, J. G., Waisberg, J., Matos, L. L. D., \& D’Elia, G. (2014). Impact of bariatric surgery on depression and anxiety symptons, bulimic behaviors and quality of life. Revista do Colégio Brasileiro de Cirurgiões, 41, 155-160.

Taube-Schiff, M., Van Exan, J., Tanaka, R., Wnuk, S., Hawa, R., \& Sockalingam, S. (2015). Attachment style and emotional eating in bariatric surgery candidates: The mediating role of difficulties in emotion regulation. Eating Behaviors, 18, 36-40.

Taylor, S., \& Asmundson, G. J. (2004). Treating health anxiety: A cognitive-behavioral approach. New York, NY: Guilford Press. 
Taymur, I., Budak, E., Onen, S., Bicer, B., Dilektaslı, E., Cayci, M., ... \& Gungor, B. B. (2016). The relationship between childhood and adult attention-deficit-hyperactivity disorder and general psychopathological features in individuals who apply for bariatric surgery. Bariatric Surgical Practice and Patient Care, 11(3), 116-122.

Toussi, R., Fujioka, K., \& Coleman, K. J. (2009). Pre-and postsurgery behavioral compliance, patient health, and postbariatric surgical weight loss. Obesity, 17(5), 996-1002.

Turrell, G. (2000). Income non-reporting: implications for health inequalities research. Journal of Epidemiology \& Community Health, 54(3), 207-214.

Tzovaras, G., Papamargaritis, D., Sioka, E., Zachari, E., Baloyiannis, I., Zacharoulis, D., \& Koukoulis, G. (2012). Symptoms suggestive of dumping syndrome after provocation in patients after laparoscopic sleeve gastrectomy. Obesity Surgery, 22(1), 23-28.

Vega, W. A., Zimmerman, R. S., Warheit, G. J., Apospori, E., \& Gil, A. G. (1993). Risk factors for early adolescent drug use in four ethnic and racial groups. American Journal of Public Health, 83, 185-189.

Wang, Y., Ho, S. Y., Wang, M. P., Lo, W. S., Lai, H. K., \& Lam, T. H. (2015). Hong Kong Chinese adolescents' self-reported smoking and perceptions of parenting styles. International Journal of Behavioral Medicine, 22(2), 268-275.

Waters, E., Merrick, S., Treboux, D., Crowell, J., \& Albersheim, L. (2000). Attachment security in infancy and early adulthood: A twenty-year longitudinal study. Child Development, 71(3), 684-689.

Wee, C. C., Huskey, K. W., Bolcic-Jankovic, D., Colten, M. E., Davis, R. B., \& Hamel, M. (2014). Sex, race, and consideration of bariatric surgery among primary care patients with moderate to severe obesity. Journal of general internal medicine, 29(1), 68-75. 
Weissman, A. N., \& Beck, A. T. (1978). Development and validation of the Dysfunctional Attitude Scale: A preliminary investigation. Paper presented at the annual meeting of the American Educational Research Association, Toronto, Ontario, Canada.

Wheeler, E., Prettyman, A., Lenhard, M. J., \& Tran, K. (2008). Adherence to outpatient program postoperative appointments after bariatric surgery. Surgery for Obesity and Related Diseases, 4(4), 515-520.

Whiteside, U., Chen, E., Neighbors, C., Hunter, D., Lo, T., \& Larimer, M. (2007). Difficulties regulating emotions. Do binge eaters have fewer strategies to modulate and tolerate negative affect? Eating Behaviors, 8, 162-169.

Wicklin, R. (2017). Mean imputation in SAS. Retrieved from: https://blogs.sas.com/content/iml/2017/12/04/mean-imputation-sas.html

Wilhelm, K., Gillis, I., \& Parker, G. (2016). Parental bonding and adult attachment style: The relationship between four category models. International Journal of Women's Health and Wellness, 2, 016.

Wilson, J. A., Romagnuolo, J., Byrne, T. K., Morgan, K., \& Wilson, F. A. (2006). Predictors of endoscopic findings after Roux-en-Y gastric bypass. The American Journal of Gastroenterology, 101(10), 2194-2199.

Winnipeg Regional Health Authority (n.d.). Metabolic and Bariatric Surgery Program. http://www.wrha.mb.ca/prog/surgery/metabolic-bariatric/index.php)

World Health Organization [WHO]. (2017). Obesity and overweight [Fact sheet]. Retrieved from: http://www.who.int/news-room/fact-sheets/detail/obesity-and-overweight World Health Organization [WHO]. (2018a). Tobacco [Fact sheet]. Retrieved from: http://www.who.int/en/news-room/fact-sheets/detail/tobacco 
World Health Organization [WHO]. (2018b). Cancer [Fact sheet]. Retrieved from: http://www.who.int/cancer/prevention/en/

Wound Care Centers. (n.d.). Dehisced wounds. Retrieved from: http://www.woundcarecenters.org/article/wound-types/dehisced-wounds

Wu, C. S., Wong, H. T., Shek, C. H., \& Loke, A. Y. (2014). Multi-dimensional self-esteem and substance use among Chinese adolescents. Substance Abuse Treatment, Prevention, and Policy, 9(1), 42.

Wu, L., Winkler, M. H., Wieser, M. J., Andreatta, M., Li, Y., \& Pauli, P. (2015). Emotion regulation in heavy smokers: Experiential, expressive and physiological consequences of cognitive reappraisal. Frontiers in Psychology, 6. doi: https://doi.org/10.3389/fpsyg.2015.01555

Yang, X., Li, J., \& Shoptaw, S. (2008). Imputation-based strategies for clinical trial longitudinal data with nonignorable missing values. Statistics in Medicine, 27(15), 2826-2849.

Zhai, H., Yang, Y., Sui, H., Wang, W., Chen, L., Qiu, X., ... \& Yang, J. (2015). Self-esteem and problematic drinking in China: a mediated model. PloS one, 10(10), e0140183.

Zhang, W., Mason, E. E., Renquist, K. E., \& Zimmerman, M. B. (2005). Factors influencing survival following surgical treatment of obesity. Obesity Surgery, 15(1), 43-50.

Zhao, X., Lynch, J. G., \& Chen, Q. (2010). Reconsidering Baron and Kenny: Myths and truths about mediation analysis. Journal of Consumer Research, 37(2), 197-206.

Zvolensky, M. J., Gibson, L. E., Vujanovic, A. A., Gregor, K., Bernstein, A., Kahler, C., ... \& Feldner, M. T. (2008). Impact of posttraumatic stress disorder on early smoking lapse and relapse during a self-guided quit attempt among community-recruited daily smokers. Nicotine \& Tobacco Research, 10(8), 1415-1427. 